\title{
Three-dimensional reconstruction and the phylogeny of extinct chelicerate orders
}

Arachnids are an important group of arthropods. They are: diverse and abundant; a major constituent of many terrestrial ecosystems; and possess a deep and extensive fossil record. In recent years a number of exceptionally preserved arachnid fossils have been investigated using tomography and associated techniques, providing valuable insights into their morphology. Here we use X-ray microtomography to reconstruct members of two extinct arachnid orders. In the Haptopoda, we demonstrate the presence of 'clasp-knife' chelicerae, and our novel redescription of a member of the Phalangiotarbida highlights leg details, but fails to resolve chelicerae in the group due to their small size. As a result, tomographic studies of three-dimensionally preserved fossils now exist for three of the four extinct orders, and for fossil representatives of several extant ones. Such studies constitute a valuable source of high fidelity data for constructing phylogenies. To illustrate this, here we present a cladistic analysis of the chelicerates to accompany these reconstructions. This is based on a previously published matrix, expanded to include fossil taxa and relevant characters, and allows us to: cladistically place the extinct arachnid orders; explicitly test some earlier hypotheses from the literature; and demonstrate that the addition of fossils to phylogenetic analyses can have broad implications. Phylogenies based on chelicerate morphology - in contrast to molecular studies - have achieved elements of consensus in recent years. Our work suggests that these results are not robust to the addition of novel characters or fossil taxa. Hypotheses surrounding chelicerate phylogeny remain in a state of flux. 
1 Russell Garwood ${ }^{1}$ and Jason Dunlop ${ }^{2}$

$2{ }^{1}$ School of Earth, Atmospheric and Environmental Sciences and The Manchester X-

3 Ray Imaging Facility, School of Materials, The University of Manchester, Manchester 4 M13 9PL, UK.

$5 \quad{ }^{2}$ Museum für Naturkunde, Leibniz Institute for Research on Evolution and Biodiversity 6 at the Humboldt University Berlin, 10115 Berlin, Germany. 
8 Arachnids and their relatives (Chelicerata) form a major branch of the arthropods, 9 with around 112,000 living species (Zhang 2011). They also have an extensive 10 palaeontological record, including more than 2,200 fossil species at the time of writing (Dunlop, Penney \& Jekel 2014). Chelicerates can be found back into the Cambrian (Waloszek \& Dunlop 2002; Dunlop, Anderson \& Braddy 2004), although their record through deep time is patchy and tends to be concentrated into windows of exceptional preservation such as the late Carboniferous Coal Measures and various Cretaceous and Cenozoic ambers. Currently, sixteen arachnid orders can be recognised. Twelve have living representatives: scorpions (Scorpiones), harvestmen (Opiliones), pseudoscorpions (Pseudoscorpiones), camel spiders (Solifugae), palpigrades (Palipgradi), mites (Acariformes and Parasitiformes), ricinuleids (Ricinulei), spiders (Araneae), whip spiders (Amblypygi), whip scorpions (Thelyphonida) and schizomids (Schizomida). Four arachnid orders are extinct: trigonotarbids (Trigonotarbida), phalangiotarbids (Phalangiotarbida), haptopodids (Haptopoda) and the spider-like uraraneids (Uraraneida). To this can be added two marine groups with living representatives, the sea spiders (Pycnogonida) and horseshoe crabs (Xiphosura), as well as two extinct groups which were likely to have been primarily aquatic, the sea scorpions (Eurypterida) and the rare chasmataspidids (Chasmataspidida).

Resolving relationships between the arachnid and/or chelicerate lineages remains a challenge. Important cladistic studies include the comprehensive morphological analyses of Weygoldt \& Paulus (1979), and Shultz (1990, 2007), as well as numerous applications of molecular data - sometimes with morphology combined (e.g. Wheeler \& Hayashi 1998; Giribet et al. 2002; Pepato, da Rocha \& Dunlop 2010; Rehm et al. 2011). Few of these include fossil terminals (but see Giribet et al. 2002 and Shultz 2007) - despite the fact that extinct species valuable source of data (Edgecome 2010). Several arthropod-wide analyses - both molecular and morphological - also include chelicerates (Regier et al. 2010; Legg, Sutton \& Edgecombe 2013; Rota-Stabelli et al. 2013). Yet, as noted in a recent review (Dunlop, Borner \& Burmester 2014), there is still no single accepted phylogeny for arachnids and their relatives, and there are evident discrepancies between trees derived from morphological and molecular data. Dunlop, Borner \& Burmester (2014) thus recognised a minimum consensus tree, i.e. supported by various methodologies, of the form (Pycnogonida (Xiphosura (Scorpiones (Araneae 42 (Amblypygi (Thelyphonida + Schizomida)))))). This rather extensively pruned 43 phylogeny still excludes diverse and important groups like mites, harvestmen and pseudoscorpions, and does not place any of the fossil taxa. Xiphosura was recently interpreted as paraphyletic (Lamsdell 2013), at least with respect to Palaeozoic

46 'synziphosurines' which may include lineages eventually evolving into both crown47 group horseshoe crabs and, separately, into arachnids.

Fossils have sometimes proved controversial in phylogenetic reconstruction, and for 
1998). Extinct taxa offer direct evidence of early - and possibly quite different - body plans, but often have large amounts of missing data when compared to living taxa. Furthermore, scoring morphological character states in fossils involves a degree of interpretation, and objective inferences have to be made. Despite the challenges inherent in using fossils in such analyses, recent studies have demonstrated the utility and importance of doing so in a range of different analyses (Legg, Sutton \& Edgecombe 2013, Sharma \& Giribet 2014). Furthermore, in recent years the level of interpretation required has been reduced through a number of improvements in our understanding of fossil arachnid (and arthropod) data. For example, the application of various techniques such as X-ray computed tomography - especially microtomography ( $\mu C T$, e.g. Garwood, Dunlop \& Sutton 2009) - has allowed the anatomy of some fossils to be reconstructed in unparallelled three-dimensional detail. For a review of such methodologies see Sutton, Rahman \& Garwood (2014).

The principal aim of this study is to draw together recently published examples of well-preserved and (where possible) three-dimensionally reconstructed fossils in a phylogenetic analysis, and to augment these with novel data for two extinct arachnid orders: Phalangiotarbida and Haptopoda. Our intention is not to present a fully resolved phylogenetic tree, and we do not consider the topology recovered the sole solution to arachnid phylogeny. Rather, we use it to identify common trends and explore the impact of fossil data on tree topologies when scored into an modified version of a previously published dataset. In addition to twenty-seven newly added fossil taxa, the matrix - which is amended from that of Pepato, da Rocha \& Dunlop (2010) - has sixteen new characters to capture the fullest possible range of fossil morphology. This exercise allows us to assess how robust the placement of extinct taxa is, how these impact on the relationships recovered between extant groups, and to explicitly test some earlier hypotheses from the literature. We also hope that our matrix will constitute a starting point for further studies, and provide a useful contribution into which new fossil discoveries can be integrated. Following materials and methods information, we present first the results of our tomographic reconstructions, and then results and discussion for our cladistic analysis. We subsequently discuss the impact of fossils. Character descriptions are included as an appendix.

\section{Materials and Methods}

\section{Material and Tomography}

All tomographic reconstructions presented in the current study are based on material from the Coseley Lagerstätte, near Dudley, Staffordshire, UK. They are thus Late Carboniferous, from the similis-pulchra zone of the British Middle Coal Measures; Duckmantian in age (ca. 315 Ma; Pointon et al. 2012), or Westphalian B using more traditional terminology. Their preservation is as three-dimensional voids some partially infilled with kaolinite - within siderite nodules. Scans were conducted at the Natural History Museum, London on a Nikon HMX-ST 225 scanner with a tungsten reflection target. 
92 Two specimens of Plesiosiro madeleyi (NHM I. 15899, NHM I. 7923) from the 93 (monotypic) extinct order Haptopoda were scanned. They were selected as the most 94 three-dimensional representatives of all the NHM specimens of this species, and 95 NHM I. 7923 was chosen for subsequent processing as the most complete example. 96 This was scanned at $180 \mathrm{kV} / 175 \mu \mathrm{A}$, with a $0.25 \mathrm{~mm}$ copper filter, and 3142 97 projections of exposure $354 \mathrm{~ms}$, to provide a reconstructed dataset with a $19.5 \mu \mathrm{m}$ 98 voxel size.

99 Material from two species of another extinct order, Phalangiotarbida, were scanned. 100 One was not well-preserved enough to justify further reconstruction: Goniotarbus 101 tuberculatas (BU 696, Lapworth Museum Birmingham, also Coseley). However, the 102 NHM specimen In 22838, the holotype of Goniotarbus angulatus, was better 103 resolved, and revealed important limb morphology. It was last described by 104 Petrunkevitch (1953), whose work has, in the past, necessitated significant revision 105 (e.g. Dunlop 1996a, Garwood and Dunlop 2011). Accordingly this phalangiotarbid 106 specimen was selected for further processing. The scan was conducted at $107225 \mathrm{kV} / 190 \mu \mathrm{A}$, and without added filtration. 3142 projections of exposure $180 \mathrm{~ms}$ 108 were collected, and a reconstructed dataset with a $16.0 \mu \mathrm{m}$ voxel size created.

\section{Digital visualisation}

Both scans were used to create three-dimensional, virtual fossils using the custom SPIERS software suite (Sutton et al. 2012) following the methods of Garwood et al. (2012). The distal limbs of Plesiosiro madeleyi were not recovered by the scan where they were truncated by the edge of the nodule. Several of the walking legs of Goniotarbus angulatus were absent. Both models were scaled, and then exported to be presented here as VAXML models (SI file 1). SPIERS-generated isosurfaces were then ray-traced in Blender for figures and videos (Garwood and Dunlop 2014) - for Goniotarbus angulatus enough of the limbs were preserved to allow missing

\section{Microscopy}

Hand specimen photographs of Plesiosiro madeleyi are available in the redescription of Dunlop (1999). No comparable modern photographs of Goniotarbus angulatus exist. Accordingly a plate of hand specimen photographs is published herein showing the holotype, and only known specimen (NHM In 22838: Fig. 2). This was studied and photographed using a Leica MZ16A stereomicroscope and incident light. Photographs taken at multiple focal depths were combined using the software CombineZM (see Bercovici et al. 2009). Photographs of the whole fossil - which was too large for the field of view - were created by manually stitching sections using the open source raster graphics editor GIMP 2.8, and figures were assembled in 130 Inkscape 0.48. For comparative purposes specimens of a related species 131 (Petrunkevitch 1949), Goniotarbus tuberculatus (NHM In 31249, NHM In 18340, and NHM In 22840), were also studied. 
134 The current analysis of 86 taxa and 192 characters is a modified version of 'Matrix A' 135 created by Pepato, da Rocha \& Dunlop (2010). A particular focus of the previous 136 study was to clarify the position of, and relationships within, the mites. Consequently 137 the analysis had a large number of mite-specific characters. The current study has 138 different goals, and for ease of analysis and clarity we exclude numerous characters 139 which are only helpful for resolving ingroup relationships within one or both of the 140 two major mite lineages (i.e. acariforms and parasitiforms). We remove two further 141 characters based upon the reviews of the current manuscript, which are available 142 with this paper. In addition to these changes, we added 16 characters relevant for 143 fossil taxa, and modified others to make them applicable to newly introduced fossil 144 terminals. Examples of novel characters include: a prosomal shield with a meso- and 145 metapeltidium demarcated; the presence of genal spines; the prosoma and 146 opisthosoma forming a single functional tagma; 'elbowed' chelicerae in those taxa 147 with three-segmented chelicerae; a sixth limb modified as a paddle (or pusher); a 148 shortened first opisthosomal tergite; six abbreviated opisthosomal tergites; the 149 absence of a sternite for opisthosomal segment one; fusion of opisthosomal tergites 150 7-10; a median abdominal (genital) appendage; ventral sacs; a dorsal anal 151 operculum; eurypterid gill tracts; and development with a nymphal stage. Full 152 character descriptions for the updated matrix are included as an appendix. We have 153 also modified a character to explicitly code ingesting solid material, rather than 154 extra-oral digestion. The former is easier to code for fossils, often being apparent 155 from the morphology of mouthparts, whereas the latter is more closely based on 156 behaviour, something which is not typically preserved in fossils. Similarly the 157 presence of opisthosomal venom glands has been altered to code for a telson with 158 an aculeus and vesicle (the 'sting'), the latter being verifiable in fossil scorpions. 159 Finally, the character recording the number of cheliceral articles now has more than 160 three articles as an option to reflect the state observed in outgroups (Haug et al. 161 2012a, b; Briggs and Collins 1999), and some fossil horseshoe crabs (Sutton et al. 162 2002; Briggs et al. 2012).

Taxon selection

164

165

166

167

168

169

170
As noted above, the focus on mites in Pepato, da Rocha \& Dunlop's (2010) Matrix A differed from the present study. Accordingly there were a large number of acarid terminals, which we pruned for this study. We concurrently added 27 fossil taxa to the matrix. These had on average $59 \%$ missing data in comparison to $4 \%$ for extant taxa - however we do not consider this problematic on the basis of multiple publications in recent decades demonstrating that this need not result in lack of resolution, and that excluding taxa on the basis of missing data is inadvisable (Kearney \& Clark 2003; Cobbett, Wilkinson \& Wills 2007; Wiens \& Morrill 2011; Weins $\&$ Tu 2012). On the basis of the reviews of the current manuscript, the artiopodan Emeraldella brocki, from the description by Stein and Selden (2012) was included as an outgroup. This is has been recovered in the mandibulate stem lineage (Stein and 
175 Selden 2012; Ortega-Hernández, Legg \& Braddy 2013), or alternatively as more 176 closely related to the chelicerates (Legg, Sutton \& Edgecombe 2013). Two Cambrian 177 arthropods belonging to an assemblage variously referred to as the Megacheira, or 178 the great appendage arthropods, were added to reflect increasing evidence that 179 these fossils may be closely related to chelicerates (e.g. Dunlop 2006; Edgecombe, 180 García-Bellido \& Paterson 2011; Haug et al. 2012a, b; but see also Legg 2013). The 181 megacheiran genus Alalcomenaeus was coded on the basis of a comprehensive 182 description of $A$. cambricus by Briggs and Collins (1999), and recently reported 183 neural anatomy reported by Tanaka et al. (2013) for Alalcomenaeus sp., which 184 minimised the degree of missing data. To assess megacheiran monophyly we added 185 a further fossil, Leanchoilia superlata, which was recently redescribed in detail by 186 Haug et al. (2012a).

187 For analyses of extant taxa only a sea spider (Pycnogonida) was selected as the 188 outgroup as justified in Pepato, da Rocha \& Dunlop (2010). To the previously coded 189 pycnogonids we added two well-resolved Palaeozoic fossil examples - the Silurian 190 species Haliestes dasos described by Siveter et al. (2004) and the Devonian 191 Palaeoisopus problematicus redescribed by Bergström, Stürmer \& Winter (1980). 192 The recently discovered species Pentapantopus vogteli (Kühl, Poschmann \& Rust 193 2013) resembles $H$. dasos and also some modern pycnogonids - but as highlighted 194 in the original publication - incomplete preservation and a limited understanding of 195 their ontogeny precluded placement of the species. Accordingly we have opted to 196 omit the species from this analysis, as with the fossil of Rudkin et al. (2013), which 197 we consider to be controversial as its incomplete and does not reveal a number of 198 important sea spiders features. As previously noted, Lamsdell (2013) recently 199 challenged the monophyly of the horseshoe crabs (Xiphosura) which have 200 traditionally been interpreted as having a stem lineage (the synziphosurines) 201 leading up to a crown-group Xiphosurida. To test this suggestions we included three 202 of the best preserved putative synziphosurine taxa. From the Silurian we scored 203 Offacolus kingi based on the description of Sutton et al. (2002) and Dibasterium 204 durgae based on Briggs et al. (2012), as well as the Devonian fossil Weinbergina 205 opitzi redescribed by Stürmer \& Bergström (1981) and Moore et al. (2005).

206 Three Silurian representatives of the extinct Eurypterida were scored: 207 Parastylonurus ornatus based on Waterston (1979), Mixopterus kiaeri based on 208 Størmer (1934) and Eurypterus (formerly Baltoeurypterus) tetragonophthalmus 209 based on Selden (1981). This allowed us to assess the issue of whether sea 210 scorpions are closely related to scorpions; which impacts on the monophyly of 211 arachnids and the likely number of independent terrestrialisation events (Garwood \& 212 Edgecombe 2011; Dunlop et al. 2013). From the extinct Chasmataspidida we 213 included the Ordovician fossil Chamataspis laurencii following Dunlop, Anderson \& 214 Braddy (2004) and the Devonian Octoberaspis ushakovi after Dunlop (2002). 215 Eurypterids have been recovered as paraphyletic with respect to chasmataspids in 216 some studies (Shultz 2007), as posited by Tetlie \& Braddy (2004). We also wanted to 217 test the impact of fossils on Shultz's (2000) Stomothecata hypothesis (i.e. 218 Scorpiones + Opiliones) and to this end we coded five Palaeozoic scorpions: the 
219 Silurian Proscorpius osborni based on Dunlop et al. (2008); the Devonian 220 Palaeoscorpius devonicus based on Kühl et al. (2012); the Lower Devonian genus 221 Waeringoscorpio, based on the redescription of $W$. hefteri and description of $W$. 222 westerwaldensis by Poschmann et al. (2008); Lower Carboniferous species 223 Pulmonoscorpius kirktonensis, coded from Jeram (1993) with lung details from Jeram 224 (1990); and the Carboniferous Compsoscorpius buthiformis based on Legg et al. 225 (2012). Adding the recently described Carboniferous stem mite harvestman 226 Hastocularis argus from Garwood et al. (2014) and closely related Eophalangium 227 sheari (Dunlop et al. 2003) allowed more robust assessment of the extent to which 228 fossils impact on the proposed sister group relationship between scorpions and 229 harvestmen.

230 The extinct arachnid order Trigonotarbida has been recovered as sister group to the 231 so-called Tetrapulmonata (i.e. spiders and their closest relatives), but relationships 232 with the rare order Ricinulei have also been suggested in the literature (Dunlop, 233 Kamenz \& Talarico 2009, and references therein). For trigonotarbids we scored the 234 Devonian genus Palaeocharinus spp. from specimens assigned to Palaeocharinus 235 rhyniensis Hirst, 1923 and Palaeocharinus hornei (Hirst, 1923) but which we 236 consider to be synonymous. Coding was based on Dunlop (1994a) and Garwood and 237 Dunlop (2014). We also included two Carboniferous species we have previously 238 reconstructed using CT scans, namely Anthracomartus hindi based on Garwood \& 239 Dunlop (2011) and Eophrynus prestvicii based on Dunlop \& Garwood (2014). 240 Another extinct (Devonian - Permian) arachnid order, the probably spider-like 241 Uraraneida, was coded on the basis of Selden, Shear \& Sutton (2008). Finally, the 242 two remaining extinct arachnid orders were coded based on the digital visualisations 243 presented herein. Characters for the Carboniferous Haptopoda derive from the 244 model of Plesiosiro madeleyi and the previously published account of Dunlop (1999). 245 Phalangiotarbida coding was again based on the model presented herein for 246 Goniotarbus tuberculatus, plus data from Pollitt, Braddy \& Dunlop (2004) for 247 Bornatarbus mayasii (both Carboniferous).

248 Cladistic Analysis.

249 The matrix was analysed with TNT v.1.1. (Goloboff, Farris and Nixon, 2008; made 250 available with the sponsorship of the Willi Hennig Society), using unordered 251 multistate characters, and traditional search options. Searches comprising tree 252 bisection-reconnection [TBR] with 1,000 replicates, saving 100 trees per cycle were 253 conducted on the full matrix ( $\mathrm{SI}$ file 2), and a pruned version of the matrix excluding 254 fossil taxa (SI file 3). The data matrix is also available in the public database 255 Morphobank (http://www.morphobank.org; Project 1274). For equally weighted 256 analyses (EW) with fossils, TNT was used to create strict consensus trees which were 257 exported as SVGs into Inkscape, and numerous analyses were run to explore the 258 data with differing taxa and characters excluded to explore their impact. Results for 259 equally weighted analyses lacking fossils were exported as .tre files of the strict 260 consensus, and trees collapsed in Figtree 1.4.1 before being exported to Inkscape. 261 Analyses were also run using implied weighting (IW) to assess the impact of 
262 homoplasy on the results. Goloboff (1993) and Goloboff et al. (2008) provide an

263 overview of this weighting scheme, whilst Legg, Sutton \& Edgecombe (2013), Legg

264 and Caron (2013) and Ortega-Hernández, Legg and Braddy (2013) provide

265 justification of its use in a palaeontological context. We note, however, the 266 comments of reviewer \#1 of the current manuscript - available with the paper 267 criticizing this weighting scheme; no peer-reviewed contribution discussing these 268 issues is currently available in the literature. Due to a number of difficult to place 269 groups (Phalangiotarbida, Ricinulei, Parasitiformes) and resulting instability, when 270 run with a variety of concavity constants $(k=0.25,1.0,3.0$, and 10.0) tree topology 271 changed. Here we present a strict consensus of the most parsimonious trees for

272 each concavity constant. For the analyses including fossils, resampling was carried 273 out in TNT: we provide jackknife (Farris et al., 1996; 33\% removal probability, 1000 274 replicates), bootstrap (Felsenstein, 1985; 1000 replicates) and Bremer support 275 (Bremer, 1994) values for the equal weights tree. Nodal support values of the first 276 two of these are shown as absolute frequencies. For implied weights trees we show 277 support through symmetric resampling - chosen because it is unaffected by 278 character weighting (Goloboff et al. 2003) - using a change probability of 33\%, and 2791000 replicates, and reporting absolute frequencies.

280 Tomography Results

Reconstruction of Plesiosiro madeleyi

282

The digital visualisation of haptopodid Plesiosiro madeleyi (NHM I.7923; Figure 1A-D) 283 presented herein largely corroborates previous work on this species (Pocock 1911; 284 Petrunkevitch 1949; Dunlop 1999). Some elements - such as distal limb articles - are 285 not resolved in the CT scan as they run along the crack in the nodule. The most 286 complete leg is shown in Fig.1D. Accordingly we refer the reader to Dunlop (1999) 287 for these details - which include a full description and measurements of the scanned 288 specimen - and focus here on clearly resolved and/or novel anatomical elements. 289 Note that the scanned specimen shows a small amount of distortion due to lateral 290 compression.

291 As previously reported, the posterior margin of the prosomal shield terminates with 292 a posteriorly directed ridge, obscuring some of tergite one (Dunlop 1999; see SI file 293 1, animation in SI file 4). Clipping the digital visualisation provides no clear evidence 294 for any kind of locking structure between the prosomal shield and the first tergites, 295 such as is seen in the extinct trigonotarbids for example. Instead the prosoma296 opisthosoma junction in Plesiosiro madeleyi forms a simple ' $z$ '-shaped arrangement 297 in lateral section. Median eyes are resolved as depressions either side of a dorsal 298 median ridge on the prosomal shield (Fig. 1A), reflecting the same observation in 299 hand specimens. This is unusual for arachnids - in which the median eyes are 300 normally raised structures - and may be a taphonomic artefact caused by the eyes 301 inverting prior to fossilisation (see also remarks in Dunlop 1999). The lateral 302 prosomal shield tubercles are shown in this specimen to be broader than the 303 rounded structures previously described, being $0.8 \mathrm{~mm}$ long latero-posteriorly 
304 directed ridges, whose dorsal surface projects anteriorly at the anterior prosomal 305 shield margin in parasagittal section. They have been interpreted as possible lateral 306 eye tubercles, but evidence of explicit lenses is lacking. It has also been speculated 307 that Plesiosiro madeleyi was a harvestman (see below), but these lateral tubercles 308 also showed no obvious openings for repugnatorial glands; as would be expected if 309 these structures were raised ozophores similar to the condition in cyphophthalmid 310 harvestmen. Overall, the results of the phylogeny presented herein support Dunlop 311 (1999) in the suggestion that these projections probably represent lateral eye 312 tubercles. Immediately posterior to the tubercles are small depressions.

313 The ventral prosoma is well-resolved, and confirms the presence of anterior and 314 posterior sclerites in the sternum (Fig. 1C), the former bearing an anterior pair of 315 protrusions. Significantly, the scan unequivocally demonstrates chelicerae of a 316 'clasp-knife' type, comprising a proximal (minimum of $0.7 \mathrm{~mm}$ in length) and distal $317(0.9 \mathrm{~mm})$ article (Fig. 1B). There is no evidence of a third cheliceral article as 318 reported by Petrunkevitch (1949). The chelicerae are ventral to the median anterior 319 projection, their attachment being aligned essentially level with the median eyes. 320 Palpal coxae cannot be resolved due to the crack in the nodule, but the model 321 suggests that the chelicerae were probably tucked between the bases of the 322 pedipalps in life. The chelicerae are preserved with the proximal article dorsally 323 oriented, with a geniculate joint, and the distal article ventrally directed. Thus they probably had something approaching an 'orthognath' bite (i.e. hinged so cheliceral movement is parallel to the sagittal plane), similar to the mesothele and mygalomorph spiders (Kraus \& Kraus 1993). The opisthosomal segmentation pattern for Plesiosiro madeleyi resolved here - i.e. 12 segments in total - corroborates that reported by Dunlop (1999).

\section{Reconstruction of Goniotarbus angulatus}

Digital reconstruction of the holotype of phalangiotarbid Goniotarbus angulatus 332 (NHM In22838) reveals an arachnid with a broad prosoma-opisthosoma boundary 333 (Fig. $1 \mathrm{H}, 2 \mathrm{~A}, \mathrm{SI}$ file 1, animation in SI file 4). The total body length is $17.0 \mathrm{~mm}$ 334 whereby the prosomal shield is $6.5 \mathrm{~mm}$ long and $7.1 \mathrm{~mm}$ wide at its curved posterior 335 margin. A median bulge causes crowding of - and obscures in part - the anterior336 most opisthosomal tergites (Fig. 2D). The prosomal shield has an anteriorly 337 positioned median eye tubercle, however the eye arrangement is not readily 338 apparent - perhaps the reason previous works reported either two (Pocock 1911) or 339 six (Petrunkevitch 1953) lenses. Careful study suggests that are three depressions in 340 a triangular arrangement on one side - a number matching the state observed in 341 other phalangiotarbids (Pollitt, Braddy \& Dunlop 2004) - however, this isn't seen on 342 the opposing side of the prosomal shield, and thus we treat the observation with 343 caution, and discuss the impact of different codings below. The dorsal surface of the 344 prosomal shield is demarcated by three pairs of radiating linear depressions. These 345 are not so clearly visible towards the middle, but become increasingly pronounced 346 laterally (SI file 1 ). The median prosomal shield bears a subtly raised region with 347 concave lateral margins, widening anteriorly towards the eyes and also posteriorly. 
348

349

350

351

352

353

354

355

356

357

358

359

360

361

362

363

364

365

366

367

368

369

370

371

372

373

374

375

376

377

378

379

380

381

382

383

384

385

386

387

388

389

390

The opisthosoma is $10.6 \mathrm{~mm}$ long and maximally $7.5 \mathrm{~mm}$ wide. Opisthosomal segments 1-6 are very short and closely spaced, as is typical for members of this extinct order (Fig 1H, 2D). Tergites 1 and 2 express anterior curvature at their edges, accommodating the curved prosomal margin (see above). Tergites 4-6 have straighter margins, and 6 is slightly longer than the five preceding tergites (Fig. 2D). Other data (e.g. Pollit, Braddy \& Dunlop 2004) suggest that the phalagiotarbid ground pattern was an opisthosoma with 10 clearly expressed tergites dorsally. In Goniotarbus angulatus (and many other species) tergites 7-10 appear to be fused into a single dorsal plate covering the back end of the opisthosoma. However, in NHM In 22838 this original segmentation is marked by subtle, V-shaped linear depressions (Fig 2E). The presence of a posterior depression to demarcate the original tergite ten corroborates the observation reported by Petrunkevitch (1953), which was missing in the original description of Pocock (1911). The posterior opisthosoma bears the dorsal anal operculum; marked by a pit in NHM In 22838 with possible discharge visible in the CT scan (Fig. 1H, 2A,E). This might suggest a small degree of decay prior to fossilisation.

The ventral surface is well-resolved (Fig. 1I, 2B). Scans reveal a pronounced anterior median ventral ridge near the expected position of the chelicerae (Fig $1 F, I$ ), tucked between the small palpal coxae which are not visible in the hand specimen. The four triangular leg coxae are large, and all abut the sternum. The mesal surfaces of the first coxae (length $2.2 \mathrm{~mm}$ ) are separated by the aforementioned ridge. Coxal margins otherwise appear to be in contact with the surrounding coxae (Fig. 1I, 2B). The coxae increase in size posteriorly - coxae 4 are $3.2 \mathrm{~mm}$ long - but these too abut sternum medially. The sternum itself (Fig. 2C) is subdivided into five plates in a '1-22 ' arrangement from anterior to posterior. The ventral opisthosoma comprises the short sternites 1-4 which are crowded anteriorly between the coxae of leg 4 (Fig. 2B, total length: $1.8 \mathrm{~mm}$ ). Sternite 5 is significantly longer than the preceding sternites, and all remaining sternites increase in length posteriorly to number 9 (length 3.9 $\mathrm{mm}$ ). All sternites have straight posterior margins, and are divided longitudinally into three plates by two suture lines running from the distal termination of coxae four, and curving outwards to terminate at the opisthosomal margin towards the posterior end of sternite nine (Fig. 2B). Some previous studies have noted possible openings for (?tracheal) spiracles among the anteriormost sternites (Dunlop \& Horrocks 1997, Fig. 2), but these could not be identified unequivocally here. There are, however, two enigmatic raised structures on sternite 5 whose identity and function remains uncertain.

The preservation of the limbs is patchy. Based on the very small pedipalp size we presume that the phalangiotarbid chelicerae must have been tiny. This would explain their poor resolvability in the current scans. At the anterior margin of the previously described ridge between the first coxae there is a ventrally projecting feature (Fig. 1F). Further details are unrecovered due to lack of resolution, but this could represent a small pair of chelicerae. The pedipalps are also small, hanging ventrally beneath the anterior margin of the prosomal shield; although it should be 
391

392

393

394

395

396

397

398

399

400

401

402

403

404

405

406

407

408

409

410

411

412

413

414

415

416

417

418

419

420

421

422

423

424

425

426

427

428

429

430

431

432

noted that the exact prosomal shield margin is hard to differentiate from the crack along which the nodule was split in this specimen, and thus it is possible they projected anterior of the prosomal shield in life. Individual articles in the pedipalps could not be resolved in the CT scan. The first right walking leg is truncated midway along the tibia. All other legs on this side are truncated at the trochanter-femur joint. The legs on the left side are more complete (Fig. 1E,G). On the basis of the preserved articles, leg length appears to increase posteriorly from 1 to 4 . Limb article proportions are generally similar throughout - on the most complete leg (left leg 1, Fig $1 \mathrm{E}$ ) the measurements are: trochanter, $1.0 \mathrm{~mm}$; femur, $1.6 \mathrm{~mm}$; patella, $1.7 \mathrm{~mm}$; tibia, $1.6 \mathrm{~mm}$; metatarsus, $1.1 \mathrm{~mm}$ and tarsus, $1.2 \mathrm{~mm}$. Details of any terminal claws (apotele) on the legs are equivocal.

\section{Cladistics Results and Discussion}

Analysis using traditional search options (TBR) and equal weights (EW) resulted in 383 trees of 455 steps (average weighted character fit, WCF, 101.5; Goloboff 1993), presented here as a strict consensus (Fig. 3). Using implied weights (IW), results differed with changing concavity constants: $k=0.25$ resulted in 3 trees of 80.38824 steps (all with WCF $=107.6$ ); $\mathrm{k}=1.0$ in 3 trees of 60.05750 steps (all with WCF $=$ 127.94 ); $k=3.0$ in 12 trees of 37.26555 steps (all with $\mathrm{WCF}=150.73$ ); and $k=$ 10.0 in 6 trees of 16.71747 steps (all with WCF $=171.28$ ). A consensus of the MPTs for each $k$ value is shown in Fig. 4. Without fossil taxa, 40 trees of 384 steps were recovered under the same EW search parameters (average WCF 150.9). In general, several relationships are consistent across all search parameters and our results and their implications - are discussed in further detail below.

\section{Chelicerata}

The two analyses including fossils are rooted on the artiopodan Emeraldella brocki. In the EW tree (Fig. 3) the megacheiran taxa form a clade, sister group to (Eurypterida + (Chasmataspida + Xiphosura)). This relationship - defined through the presence of lateral eyes and a pair of median eyes - has essentially no support in the current analysis. In all IW analyses these taxa are found either in a polytomy with all remaining taxa, or as a clade sister group to these (Fig. 4). All IW analyses thus recover Chelicerata (i.e. those taxa which were traditionally assigned to Pycnogonida, Merostomata and Arachnida; Dunlop 2010) - a relationship with stronger support, and in keeping with the idea that Alalcomenaeus and L. superlata could be considered possible stem-chelicerates in the literature (e.g. Edgecombe, García-Bellido \& Paterson 2011; Haug et al. 2012a, b; although see also Legg, Sutton and Edgecombe 2013). We highlight, however, that due to a lack of further Cambrian fossil taxa we do not consider this a robust test of megacheiran relationships. Megacheirans were not our focus group, and study of a range of early Palaeozoic arthropods is needed to resolve the origins of chelicerates and their probable stem-group in detail. We refer to Chen et al. (2004), Haug et al. (2012a, b), Legg et al. (2012), Legg (2013), and Legg, Sutton and Edgecombe (2013) for work in this direction. At the base of the chelicerates in IW analyses we find a clade 
433 comprising Dibasterium durgae and Offacolus kingi as sistergroup to all other 434 chelicerates. This position for $O$. kingi and $D$. durgae results from their chelicerae, 435 which possess more than three articles, and the presence of exopods on all the 436 postcheliceral prosomal appendages, shared with the Cambrian taxa included, but 437 no other chelicerates. Under EW this clade is sister group to the arachnids and 438 pycnogonids instead: another grouping with essentially no support, in which we 439 place little confidence.

440 Merostomata?

441 Excluding Dibasterium durgae and Offacolus kingi, the remaining horseshoe crabs in 442 our analysis resolved in a clade together with the extinct eurypterids and 443 chasmataspidids. In EW analysis, this group is defined by the increase in head shield 444 segments and reduction of cheliceral segments to three relative to the Megachiera 445 and outgroup, whilst with IW these share the synapomorphy of a cephalic doublure 446 (where known). In IW analyses this clade is sister group to an (Arachnida + 447 Pycnogonida) clade (see below), whilst EW analyses have synziphosurine taxa in this 448 position, as previously highlighted. Using EW Chasmataspidida, the remaining 449 Xiphosura, and Eurypterida each form a monophyletic group, with the relationships 450 (Xiphosura (Chasmataspidida+Eurypterida)). Under IW, the position of the 451 synziphosurine Weinbergina opitzi is unstable - at high $k$ values $(k=3.0, k=10.0)$ it is 452 sister group to (Eurypterida (Chasmatsapidida (modern Xiphosurida)), whereas at 453 lower values it is resolved as sistergroup to (C. laurencii + modern Xiphosurida). At 454 all $\mathrm{k}$ values, the eurypterids form a clade, whilst chasmataspids are either split by $W$. 455 opitzi, or form a grade to modern Xiphosura. In an extant-taxa-only analyses under 456 EW and IW, rooted on pycnogonids, Xiphosurida form a monophyletic sister clade to 457 Arachnida.

458 This overall result with fossils included is interesting in that horseshoe crabs and 459 eurypterids were traditionally grouped together as the class Merostomata; the 460 aquatic counterpart to a largely terrestrial class Arachnida. As argued by authors 461 like Kraus (1976), this is primarily an ecological distinction rather than a 462 phylogenetic one. Previous cladistic studies consistently failed to recover 463 Merostomata and usually placed eurypterids closer to arachnids instead (Weygoldt \& 464 Paulus 1979; Shultz 1990, 2007; see also below). We also failed to recover 465 Merostomata in its traditional sense, since our synziphosurines are paraphyletic, 466 with $D$. durgae and $O$. kingi recovered elsewhere. In IW analyses we are, however, 467 left with a monophyletic unit comprising remaining Xiphosura sensu stricto (albeit 468 here including the synzophosurine W. opitzi; see below), Eurypterida and 469 Chasmataspidida. Were this clade to prove robust - but see Lamdsdell (2013) for an 470 alternative model - the name Merostomata remains available for this taxon.

471 Xiphosura / Xiphosurida

472 Lamsdell (2013) analysed many of the Palaeozoic fossils traditionally assigned to 473 horseshoe crabs, concluding that Xiphosura is not monophyletic and that the fossils 
474 placed here actually comprise a paraphyletic assemblage of basal chelicerates and 475 stem taxa for the lineage leading up to modern Xiphosurida. Our taxon coverage 476 was not nearly as extensive as Lamsdell's, but in concordance with his study we also 477 failed to recover a monophyletic Xiphosura. Both here under IW (but not EW, see 478 above) and in Lamsdell (2013) Offacolus kingi resolved in a basal position among 479 Chelicerata (Fig. 4). On the basis of our support values, we certainly consider this 480 the stronger of the two possibilities we present herein. Lamsdell did not score 481 Dibasterium durgae - the species was described while his paper was in press - but 482 added a comment in proof addressing the fact that the original description by Briggs 483 et al. (2012) recovered a monophyletic Xiphosura, a result repeated in Legg, Sutton $484 \&$ Edgecombe (2013). Lamsdell (2013) questioned a number of the characters in this 485 matrix. The IW results presented herein agree in part with those of Lamsdell, in 486 recovering a paraphyletic synziphosurine grade at the based of the chelicerate tree. 487 Our analysis differs from Lamsdell's scheme in recovering, at least under some 488 parameters of analysis, the synziphosurine Weinbergina opitzi in a clade together 489 with the living horseshoe crabs. In his 2013 paper Weinbergina was part of a newly 490 formulated Prosomapoda assemblage; essentially comprising the sister group of the 491 horseshoe crabs sensu stricto, the eurypterids and the arachnids. Lamsdell's 492 hypothesis that synziphosurines include basal chelicerates - rather than just basal 493 horseshoe crabs - has much to recommend it, and the position(s) recovered, but we 494 also note that whilst two cladistic analyses have now recovered this result, both are 495 limited in their taxon sampling in comparison to, for example, Legg, Sutton \& 496 Edgecombe (2013). Only through continued analysis and work on fossil chelicerates 497 can light be shed on this issue. A Xiphosurida crown group - represented here by the 498 two living horseshoe crabs - was, unsurprisingly, recovered as monophyletic.

\section{Eurypterida}

500 The most recent evidence in favour of eurypterids being the sister group of the 501 arachnids was published by Kamenz et al. (2011), who identified the enigmatic 'horn 502 organ' in the opisthosoma of an exceptionally preserved eurypterid as a potential 503 precursor of a spermatophore. Sperm transfer via spermatophores was thus 504 proposed as a putative synapomorphy for (Eurypterida + Arachnida) and the name 505 Sclerophorata was introduced by Kamenz et al. (2011) for this clade; nomenclature 506 also followed by Lamsdell (2013). Despite this, Eurypterida did not resolve in the 507 present study together with Arachnida, rather they were drawn into the previously 508 discussed merastomatid clade through their cephalic doublure (a character missing 509 in Dibastierum and Offacolus, but present in modern xiphosuran taxa), and 510 'elbowed' chelicerae where known. Eurypterids were recovered as monophyletic in 511 all analyses, with the internal relationships (Parastylonurus ornatus (Eurypterus 512 tetragonophthalmus + Mixopterus kiaeri)). Until recently there were two very good 513 synapomorphies for Eurypterida: a median abdominal (or genital) appendage on the 514 underside of the opisthosoma and a plate-like metastoma covering the back end of 515 the coxal gnathobases. Both these characters were subsequently identified by 516 Dunlop (2002) in at least one genus of chasmataspidid (including Octoberaspis), but 517 the group is defined here by the fusion of the anteriormost abdominal appendages 
518 to form a large genital operculum.

\section{Chasmataspidida}

520 In the EW analysis, the chasmataspidids are recovered as monophyletic on the basis 521 of genal spines in both coded species, and this clade is in turn sister group to the 522 eurypterids. The chasmataspidid-eurypterid clade is defined by the combined 523 presence of a metasoma, twenty-segmented body, and presence of a median 524 abdominal appendage. Eurypterids and chasmataspidids also share a very short first 525 opisthosomal tergite. In IW analyses, chasmataspidids are recovered as a grade 526 relative to the extant Xiphosura at higher $k$ values $(k=3.0, k=10.0)$, or split by $W$. 527 opitzi. Neither IW or EW topologies have strong support. That the group is 528 paraphyletic is in accordance with Tetlie \& Braddy (2004) and Shultz (2007), but 529 contra Dunlop et al. (2004). The IW results reflect a fundamental conflict relating to 530 chasmataspidids: in addition to the similarities between some chasmataspidids (e.g. 531 Diploaspis casteri, Octoberaspis ushakovi) and eurypterids, other taxa more closely 532 resemble horseshoe crabs (e.g. Chasmataspis laurencii, which is found as sister 533 group in IW analyses to Xiphosurida). Indeed when Chasmataspis laurencii groups 534 with xiphosurids it does so on the basis of the presence of a cardiac lobe. We note, 535 however, that all chasmataspids described to date share a similar and distinctive 536 body plan in which the opisthosoma consists of a short preabdomen and long nine537 segmented postabdomen. These synapomorphies are be outweighed in the IW 538 analysis by those shared with xiphosurans.

\section{Pycnogonida}

540 One result of the present analysis merits particular comment, namely the position of 541 Pycnogonida. The sea spiders usually resolve either as sister group of all other 542 chelicerates - which collectively form the Euchelicerata sensu Weygoldt \& Paulus 543 (1979) - or sometimes as sister group of all other arthropods in studies with a 544 broader taxon sampling; see Dunlop \& Arango (2005) for a review. In the present 545 study, in the trees including fossil taxa, Pycnogonida are monophyletic. This is to be 546 expected as there are many synapomorphies for both fossil and living sea spiders 547 such as the proboscis used for feeding or the unique oviger appendage. However in 548 the current analysis, Pycnogonida resolved in a more derived position based on our 549 dataset, specifically as the sister group of Arachnida. This result is controversial, but 550 has precedence among some mitochondrial DNA studies (e.g. Podsiadlowski \& 551 Braband 2006; Jeyaprakash \& Hoy 2009) which also recovered an ingroup position 552 for sea spiders. The work of Simon \& Hadrys (2013) makes apparent the problems of 553 using mtDNA for deep divergences in arthropod taxa, and indeed, Dunlop, Borner \& 554 Burmester (2014) cautioned that the mtDNA results in question may be an artefact. 555 We strongly suspect that is the case here. The position of of pycnogonids in this 556 study probably results from long branch attraction, coupled with taxon selection. 557 The pycnogonid clade has a multitude of synapomorphies, whilst the effect of the 558 outgroup is to place synziphosurine and merastomatid taxa at the base of the tree. 559 The limited number of completely preserved pycnogonid taxa precludes breaking up 
560 this long branch with such fossils. Rather this issue could be addressed in future 561 studies by adding further outgroup taxa sampling the origins of, and early splits 562 within, the total group chelicerates. These should include a range of Cambrian 563 arthropods. In addition to further megacheirans and xenopods, definitively 564 mandibulate taxa would be beneficial, as could be adding a non-arthropod outgroup, 565 or including novel characters suites to better test the polarity of pycnogonid 566 characters. Within the pycnogonids under EW the fossil taxa are recovered as a 567 grade to a polytomy comprising extant species, whereas in IW fossil taxa are 568 recovered as an internal clade due to multi-segmented chelicerae - the remaining 569 taxa are a polytomy. In extant-taxa only trees Pycnogonids are not monophyletic as

570 we have chosen to root the tree with a single species as the outgroup.

571

572

573

574

575

576

577

578

579

580

581

582

583

584

585

586

587

588

589

590

591

592

593

594

595

596

597

598

599

600

\section{Arachnida}

The present dataset universally recovers Arachnida as a monophyletic group, sharing the apomorphies across all analyses of lost appendages (at least in postembryonic instars) on opisthosomal segment 1 , and a tibial origin of the apotele depressor. In IW analysis this includes the presence of slit sense organs (albeit secondarily absent in Palpigradi). All arachnid orders with more than one taxon included were found to be monophyletic, with a single exception, highlighted below. A monophyletic Arachnida is in concordance with the majority of the published morphological (Weygoldt \& Paulus 1979; Shultz 1990, 2007) and molecular (Wheeler \& Hayashi 1998; Regier et al. 2010) analyses. However, as outlined below, relationships between the arachnid orders differs between the trees we present are dependent on analytical parameters.

Despite potential synapomorphies for a scorpion + eurypterid clade - such as a fivesegmented postabdomen (e.g. Dunlop \& Webster 1999) - this was not our most parsimonious result. The similarities between scorpions and sea scorpions would thus be homoplastic. This is supported by the results of the only published eurypterid phylogeny (Tetlie 2007; a tree based on an unpublished phylogeny from the author's PhD thesis ), who found that the most scorpion-like genera with strongly raptorial forelimbs and curved telsons (Mixopterus, Carcinosoma) resolve in a derived position within Eurypterida; again indicative of convergent character aquisition.

\section{Opiliones, Pseudoscorpiones, Scorpiones, Phalangiotarbida}

In all analyses excluding IW with low $k$ values $(k=0.25, k=1.0)$, we recover a weakly supported clade of the form ((Pseudoscorpiones + Scorpiones) + (Phalangiotarbida + Opiliones)). With extant taxa only under EW, a clade of the form (Opiliones (Scorpiones + Pseudoscorpiones)) is recovered, whilst in IW extant only analyses and with fossils and low k values, Stomothecata (i.e. Opiliones + Scorpiones) is recovered. In this case the relationship for the other members of the clade is (Phalangiotarbida + (Pseudoscorpiones + (all other non-stomothecata arachnids))). Synapomorphies for ((Pseudoscorpiones + Scorpiones) + (Phalangiotarbida + 
601 Opiliones)) include bicondylar femoropatella articulation, bicondylar patellotibial 602 articulation, and the presence of a cheliceral tergal-deutomerite muscle. We note, 603 however, that these characters are unknown for fossil taxa, including both 604 phalangiotarbid species. In a wider context, the position of Scorpiones has been one 605 of the most divisive issues in arachnid phylogeny. These animals have been 606 variously interpreted as closely related to eurypterids (see above), as sister group to 607 all other arachnids (Pocock 1893; Börner 1904; Weygoldt \& Paulus 1979) or more 608 recently as the sister group of Opiliones (Shultz 2000, 2007) based on the shared 609 presence of a preoral chamber formed from projections of the anterior leg coxae 610 (the stomotheca, hence Stomothecata). A recent alternative proposal from Sharma 611 et al. (2014) is Arachnopulmonata - a sister group relationship between the 612 scorpions and tetrapulmonates (spiders and their relatives, a group introduced 613 below). We recover Scorpiones and Opiliones within a clade, but with 614 Pseudoscorpiones and Phalangiotarbida included. The novel clade 615 (Pseudoscorpiones + Scorpiones) is an interesting result, because although 616 scorpions and pseudoscorpions look superficially similar, features like their large 617 pedipalpal claws are generally interpreted in modern analyses as homoplastic. Some 618 (non cladistic) studies did place pseudoscorpions and scorpions together, with 619 Savory (1971) introducing the name Scorpionides for these two orders, but again 620 this was largely based on inferences from gross morphology rather than explicit and 621 testable synapomorphies. Pepato, da Rocha \& Dunlop (2010) recovered (Scorpiones 622 + Pseudoscorpions) under some parameters of analysis and indeed our tree builds 623 upon their morphological dataset. In our EW analysis they are united by the nature 624 of their palpal chelae, presence of a patellotibial extensor, ventrally/posteroventrally 625 orientated anterior transpatellar muscle insertion, loss of the posterior patellotibial 626 muscle, and isolecithal/telolecithal eggs.

627 In most other cladistic studies (Weygoldt \& Paulus 1979; Shultz 1990, 2007; Wheeler 628 \& Hayashi 1998; Giribet et al. 2002) Pseudoscorpiones were placed as the sister 629 group of Solifugae, together forming the clade Haplocnemata; a name introduced by 630 Börner (1904). Putative synapomorphies identified for Haplocnemata include a very 631 short femur and a correspondingly long patella - in some schemes they were named 632 Apatellata because of confusion about whether these arachnids even had a proper 633 'knee' joint - and two pairs of tracheae opening on the the third and fourth 634 opisthosomal segments. We do not recover Haplocnemata in any of our analyses. A 635 number of morphological characters found in common between Pseudoscorpions 636 and Parasitiformes among the mites do not result in the grouping of these taxa in 637 any analyses. In our low $\mathrm{k}$ values $(\mathrm{k}=0.25, \mathrm{k}=1)$ analyses we recover stomothecata 638 in a form whereby many of the fossil scorpion taxa form a polytomy at the base of a 639 clade comprising the remaining scorpions and the harvestmen. This clade is a 640 polytomy between the fossil scorpion Compsoscorpius buthiformis, the crown group 641 Scorpiones, and the Opiliones. A plesiomorphic scorpion grade leading to crown 642 Stomothecata is novel, but only appears under a limited range of analytical 643 parameters.

644 Apart from the low $k$ values analyses where they are sister group to the non- 
645 Stomothecata arachnids, the Phalangiotarbida are recovered as sister group to the 646 Opiliones. This grouping has low support, and is supported only by the number of 647 body segments in the EW analysis. Previous hypotheses of relationships with 648 Opiliones were put forward by Petrunkevitch (1948) - and this is the first cladistic 649 support for this hypothesis. Alternatives of close relationships with the 650 Opilioacariformes among the mites (Dunlop 1995) or with the tetrapulmonate 651 arachnids (see below; Pollitt, Braddy \& Dunlop 2004) were not supported here. We 652 are cautious of this result however, which we believe lacks stability - in part, we 653 suspect, because of a lack of synapomorphies phalangiotarbids share with other 654 orders. Phalangiotarbids are unusual-looking creatures and preserve a series of 655 novel autapomorphies - short tergites, divided sternites, dorsal anal operculum, etc. 656 - none of which suggest an animal close to the morphological ground pattern of the 657 arachnids. Furthermore, important questions regarding the group's anatomy remain 658 unclear: for example the nature of their eyes. Many phalangiotarbid taxa possess six 659 eyes located on a median ocular tubercle. Pollitt, Braddy \& Dunlop (2004) tentatively 660 identified these as three pairs of lateral eyes. However, phalangiotarbid eyes could 661 equally represent one median eye pair, and two lateral pairs located in close 662 proximity to each other. We have coded the taxa as having the latter - many spiders 663 have a single tubercle bearing two median plus lateral eyes - but note the exact 664 nature of the eyes is impossible to ascertain in extinct groups. If phalangiotarbids 665 are coded as possessing three pairs of lateral eyes, they are recovered under EW in 666 a basal polytomy of non-palpigrade arachnids, along with clades comprising 667 Opiliones, (Pseudoscorpiones + Scorpiones), Pantetrapulmonates, and a clade 668 comprising all remaining taxa (Ricinulei + (Parasitiformes + (Solifugae + 669 Acariformes))). With IW under this coding they match the position seen in the low $\mathrm{k}$ 670 values trees presented herein. Unfortunately even tomography could not resolve key 671 features such as the nature of the chelicerae (chelate or 'clasp-knife'?) that could

672 support a more robust placement. In order to achieve any certainty, widespread 673 application of these techniques to currently known phalangiotarbids, or new fossil 674 discoveries, will be key.

675

676 Palpigradi

677 Palpigradi are enigmatic arachnids which appear to retain a suite of plesiomorphic 678 character states, such as chelicerae with three articles, multiple claws on the 679 pedipalp and a telson. Although superficially resembling whip scorpions 680 (Thelyphonida) they are widely perceived as 'primitive' arachnids and tend to 681 emerge as an early branching clade. A definitive position is hard to resolve and 682 previous studies showed little consistency in their results. We add no further 683 certainty here: the group resolves variously as sister group to all other arachnids 684 (EW) - reflecting the perception they may be plesiomorphic in their anatomy - but 685 also as sister group to a (Solifugae + Acariformes) clade at low k IW analyses, or at 686 higher $\mathrm{k}$ values as sister group to all arachnids minus the ((Pseudoscorpiones + 687 Scorpiones) + (Phalangiotarbida + Opiliones)) grouping. They appear as the earliest 688 branching members of the equivalent clade minus fossils in extant taxa only 689 analyses. The discovery of fossils with a plesiomorphic morphology for the group 
690 (palpigrades' fossil record is essentially non-existent: the only fossil cannot be 691 identified to family level) could provide key evidence to help move beyond this

692 impasse.

693

694

695

696

697

698

699

700

701

702

703

704

705

706

707

708

709

710

711

712

713

714

715

716

717

718

719

720

721

722

723

724

725

726

727

728

729

730

731

\section{Poecilophysidea}

As noted above, Solifugae were traditionally allied with Pseudoscorpiones in most of the recent phylogenetic studies. Authors such as Alberti \& Perreti (2002) challenged this proposal and demonstrated similarities, particularly in male genital characters, between Solifugae and the acariform branch of the mites. Two independent studies (Dabert et al. 2010; Pepato, da Rocha \& Dunlop 2010) formally recovered (Solifugae + Acariformes) based on molecular and molecular/morphological data respectively. A similar result was achieved molecular in a consensus supertree by Rota-Stabelli et al. (2013). This clade was formally named Poecilophysidea by Pepato, da Rocha \& Dunlop (2010) drawing on a historical name used for a solifuge-like mite. Our dataset - which we concede is largely derived from the Pepato, da Rocha \& Dunlop characters - also recovers Poecilophysidea under EW and three IW analyses, albeit with low support. The only exception is our IW, $k=3.0$ tree where we find solifuges as the earliest branching members of a clade also containing mites and the Ricinulei. In extant taxa-only analyses there is little resolution in this part of the tree. Where recovered, Poecilophysidea synapomorphies include a testis with a distinctly larger glandular area, and presence of a nuclear envelope. In analyses including fossils, with EW and IW $k=10.0$, we recover (Ricinulei + (Parasitiformes + Poecilophysidea)). In IW analyses at low $k$ values $(k=0.25, k=1.0)$, we recover the alternative (Palpigradi + Poecilophysidea); a result from Pepato, da Rocha \& Dunlop (2010) upon whose study this matrix is based, and who named this clade Cephalosomata. The recovered clade (Ricinulei + (Parasitiformes + Poecilophysidea)) is a novel result but one, we note, with low support.

\section{Ricinulei, Parasitiformes}

A recent topic of debate has been the position of Ricinulei (Giribet et al. 2002; Shultz 2007; Dunlop, Kamenz \& Talarico 2009). Traditionally, these rare arachnids were allied to the mites (Acari) on the synapomorphy of a hexapodal larva (Weygoldt and Paulus 1979). The proposal that mites are not monophyletic has challenged this relationship and in some studies Ricinulei were placed as the sister group of the Parasitiformes branch of the mites only (e.g. Shultz 2007). Alternatively, putative synapomorphies have been identified between Ricinulei and the extinct order Trigonotarbida, such as a locking mechanism between the prosoma and opisthosoma, tergites divided into median and lateral plates and a small terminal claw on the tip of the pedipalp (Dunlop 1996b; Dunlop, Kamenz \& Talarico 2009). To this we could add the observation of Talarico et al. (2011: fig. 2) that ricinuleids have small filtering projections immediately in front of the mouth remarkably similar to the condition seen in well preserved trigonotarbid arachnids (Dunlop 1994b, fig. 4; Garwood \& Dunlop 2010, fig. 6). One of the aims of the present study was to test whether the inclusion of trigonotarbids affects the position of Ricinulei: namely 
732 whether they are closest to one or both of the mite lineages or whether the addition

733 of trigonotarbids modifies their position, bringing them closer to the tetrapulmonate 734 arachnids. The result was not clear cut. With fossils in the EW analyses, and IW $735 \mathrm{~K}=10$ we recover a (Ricinulei + (Parasitiformes + (Acariformes + Solifugae))) clade. 736 In IW, however, at low K-values we find the Ricinulei are recovered as sister group to 737 trigonotarbids, within the Pantetrapulmonata, on the basis of the shared characters 738 already mentioned. In this case parasitiformes create a grade at the base of the 739 pantetrapulmonate/ricinuleid clade, with low support values. For IW $k=3.0$ we 740 recover a (Solifugae + (Acariformes + (Ricinulei + Parasitiformes))) clade. The

741 groupings we recover comprising Ricinulei, Parasitiformes, Acariformes and 742 Solifugae in various arrangements are poorly-supported, and are defined by the 743 presence of divided femora in legs 3 and 4 (albeit lost in some mite taxa), and a 744 hinged patellotibial articulation.

745 In a broader sense, our analysis contributes towards the growing support that mites 746 (Acari) are not a monophyletic group. In fact this hypothesis can be traced back to 747 early observations by Grandjean $(1935,1936)$ that there are numerous fundamental 748 differences in body plan between the acariform and parasitiform mites. Diphyletic 749 origins were formally proposed by Zachvatkin (1952) and were particularly 750 championed by van der Hammen (1989), and references therein. Van der Hammen's 751 impact was limited by his rejection of cladistics and most of the early cladistic 752 analyses treated Acari as an a priori monophyletic group (Weygoldt \& Paulus 1979; 753 Shultz 1990); sometimes simply scoring a generalised 'mite' as a terminal taxon. 754 Subsequent studies tried to test mite monophyly by adding in a range of acariforms 755 and parasitiforms as terminals and, as in our scheme, often recovered the two major 756 lineages in divergent positions on the final tree (Shultz 2007; Pepato, da Rocha \& 757 Dunlop 2010). All mites share the putative synapomorphy of a gnathosoma - a 758 movable unit including the chelicerae, pedipalps and mouth lips, but this single 759 character is being increasingly outweighed by other data. Acariform mites often 760 resolve closest to camel spiders (Solifugae; as in some trees in this study) while 761 parasitiform mites may resolve close to ricinuleids (this study; see below) or 762 Pseudoscorpiones (Regier et al. 2010).

763

764

765

766

767

768

769

770

771

772

773

774

Pantetrapulmonata

Shear \& Selden (1986), Shear et al. (1987) and Selden et al. (1991) did pioneering work on integrating the extinct order Trigonotarbida into cladistic analyses of living arachnids. Through identifying characters like the presence of two pairs of book lungs and 'clasp-knife' chelicerae where the fang articulates against a basal segment they concluded that Trigonotarbida is the sister group of Tetrapulmonata (see below). Further characters and character states in our analysis derived from recently generated tomographic datasets (Garwood et al. 2009; Garwood \& Dunlop 2011, Dunlop \& Garwood 2014) continue to support this hypothesis both in the EW and IW trees, with the exception of low K-values where trigonotarbids are sister group to ricinuleids, and this clade is sister group to other tetrapulmonates. There is moderate support for this arrangement, which is otherwise not recovered elsewhere. 


\section{PeerJ Reviewing Manuscript}

775 Shultz (2007) formally named the (Trigonotarbida + Tetrapulmonata) group

776 Pantetrapulmonata; a name we also adopt here.

777 Tetrapulmonata

778 Our data also strongly supports Tetrapulmonata (i.e. Haptopoda, Amblypygi, 779 Thelyphonida, Schizomida, Araneae and Uraraneida); an unsurprising result as this is 780 probably one of the least controversial clades within the arachnids (reviewed by 781 Dunlop, Borner \& Burmester 2014). An evolutionary lineage including spiders, whip 782 spiders and whip scorpions can be traced back in some form to early studies such as 783 Pocock (1893) and Börner (1904), and is widely recovered from both morphological 784 (Shultz 2007) and molecular (Regier et al. 2010, Sharma et al 2014) datasets.

785

786

787

788

789

790

791

792

793

794

795

796

797

798

799

800

801

802

803

804

805

806

807

808

809

810

811

812

813

814

\section{Schizotarsata}

Our novel tomographic data for Haptopoda is important in that it confirms that these animals had 'clasp-knife' chelicerae comprising only two articles (Fig. 1B): a basal paturon and a fang. This in turn reinforces the supposition that Haptopoda belong to Tetrapulmonata, and are not Opiliones (contra Shear \& Kukalová-Peck 1990, p. 1812) in which case we would have expected chelate chelicerae with three articles. As per Shultz (2007), Haptopoda resolves in our trees as the sister group of Pedipalpi (see below). This supports his proposed clade Schizotarsata, which as before can be defined on the synapomorphy of walking legs II-IV sharing a specific pattern of three distal tarsomeres.

\section{Pedipalpi}

Amblypygi, Thelyphonida and Schizomida were originally combined as a single arachnid order, Pedipalpi (e.g. Börner 1904). This name is now usually used to recognise a clade of these three taxa. Thelyphonida and Schizomida are unquestionably sister taxa and until 1945 were treated as a single order (e.g. Pocock 1911). There remains debate about the position of the whip spiders (Amblypygi). Pedipalpi has a number of putative synapomorphies including an elongate first pair of legs and the raptorial pedipalps which give the clade its name. To this Shultz (1999) added numerous skeleto-muscular characters; albeit not tested across all Arachnida. The alternative hypothesis is Labellata (Amblypygi + Araneae) whereby whip spiders and spiders share characters such as a narrow pedicel between the prosoma and opisthosoma, a coalescence of the nerve ganglia in the prosoma, and a postcerebral sucking stomach. These two hypotheses and their apomorphies were compared by Alberti \& Michalik (2004, fig. 48). Pedipalpi was recovered by Shultz (1990, 2007), Giribet et al. (2002) and Regier et al. (2010). Labellata was supported by Weygoldt \& Paulus (1979), Wheeler \& Hayashi (1998) and Alberti \& Michalik (2004). In the present analysis Pedipalpi resolves as the most parsimonious solution, with the extinct Haptopoda as its sister group as noted above. The divided prosomal shield of Schizomida is thus assumed here to be homoplastic with respect to the Cephalosomata group (see above). 
816 This paper builds upon the work of Legg, Sutton \& Edgecombe (2013) in formally 817 testing the position of the extinct order Uraraneida. The Devonian genus Attercopus 818 fimbriunguis was initially interpreted as a trigonotarbid (Shear et al. 1987) and was 819 later proposed as the oldest spider (Selden et al. 1991). Subsequently, new 820 Devonian material came to light which - combined with data from a Permian fossil 821 originally thought to be a mesothele spider (Eskov \& Selden 2005) - revealed that 822 there was a lineage of Palaeozoic arachnids which resembled spiders, but lacked 823 spinnerets and retained a flagelliform telson rather like a whip scorpion. Selden et al. 824 (2008) redescribed these fossils and proposed a new order, Uraraneida, to 825 accommodate them. They also suggested that uraraneids were probably close to the 826 origins of spiders, sharing with them the presence of silk spigots, but not fully 827 developed spinnerets. Predictably, we recovered (Uraraneida + Araneae) with strong 828 support. Araneae are united in this analysis by the presence of opisthosomal 829 spinnerets, and (Urarineida + Araneae) by silk glands, a naked cheliceral fang and 830 the putative presence of a cheliceral venom gland if there really is a gland pore on 831 the fang of $A$. fimbriunguis. We propose here the clade name Serikodiastida to 832 formally recognise this relationship. The name derives from the Greek serikodiastes

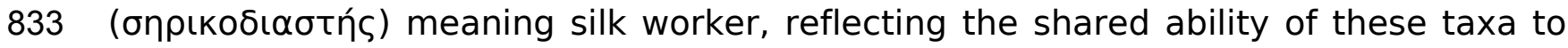
834 produce silk.

Glossary

836 Chelicerata s.l. - pycnogonids + euchelicerates.

837 Euchelicerata - xiphosurids, eurypterids + arachnids.

838 Merostomata - xiphosurids + eurypterids.

839 Metastomata - eurypterids + arachnids.

840 Stomothecata - scorpions + opilionids.

841 Haplocnemata/Apatella - pseudoscorpions + solifuges (widely supported).

842 Acaromorpha - ricinuleids, acariformes + parasitiforms (widely supported).

843 Pantetrapulmonata - trigonotarbids + tetrapulmonates

844 Arachnopulmonata - scorpions + tetrapulmonates

845 Tetrapulmonata - spiders, amblipygids, whip scorpions + schizomids. This almost 846 certainly includes uraraneids since their publication in 2008 (Selden et al 2008).

847 Schizotarsata - haptopods + pedipalpids.

848 Pedipalpi - amblypygids + thelyphonids + schizomids.

849 Labellata - spiders + amblypygids.

850 Cryptoperculata - opilionids, ricinuleids + mites.

851 Dromopoda - opilionids, scorpions + haplocnemataids

852 Poecilophysidea - solifuges + acariform mites.

853 Cephalosomata - palpigrades, solifuges + acariform mites.

854 Serikodiastida - A name coined herein for uraraneids + Araneae.

855 Impact of fossils 
856

857

858

859

860

861

862

863

864

865

866

867

868

869

870

871

872

873

874

875

876

877

878

879

880

881

882

883

884

885

886

887

888

889

890

891

892

893

894

895

896

897

898

899

One aim of this study was to include fossils with excellent and (where possible) three-dimensional preservation in a phylogenetic analysis, in order to place extinct arachnid orders. It also allows us to explore the impact their inclusion has on our understanding of chelicerate relationships. A quantitative assessment of this impact is beyond the scope of the current paper, and will be an avenue of exploration for future work. Nevertheless, we believe adding fossils to this matrix has been illustrative. It demonstrates that the addition of fossils breaks up long branches - the most extreme example being the Pedipalpi, which is defined by 28 synapomorphies in the analysis of extant taxa only, but has only three synapomorphies following the introduction of Haptopoa and Trigonotarbida. The addition of further crown group members of the constituent clades would not have this effect (see also Edgecombe 2010, Legg, Sutton \& Edgecombe 2013). Despite the addition of fossils, long branches remain problematic in some parts of the trees presented herein - most prominently in the pycnogonids. This is an ancient group with a sparse fossil record (Dunlop \& Arango 2005, Dunlop 2010) - accordingly the discovery of novel and complete fossil species will be key to the group's correct placement. Recently discovered species (Kühl, Poschmann \& Rust 2013; Rudkin et al. 2013) have proven too incomplete in their preservation for confident placement of species, compounded by poor understanding of their ontogeny. The addition of fossils also results in some changes in tree topology. Stomothecata is present in the IW extantonly analysis - its absence from EW trees suggests the grouping is not stable to the addition of novel characters. With the addition of fossils in IW analyses, it is only recovered at low $\mathrm{k}$ values. The lack of support for Stomothecata comes about in part because two fossil scorpions and the tetropthalmid harvestman Hastrocularis argus (Garwood et al. 2014) lack a stomotheca composed of palpal and first leg coxapophyses. Similarly, the addition of fossils - most notably Offacolus kingi (Sutton et al. 2002) and Dibasterium durgae (Briggs et al. 2012) - results in a paraphyletic Synziphosura as previously discussed (Lamsdell 2013). Such cases suggest the plesiomorphic elements present in fossils' anatomy appear key to their placement, and this can have significant impact on our understanding of chelicerate evolution. In this example, the addition of fossils (based on IW analyses) would imply a last common chelicerate ancestor that was synziphosurine in form and so directly impacts on our model of chelicerate origins. Finally, the addition of fossils to the current analysis makes the resulting topology better resolved as shown in Figure 3, and adds stability. A strict consensus tree of analyses conducted at $k=0.25,1.0,3.0$ and 10.0 using just extant taxa resolves all arachnid orders in a polytomy, demonstrating the changeability of tree topology with differing concavity constants. The same tree with fossils (i.e. a consensus of analyses with varying concavity constants) in is still largely a polytomy, but there is slightly better resolution - a nested clade appears in the arachnids including all taxa non-scorpion, opilionid and pseudoscorpion taxa.

We believe this study demonstrates fossils' utility in phylogenetic analyses - as reflected in other works (see overview by Edgecombe, 2010) - even in a group often assumed to have a patchy fossil record. However, we reiterate the caveat that even 
900 with fossils a number of our clades are poorly supported, and indeed there are still 901 significant changes in tree topology between differing analytical parameters.

\section{Conclusion}

903 Adding a small number of fossils to a phylogenetic analysis of the chelicerates 904 changes the topology of the trees recovered, reducing support for several clades, 905 and increasing support for others. Recent decades have seen morphologically-driven 906 cladistic analyses achieve elements of consensus - arguably in contrast to the more 907 variable findings of molecular studies. The skeletomuscular characters of 908 morphological analyses are, in this analysis, not robust to the addition of novel 909 characters and fossil taxa. This instability could result from a paucity of fossils that 910 sample the timing of cladogenesis (Legg, Sutton \& Edgecombe 2013), or from the 911 fact that chelicerate origins lie in an ancient rapid radiation, as reported for the 912 insects (Whitfield \& Kjer 2008). Whatever the cause, we suggest that chelicerate 913 phylogeny - as molecular studies suggest - remains in a state of flux. Furthermore, 914 we believe the discovery of novel fossils sampling periods closer to both chelicerate 915 and arachnid origins will be integral to changing this. 
917 Figure 1. Digital visualisations of the haptopod Plesiosiro madeleyi (NHM 17923; A918 D), and phalangiotarbid Goniotarbus angulatus (NHM In22838; E-I). A. Dorsal view of 919 P. madeleyi, showing opisthosomal segmentation and prosomal shield architecture. 920 B. Lateral view of the anterior ventral prosoma, nearest limbs and lateral prosoma removed, showing the nature of haptopod chelicerae. C. Ventral view, showing 922 ventral segmentation, and divided sternum. D. Haptopod walking leg. E. First left walking leg of $G$. angulatus, showing typical segmentation. F. Lateral view of the anterior ventral prosoma, showing the small pedipalps, median ridge, and possible chelicerae - below the resolution of the scan. G. Fourth right walking leg. $\mathrm{H}$. Dorsal view showing median eyes and dorsal opisthosomal segmentation. I. Ventral view showing opisthosomal segmentation and coxo-sternal region. Abbreviations: 1-10 opisthosomal segment number; as - anterior sclerite; ch - chelicerae; cx - coxa; fa fang; fe- femur; L1-L4 - walking legs 1-4; me - media eyes; mt - metatarsus; pa paturon; pp - pedipalps; ps - posterior sclerite; pt - patella; ta - tarsus; ti - tibia; tr trochanter. Scale bars: A,C,F-I $=3 \mathrm{~mm} ; \mathrm{B}, \mathrm{D}, \mathrm{E}=1 \mathrm{~mm}$.

932 Figure 2. Holotype and only known specimen of phalangiotarbid Goniotarbus 933 angulatus (NHM In22838). A. Dorsal view, showing prosoma and opisthosoma, and 934 legs $4 \mathrm{~L}$ and $2 \mathrm{~L}$. Proximal portions of Leg $1 \mathrm{~L}$ are visible at the anterior of the fossil, as 935 are the trochanters of several of the legs on the right. B. Ventral view showing coxo936 sternal arrangement and ventral opisthosomal segmentation. Proximal portions of 937 Leg $1 \mathrm{~L}$, then $2 \mathrm{~L} 3 \mathrm{~L}$ and $4 \mathrm{~L}$ are visible. C. A close up of the sternum, anterior to the 938 left showing five constituent plates. D. Detail of the anterior opisthosomal 939 segmentation, including the posterior median bulge of the prosomal shield, and 940 associated accommodation in the anterior opisthosomal segments. E. The 941 posteriormost segments (7-10) fused to create a single dorsal plate, with a terminal 942 anal operculum. Scale bars: $A, B=2 \mathrm{~mm} ; C-E=1 \mathrm{~mm}$.

943 Figure 3. Results of the cladistic analysis presented herein under equal weights 944 (EW). The trees show the strict consensus of equally weighted analyses of the 945 matrices presented here (SI file 2,3, morphobank project 1274). A. Tree showing the 946 analysis results with fossils included. Bremer, jackknife and bootstrap support values 947 are provided for each node as shown in the key. B. Tree recovered with fossil 948 terminals removed - ordinal clades are collapsed for clarity.

Figure 4. Results of the cladistic analysis presented herein under implied weights 950 (IW). The trees show the strict consensus of implied weights analyses of the 951 matrices presented here (SI file 2, morphobank project 1274). Symmetric resampling 952 support values are provided on the basis that these are unaffected by character 953 weights. A. The topology for concavity constants ( $k$ values) 0.25 and 1.0, which are 954 identical. $\mathrm{K}=0.25$ support value above each node in red, $\mathrm{K}=1.0$ below in grey. $\mathrm{B}$. 955 Tree for $k=3.0$. C. Topology for $k=10.0$. 


\section{Acknowledgements}

957 We thank: Claire Mellish (NHM), and Jon Clatworthy (Lapworth Museum Birmingham) 958 for access to fossils in their care; David Legg for a helpful review and cladistics 959 advice; Jo Wolfe and an anonymous reviewer for their valuable comments; and 960 Sandra Thomas for advice on Latin and Greek vocabulary and grammar. We would 961 like to acknowledge the assistance provided by the Manchester X-ray Imaging 962 Facility, which was funded in part by the EPSRC (grants EP/F007906/1, EP/F001452/1 963 and EP/I02249X/1). RG is an 1851 Royal Commission Research Fellow, a Scientific 964 Associate at the Natural History Museum, London, and member of the 965 Interdisciplinary Centre for Ancient Life (UMRI). This paper was completed, in part, 966 during a SYNTHESYS visit to the Museum fur Naturkunde Berlin awarded to RG. 


\section{References}

968 Alberti, G. \& Michalik, P. (2004). Feinstrukturelle Aspekte der Fortpflanzungssysteme 969 von Spinnentieren (Arachnida). Denisia, 12, 1-62.

970 Alberti, G. \& Peretti, A. V. (2002). Fine structure of male genital system and sperm in 971 Solifugae does not support a sistergroup relationship with Pseudoscorpiones 972 (Arachnida). The Journal of Arachnology, 30, 268-274.

973 Bergström, J., Stürmer, W., \& Winter, G. (1980). Palaeoisopus, Palaeopantopus and 974 Palaeothea, pycnogonid arthropods from the Lower Devonian Hunsriick Slate, West

975 Germany. Paläontologische Zeitschrift, 54(1-2), 7-54.

976 Bercovici, A., Hadley, A., \& Villanueva-Amadoz, U. (2009). Improving depth of field 977 resolution for palynological photomicrography. Palaeontologia Electronica, 12(2), 12.

978 Börner, C. (1904). Beiträge zur Morphologie der Arthropoden. I. Ein Beitrag zur 979 Kenntnis der Pedipalpen. Zoologica, 42, 1-147.

980 Bremer, K. (1994). Branch support and tree stability. Cladistics, 10(3), 295-304.

981 Briggs, D. E., \& Collins, D. (1999). The arthropod Alalcomenaeus cambricus 982 Simonetta, from the Middle Cambrian Burgess Shale of British Columbia. 983 Palaeontology, 42(6), 953-977.

984 Briggs, D. E., Siveter, D. J., Siveter, D. J., Sutton, M. D., Garwood, R. J., \& Legg, D. 985 (2012). Silurian horseshoe crab illuminates the evolution of arthropod limbs. 986 Proceedings of the National Academy of Sciences, 109(39), 15702-15705.

987 Chen, J.-y., Waloszek, D. \& Mass, A. (2004). A new 'great-appendage' arthropod from 988 the Lower Cambrian of China and homology of chelicerate chelicerae and raptorial 989 antero-ventral appendages. Lethaia, 37, 3-20.

990 Cobbett, A., Wilkinson, M., \& Wills, M. A. (2007). Fossils impact as hard as living taxa 991 in parsimony analyses of morphology. Systematic Biology, 56(5), 753-766.

992 Dabert, M. Witalinski, W., Kazmierski, A., Olszanowski, Z., \& Dabert, J. (2010).

993 Molecular phylogeny of acariform mites (Acari, Arachnida): Strong conflict 994 between phylogenetic signal and long-branch attraction artifacts. Molecular 995 Phylogenetics and Evolution, 56, 222-241.

996 Dunlop, J. A. (1994a). Palaeobiology of the Trigonotarbida. PhD Thesis, University of 997 Manchester, 612p.

998 Dunlop, J. A. (1994b). Filtration mechanisms in the mouthparts of tetrapulmonate 999 arachnids (Trigonotarbida, Araneae, Amblypygi, Uropygi, Schizomida). Bulletin of the 1000 British Arachnological Society, 9, 267-273. 
1001 Dunlop, J. A. (1995). Are the fossil phalangiotarbids just big opilioacarid mites? 1002 Newsletter of the British arachnological Society, 74: 8-9.

1003 Dunlop, J. A. (1996a). A redescription of the trigonotarbid arachnid Pocononia whitei 1004 (Ewing 1930). Paläontologische Zeitschrift, 70(1-2), 145-151.

1005 Dunlop, J. A. (1996b). Evidence for a sister group relationship between Rininulei and 1006 Trigonotarbida. Bulletin of the British Arachnological Society, 10, 193-204.

1007 Dunlop, J. A. (1999). A redescription of the Carboniferous arachnid Plesiosiro 1008 madeleyi Pocock, 1911 (Arachnida: Haptopoda). Transactions of the Royal Society of 1009 Edinburgh, Earth Sciences 90,29-47.

1010 Dunlop, J. A. (2002). Arthropods from the Lower Devonian Severnaya Zemlya 1011 Formation of October Revolution Island (Russia). Geodiversitas, 24(2), 349-379.

1012 Dunlop, J.A. (2006). New ideas about the euchelicerate stem-lineage. In: C. 1013 Deltshev and P. Stoev (eds.), European Arachnology 2005. Acta Zoologica Bulgarica 1014 (Supplement 1): 9-27.

1015 Dunlop, J. A. (2010). Geological history and phylogeny of Chelicerata. Arthropod 1016 structure \& development, 39(2), 124-142.

1017 Dunlop, J. A. \& Arango, C. P. (2005). Pycnogonid affinities: a review. Journal of 1018 Zoological Systematics and Evolutionary Research, 43, 8-21.

1019 Dunlop, J. A., Anderson, L. I., \& Braddy, S. J. (2004). A redescription of Chasmataspis 1020 laurencii Caster \& Brooks, 1956 (Chelicerata: Chasmataspidida) from the Middle 1021 Ordovician of Tennessee, USA, with remarks on chasmataspid phylogeny. 1022 Transactions of the Royal Society of Edinburgh: Earth Sciences, 94, 207-225.

1023 Dunlop, J. A., Anderson, L. I., Kerp, H., \& Hass, H. (2003). A harvestman (Arachnida: 1024 Opiliones) from the Early Devonian Rhynie cherts, Aberdeenshire, Scotland. 1025 Transactions of the Royal Society of Edinburgh: Earth Sciences, 94(04), 341-354.

1026 Dunlop, J. A., Borner, J. \& Burmester, T. (2014). Phylogeny of the chelicerates: 1027 morphological and molecular evidence. 399-412. In Wägele, J. W. \& Bartolomaeus, T. 1028 (eds). Deep Metazoan phylogeny: the backbone of the tree of life. De Gruyter, 1029 Berlin, xxv + $736 \mathrm{pp}$.

1030 Dunlop, J. A., \& Garwood, R. J. (2014). Tomographic reconstruction of the 1031 exceptionally preserved trigonotarbid arachnid Eophrynus prestvicii. Acta 1032 Palaeontologica Polonica 59(2), 443-154.

1033 Dunlop, J. A., \& Horrocks, C. A. (1997). Phalangiotarbid arachnids from the Coal 1034 Measures of Lancashire, UK. Geological Magazine, 134(03), 369-381.

1035 Dunlop, J. A., Kamenz, C., \& Talarico, G. (2009). A fossil trigonotarbid arachnid with a 
1036 ricinuleid-like pedipalpal claw. Zoomorphology, 128(4), 305-313.

1037 Dunlop, J. A., Penney, D. \& Jekel, D. (2014). A summary list of fossil spiders and their 1038 relatives. In Platnick, N. I. (ed.) The world spider catalog, version 14.5 American 1039 Museum of Natural History, online at 1040 http://research.amnh.org/entomology/spiders/catalog/index.html

1041 Dunlop, J. A., Scholtz, G., \& Selden, P. A. (2013). Water-to-Land Transitions. In 1042 Arthropod Biology and Evolution (pp. 417-439). Springer Berlin Heidelberg.

1043 Dunlop, J. A., Tetlie, O. E., \& Prendini, L. (2008). Reinterpretation of the Silurian 1044 scorpion Proscorpius osborni (Whitfield): Integrating data from Palaeozoic and recent 1045 scorpions. Palaeontology 51(2):303-320.

1046 Dunlop, J. A., \& Webster, M. (1999). Fossil evidence, terrestrialization and arachnid 1047 phylogeny. Journal of Arachnology, 86-93.

1048 Edgecombe, G. D. (2010). Palaeomorphology: fossils and the inference of cladistic 1049 relationships. Acta Zoologica, 91(1), 72-80.

1050 Edgecombe, G. D., García-Bellido, D. C., \& Paterson, J. R. (2011). A new leanchoiliid 1051 megacheiran arthropod from the lower Cambrian Emu Bay Shale, South Australia. 1052 Acta Palaeontologica Polonica, 56(2), 385-400.

1053 Eskov, K. Y. \& Selden, P. A. (2005). First record of spiders from the Permian period 1054 (Araneae: Mesothelae). Bulletin of the British Arachnological Society, 13, 111-116.

1055 Farris, J. S., Albert, V. A., Källersjö, M., Lipscomb, D., \& Kluge, A. G. (1996). Parsimony 1056 jackknifing outperforms neighbor-joining. Cladistics, 12(2), 99-124.

1057 Felsenstein, J. (1985). Confidence limits on phylogenies: an approach using the 1058 bootstrap. Evolution, 39(4), 783-791.

1059 Garwood, R., Dunlop, J. A., \& Sutton, M. D. (2009). High-fidelity X-ray micro1060 tomography reconstruction of siderite-hosted Carboniferous arachnids. Biology 1061 Letters, 5(6), 841-844.

1062 Garwood, R. J., \& Dunlop, J. A. (2010). Trigonotarbids. Geology Today, 26(1), 34-37.

1063 Garwood, R. J., \& Dunlop, J. A. (2011). Morphology and systematics of 1064 Anthracomartidae (Arachnida: Trigonotarbida). Palaeontology, 54(1), 145-161.

1065 Garwood, R. J., \& Dunlop, J. A. (2014). The walking dead: Blender as a tool for 1066 palaeontologists. Journal of Palaeontology 88(4), 735-746.

1067 Garwood, R. J., \& Edgecombe, G. D. (2011). Early terrestrial animals, evolution, and 1068 uncertainty. Evolution: Education and Outreach, 4(3), 489-501.

1069 Garwood, R., Ross, A., Sotty, D., Chabard, D., Charbonnier, S., Sutton, M., \& Withers, 
1070 P. J. (2012). Tomographic reconstruction of neopterous Carboniferous Insect Nymphs. 1071 PloS one, 7(9), e45779.

1072 Garwood, R. J., Sharma, P. P., Dunlop, J. A., \& Giribet, G. (2014). A Paleozoic stem 1073 group to mite harvestmen revealed through integration of phylogenetics and 1074 development. Current Biology, 24(9), 1017-1023.

1075 Giribet, G., Edgecombe, G. D., Wheeler, W. C. \& Babbitt, C. (2002). Phylogeny and 1076 systematic position of Opiliones: a combined analysis of chelicerate relationships 1077 using morphological and molecular data. Cladistics, 18, 5-70.

1078 Goloboff, P. A. (1993). Estimating character weights during tree search. Cladistics, 1079 9(1), 83-91.

1080 Goloboff, P. A., Carpenter, J. M., Arias, J. S., \& Esquivel, D. R. M. (2008). Weighting 1081 against homoplasy improves phylogenetic analysis of morphological data sets. 1082 Cladistics, 24(5), 758-773.

1083 Goloboff, P. A., Farris, J. S., Källersjö, M., Oxelman, B., \& Szumik, C. A. (2003). 1084 Improvements to resampling measures of group support. Cladistics, 19(4), 324-332.

1085 Goloboff, P. A., Farris, J. S., \& Nixon, K. C. (2008). TNT, a free program for 1086 phylogenetic analysis. Cladistics, 24(5), 774-786.

1087 Grandjean, F. (1935). Observations sur les Acariens (1re serie). Bulletin du Muséum 1088 National d'Histoire Naturelle Paris, 7, 119-126.

1089 Grandjean, F. (1936). Un acarien synthétique: Opilioacarus segmentatus With. 1090 Bulletin de la Société d'Histoire Naturelle de l'Afrique du Nord, 27, 413-444.

1091 Hammen, L. van der (1989). An Introduction to Comparative Arachnology. The 1092 Hague: SPB Academic Publishing.

1093 Haug, J. T., Briggs, D. E., \& Haug, C. (2012a). Morphology and function in the 1094 Cambrian Burgess Shale megacheiran arthropod Leanchoilia superlata and the 1095 application of a descriptive matrix. BMC Evolutionary Biology, 12(1), 162.

1096 Haug, J. T., Waloszek, D., Maas, A., Liu, Y. \& Haug, C. (2012b). Functional 1097 morphology, ontogeny and evolution of mantis shrimp-like predators in the 1098 Cambrian. Palaeontology, 55, 369-399.

1099 Hirst, S. (1923). XLVI.-On some Arachnid remains from the Old Red Sandstone 1100 (Rhynie Chert Bed, Aberdeenshire). Journal of Natural History, 12(70), 455-474.

1101 Jeram, A. J. (1990). Book-lungs in a Lower Carboniferous scorpion. Nature, 343, 360 1102361.

1103 Jeram, A. J. (1993). Scorpions from the Viséan of East Kirkton, West Lothian, 1104 Scotland, with a revision of the infraorder Mesoscorpionina. Transactions of the Royal 
1105

1106

1107

1108

1109

1110

1111

1112

1113

1114

1115

1116

1117

1118

1119

1120

1121

1122

1123

1124

1125

1126

1127

1128

1129

1130

1131

1132

1133

1134

1135

1136

1137

1138

1139

1140

Society of Edinburgh: Earth Sciences, 84(3-4), 283-299.

Jeyaprakash, A. \& Hoy, M. A. (2009). First divergence time estimate of spiders, scorpions, mites and ticks (subphylum: Chelicerata) inferred from mitochondrial phylogeny. Experimental and Applied Acarology, 47, 1-18.

Kamenz, C., Staude, A. \& Dunlop, J. A. (2011). Sperm carriers in Silurian sea scorpions. Naturwissenschaften, 98, 889-896.

Kearney, M., \& Clark, J. M. (2003). Problems due to missing data in phylogenetic analyses including fossils: a critical review. Journal of Vertebrate Paleontology, 23(2), 263-274.

Kraus O. (1976). Zur phylogenetischen Stellung und Evolution der Chelicerata. Entomologica Germanica, 3, 1-12.

Kraus, O., \& Kraus, M. (1993). Divergent transformation of chelicerae and original arrangement of eyes in spiders (Arachnida, Araneae). Memoirs of the Queensland Museum, 33, 579-584.

Kühl, G., Bergmann, A., Dunlop, J., Garwood, R. J., \& Rust, J. (2012). Redescription and palaeobiology of Palaeoscorpius devonicus Lehmann, 1944 from the Lower Devonian Hunsrück Slate of Germany. Palaeontology, 55(4), 775-787.

Kühl, G., Poschmann, M., \& Rust, J. (2013). A ten-legged sea spider (Arthropoda: Pycnogonida) from the Lower Devonian Hunsrück Slate (Germany). Geological Magazine, 150(3), 556-564.

Lamsdell, J. C. (2013). Revised systematics of Palaeozoic 'horseshoe crabs' and the myth of monophyletic Xiphosura. Zoological Journal of the Linnean Society, 167(1), $1-27$.

Legg, D. A. (2013). Multi-segmented arthropods from the middle Cambrian of British Columbia (Canada). Journal of Paleontology, 87(3), 493-501.

Legg, D. A., \& Caron, J. B. (2014). New middle Cambrian bivalved arthropods from the Burgess Shale (British Columbia, Canada). Palaeontology, 4, 691-711.

Legg, D. A., Garwood, R. J., Dunlop, J. A., \& Sutton, M. D. (2012). A taxonomic revision of orthosternous scorpions from the English Coal Measures aided by x-ray micro-tomography (XMT). Palaeontologia Electronica, 15(1), 1-16.

Legg, D. A., Sutton, M. D., \& Edgecombe, G. D. (2013). Arthropod fossil data increase congruence of morphological and molecular phylogenies. Nature communications, 4, 2485.

Legg, D. A., Sutton, M. D., Edgecombe, G. D., \& Caron, J. B. (2012). Cambrian bivalved arthropod reveals origin of arthrodization. Proceedings of the Royal Society B: Biological Sciences, 279 (1748):4699-4704. 
1141 Moore, R. A., Briggs, D. E., \& Bartels, C. (2005). A new specimen of Weinbergina 1142 opitzi (Chelicerata: Xiphosura) from the Lower Devonian Hunsrück Slate, Germany. 1143 Paläontologische Zeitschrift, 79(3), 399-408.

1144 Ortega-Hernández, J., Legg, D. A., \& Braddy, S. J. (2013). The phylogeny of 1145 aglaspidid arthropods and the internal relationships within Artiopoda. Cladistics, 1146 29(1), 15-45.

1147 Pepato, A. R., da Rocha, C. E., \& Dunlop, J. A. (2010). Phylogenetic position of the 1148 acariform mites: sensitivity to homology assessment under total evidence. BMC 1149 Evolutionary Biology, 10(1), 235.

1150 Petrunkevitch, A. I. (1948). The case of Phalangiotarbus subovalis Woodward. 1151 American Journal of Science, 246: 353-362.

1152 Petrunkevitch, A. (1949). A study of Palaeozoic Arachnida (Vol. 37). Connecticut 1153 Academy of Arts and Sciences.

1154 Petrunkevitch, A. (1953). Paleozoic and Mesozoic Arachnida of Europe. Geological 1155 Society of America.

1156 Pocock, R. I. (1893). On some points in the morphology of the Arachnida (s.s.), with 1157 notes on the classification of the group. Annals and Magazine of Natural History, 1158 (6)11, 1-19.

1159 Pocock, R. I. (1911). A monograph of the terrestrial Carboniferous Arachnida of 1160 Great Britain. Monographs of the Palaeontographical Society.

1161 Podsiadlowski, L. \& Braband, A. (2006.) The mitochondrial genome of the sea spider 1162 Nymphon gracile (Arthropoda: Pycnogonida). BMC Genomics, 7, 284.

1163 Pointon, M. A., Chew, D. M., Ovtcharova, M., Sevastopulo, G. D., \& Crowley, Q. G. 1164 (2012). New high-precision U-Pb dates from western European Carboniferous tuffs; 1165 implications for time scale calibration, the periodicity of late Carboniferous cycles 1166 and stratigraphical correlation. Journal of the Geological Society, 169(6), 713-721.

1167 Pollitt, J. R., Braddy, S. J., \& Dunlop, J. A. (2004). The phylogenetic position of the 1168 extinct arachnid order Phalangiotarbida Haase, 1890, with reference to the fauna 1169 from the Writhlington Geological Nature Reserve (Somerset, UK). Transactions of the 1170 Royal Society of Edinburgh: Earth Sciences, 94(3), 243-259.

1171 Poschmann, M., Dunlop, J. A., Kamenz, C., \& Scholtz, G. (2008). The Lower Devonian 1172 scorpion Waeringoscorpio and the respiratory nature of its filamentous structures, 1173 with the description of a new species from the Westerwald area, Germany. 1174 Paläontologische Zeitschrift, 82(4), 418-436.

1175 Regier, J. C., Shultz, J. W., Zwick, A., Hussey, A., Ball, B., Wetzer, R., Martin, J. W. \& 1176 Cunningham, C. W. (2010). Arthropod relationships revealed by phylogenomic 1177 analysis of nuclear protein-coding sequences. Nature, 463, 1079-1084. 
1178

1179

1180

1181

1182

1183

1184

1185

1186

1187

1188

1189

1190

1191

1192

1193

1194

1195

1196

1197

1198

1199

1200

1201

1202

1203

1204

1205

1206

1207

1208

1209

1210

1211

1212

1213

1214

1215

Rehm, P., Borner, J., Meusemann, K., von Reumont, B. M., Simon, S., Hadrys, H., Misof, B., \& Burmester, T. (2011). Dating the arthropod tree based on large-scale transcriptome data. Molecular phylogenetics and evolution, 61(3), 880-887.

Rota-Stabelli, O., Daley, A. C., \& Pisani, D. (2013). Molecular timetrees reveal a Cambrian colonization of land and a new scenario for ecdysozoan evolution. Current Biology, 23, 1-7.

Rudkin, D. M., Cuggy, M. B., Young, G. A., \& Thompson, D. P. (2013). An ordovician Pycnogonid (sea spider) with serially subdivided 'head' region. Journal of Paleontology, 87(3), 395-405.

Savory, T. H. (1971). Evolution in the Arachnida. Merrow Monographs, Watford.

Selden, P. A. (1981). Functional morphology of the prosoma ofBaltoeurypterus tetragonophthalmus (Fischer) (Chelicerata: Eurypterida). Transactions of the Royal Society of Edinburgh: Earth Sciences ,72, 9-48.

Selden, P. A., Shear, W. A. \& Bonamo, P. M. (1991). A spider and other arachnids from the Devonian of New York, and reinterpretations of Devonian Araneae.

Palaeontology, 34:241-281.

Selden, P. A., Shear, W. A., \& Sutton, M. D. (2008). Fossil evidence for the origin of spider spinnerets, and a proposed arachnid order. Proceedings of the National Academy of Sciences, 105(52), 20781-20785.

Sharma, P., \& Giribet, G. (2014). A revised dated phylogeny of the arachnid order Opiliones. Frontiers in Genetics, 5, 255.

Sharma, P. P., Kaluziak, S. T., Pérez-Porro, A. R., González, V. L., Hormiga, G., Wheeler, W. C., \& Giribet, G. (2014). Phylogenomic interrogation of Arachnida reveals systemic conflicts in phylogenetic signal. Molecular biology and evolution, msu235.

Shear, W. A. \& Kukalová-Peck, J. (1990) The ecology of Palaeozoic terrestrial arthropods: the fossil evidence. Canadian Journal of Zoology, 68, 1807-1834.

Shear, W. A. \& Selden, P. A. (1986). Phylogenetic relationships of the trigonotarbids, an extinct order of arachnids. Actas X Congreso Internacional de Arachnologia , 1, 393-397.

Shear, W. A., Selden, P. A., Rolfe, W. D. I., Bonamo, P. M. \& Grierson, J. D. (1987). New terrestrial arachnids from the Devonian of Gilboa, New York (Arachnida: Trigonotarbida). American Museum Novitates, 2901, 1-74.

Shultz, J. W. (1990). Evolutionary morphology and phylogeny of Arachnida. Cladistics, 6(1), 1-38.

Shultz, J. W. (1999). Muscular anatomy of a whipspider, Phrynus longipes (Pocock) (Arachnida: Amblypygi), and its evolutionary significance. Zoological Journal of the Linnean Society, 126, 81-116.

Shultz, J. W. (2000). Skeletomuscular anatomy of the harvestman Leiobunum aldrichi 
(Weed, 1893) (Arachnida: Opiliones: Palpatores) and its evolutionary significance. Zoological Journal of the Linnean Society, 128, 401-438.

Shultz, J. W. (2007). A phylogenetic analysis of the arachnid orders based on morphological characters. Zoological Journal of the Linnean Society, 150(2), 221265.

Simon, S., \& Hadrys, H. (2013). A comparative analysis of complete mitochondrial genomes among Hexapoda. Molecular phylogenetics and evolution, 69(2), 393-403.

Siveter, D. J., Sutton, M. D., Briggs, D. E., \& Siveter, D. J. (2004). A Silurian sea spider. Nature, 431(7011), 978-980.

Stein, M., \& Selden, P. A. (2012). A restudy of the Burgess Shale (Cambrian) arthropod Emeraldella brocki and reassessment of its affinities. Journal of Systematic Palaeontology, 10(2), 361-383.

Størmer, L. (1934). Merostomata from the Downtonian Sandstones of Ringerike, Norway. Skrifter utgitt av Det Norske Videnskaps-Akademi I Oslo, I. Matem.-Naturvid. Klasse, 1933(10): 1-125.

Stürmer, W., \& Bergström, J. (1981). Weinbergina, a xiphosuran arthropod from the Devonian Hunsrück Slate. Paläontologische Zeitschrift, 55(3-4), 237-255.

Sutton, M. D., Briggs, D. E., Siveter, D. J., Siveter, D. J., \& Orr, P. J. (2002). The arthropod Offacolus kingi (Chelicerata) from the Silurian of Herefordshire, England: computer based morphological reconstructions and phylogenetic affinities. Proceedings of the Royal Society of London. Series B: Biological Sciences, 269(1497), 1195-1203.

Sutton, M. D., Garwood, R. J., Siveter, D. J., \& Siveter, D. J. (2012). SPIERS and VAXML; A software toolkit for tomographic visualisation and a format for virtual specimen interchange. Palaeontologia Electronica, 15(2), 1-14.

Sutton, M. D., Rahman, I. A., \& Garwood, R. J. (2014). Techniques for virtual palaeontology. Wiley, London, viii +200 pp.

Talarico, G., Lipke, E. \& Alberti, G. (2011). Gross morphology, histology, and ultrastructure of the alimentary system of Ricinulei (Arachnida) with emphasis on functional and phylogenetic implications. Journal of Morphology, 272, 89-117.

Tanaka, G., Hou, X., Ma, X., Edgecombe, G. D., \& Strausfeld, N. J. (2013). Chelicerate neural ground pattern in a Cambrian great appendage arthropod. Nature, 502(7471), 364-367.

Tetlie, O. E. (2007). Distribution and dispersal history of Eurypterida (Chelicerata). Palaeogeography, Plaaeoclimatology, Palaeoecology, 252, 557-574.

Tetlie, O. E., \& Braddy, S. J. (2004). The first Silurian chasmataspid, Loganamaraspis 
1252

1253

1254

1255

1256

1257

1258

1259

1260

1261

1262

1263

1264

1265

1266

1267

1268

1269

1270

1271

1272

1273

1274

1275

1276

1277

1278

dunlopi gen. et sp. nov. (Chelicerata: Chasmataspidida) from Lesmahagow, Scotland, and its implications for eurypterid phylogeny. Transactions of the Royal Society of Edinburgh: Earth Sciences, 94, 227-234.

Waloszek, D., \& Dunlop, J. A. (2002). A larval sea spider (Arthropoda: Pycnogonida) from the Upper Cambrian 'Orsten'of Sweden, and the phylogenetic position of pycnogonids. Palaeontology, 45(3), 421-446.

Waterston, C. D. (1979). Problems of functional morphology and classification in stylonuroid eurypterids (Chelicerata, Merostomata), with observations on the Scottish Silurian Stylonuroidea. Transactions of the Royal Society of Edinburgh, 70(10-12), 251-322.

Wiens, J. J., \& Morrill, M. C. (2011). Missing data in phylogenetic analysis: reconciling results from simulations and empirical data. Systematic Biology, syr025.

Wiens, J. J., \& Tiu, J. (2012). Highly incomplete taxa can rescue phylogenetic analyses from the negative impacts of limited taxon sampling. PLoS One, 7(8), e42925.

Weygoldt, P., \& Paulus, H. F. (1979). Untersuchungen zur Morphologie, Taxonomie und Phylogenie der Cheliceratal II. Cladogramme und die Entfaltung der Chelicerata. Journal of Zoological Systematics and Evolutionary Research, 17(3), 177-200.

Wheeler, W. C., \& Hayashi, C. Y. (1998). The phylogeny of the extant chelicerate orders. Cladistics, 14(2), 173-192.

Whitfield, J. B., \& Kjer, K. M. (2008). Ancient rapid radiations of insects: challenges for phylogenetic analysis. Annu. Rev. Entomol., 53, 449-472.

Zachvatkin, A. A. (1952). [The division of the Acarina into orders and their position in the system of the Chelicerata.] Parazit Sborn,14, 5-46 [in Russian].

Zhang, Z. Q. (2011). Animal biodiversity: An outline of higher-level classification and survey of taxonomic richness. Magnolia Press. 
Three dimensional reconstruction and the phylogeny of extinct chelicerate orders: Supplementary Information

1281 Russell Garwood

1282 Jason Dunlop

\section{Character statements}

1284 Here we present character statements for the current analysis, modified after

1285 Pepato, da Rocha \& Dunlop (2010).

Cephalic/prosomal region

1287

1288

1289

1290

1291

1292

1293

1294

1295

1296

1297

1298

1299

1300

1301

1302

1303

1304

1305

1306

1307

1308

1309

1310

1311

1312

1313

1. Head shield segments $(0=$ five $[$ cephalosoma/proterosoma]; $1=$ seven [prosomal shield]).

This character refers to the number head segments (or post-acronal segments if the acron existed) included under the anterior prosomal sclerite. Pycnogonida and some Arachnida (in particular Acariformes among the mites, Solifugae, Palpigradi and Schizomida), appear to retain the original euarthropod head sensu Walossek \& Müller 1998. We consider the "sejugal furrow" and the gap between anterior coxae I-II and posterior coxae III-IV as evidence for existence of such a separate tagma in Acariformes. We subsume Shultz's (2007a) character 7 of the presence/absence of demarcation lines between the pro-, meso- and metapeltidium into this character.

2. Ophthalmic ridges ( $0=$ absent; $1=$ present)

Extant Xiphosura present a pair of longitudinal crests passing near the region of the lateral eyes or equivalent area when lateral eyes are not evident. Similar structures are present in Plesiosiro (Dunlop 1999, description herein) and 'non-hypoctonid' Thelyphonida (Mastigoproctus; Rowland \& Cooke 1973).

3. Pleural margin of prosomal shield ( $0=$ absent; $1=$ present $)$.

The broad head shield of Xiphosura with its wide pleural margins has traditionally been treated as the plesiomorphic condition relative to arachnids (e.g. Shultz 1990, character 2); although this was largely based on using trilobites and other arachnomorphs as outgroups. If Pycnogonida or indeed megacheiran taxa are used to polarise the character for euchelicerates, the wide head shield of Xiphosura could alternatively be treated as derived.

4. Cardiac lobe $(0=$ absent; $1=$ present $)$.

Extant Xiphosura express a cardiac lobe, a feature shared with several fossil species including members of Weinbergina, Eurypterida, and Chasmataspis.

5. Prosomal repugnatorial glands ( $0=$ absent; $1=$ present).

The presence of these glands producing a noxious secretion is a convincing 
1314 autapomorphy of Opiliones ( e.g. Giribet et al. 2002, character 12).

1315 6. Cucullus ( 0 = absent; $1=$ present).

1316 This unique, hinged plate covering the mouthparts but of indeterminate function is a 1317 convincing autapomorphy of Ricinulei. Females have been observed using the 1318 cucullus to hold their eggs.

1319 7. Sternal region $(0=$ broad; $1=$ narrow anteriorly; $2=$ narrow posteriorly; $3=$ 1320 narrow throughout).

1321 Irrespective of whether a sternum is present, chelicerates vary in the degree to 1322 which the coxae are consolidated together on the ventral surface of the prosoma. 1323 Coding follows Shultz (2007a, character 12), except that the sternal area in all 1324 acariform mites should be considered narrow (Alberti 2006). Following Shultz 1325 (2007a) we consider the abutting of the coxae themselves and not their endites. The 1326 presence/absence of explicit gnathobases is coded as another character.

8. Prosomal sternum ( $0=$ undivided; $1=$ divided).

1329 The sternum of Palpigradi, Amblypygi, Thelyphonida and Schizomida - plus the extinct pahalgniotarbids and haptopodids - is divided into multiple sclerites. Other arachnids which have a sternum have only a single, undivided sclerite. Not applicable to taxa without a sternum.

9. Cephalic doublure ( 0 = absent; $1=$ present $)$.

1333 In many trilobites and other Arachnomorpha, the cephalic exoskeleton continues onto the ventral side as a deflexed rim or doublure. The prosomal shield folds in on itself where the chelicerae emerge in Thelyphonida and palaeocharinid Trigonotarbida. This character is coded as ambiguous for the former.

10. Prosomal shield with lines demarcating meso- and metapeltidium $(0=$ absent; 1 $1338=$ present).

1339 Scorpiones and some Opiliones have lines on the prosomal shield demarcating three 1340 zones - the pro-, meso- and metapeltidium. This character is not applicable to taxa 1341 lacking a prosomal shield.

1342

11. Genal spines $(0=$ absent; $1=$ present $)$. Two non-arachnid chelicerates - Xiphosura and Chasmataspidida - and also Trilobita, possess genal spines. These posteriorly directed lateral extensions of the cephalic region are only seen in marine (usually bottom-dwelling) species.

12. Proboscis $(0=$ absent; $1=$ present $)$.

1348 A proboscis formed from three antimere elements terminating in a Y-shaped mouth 1349 (Dencker 1974) is autapomorphic for Pycnogonida (e.g. Weygoldt \& Paulus 1979, 1350 character 58). Attempts to homologise it with arachnid mouthparts have largely 
1351 been proved unsuccessful - see comments in Dunlop \& Arango (2005) - supporting

1352 its interpretation as a unique feeding adaptation for sea spiders.

1353 13. Mouth ( $0=$ directed anteroventrally; $1=$ directed posteroventrally).

1354 The mouth of Xiphosura points backward towards the gnathobases. This condition

1355 has been interpreted as plesiomorphic for Chelicerata. Several fossils appear to 1356 have a similar backward flexure of the digestive tube - e.g. trilobites - as indicated 1357 by the backward direction of the hypostome or remnants of the gut contents. Here 1358 we score pycnogonids as $0 / 1$, since their mouth orientation is largely dependant on 1359 the form and orientation of the proboscis (see above).

1360 14. Labium/tritosternum ( 0 = absent; 1 = present).

1361 The labium, or tritosternum in some terminologies, is a separate sclerite generally 1362 forming the lower lip of the mouth. Shultz (2007a) considered it present in 1363 Palpigradi, Araneae, Amblypygi, Thelyphonida, Schizomida, Trigonotarbida, Ricinulei, 1364 and in some acariformes among the mites. In fact, the labium in Palpigradi does not 1365 share the same relative position when compared to other Arachnida. Traditional 1366 studies of morphology regard the palpigrade labium as a protosternum, i.e. 1367 associated with the cheliceral segment (Börner 1902, Snodgrass 1948). Palpigradi is 1368 therefore scored 0 here for this character. Pseudoscorpions and Solifugae have a 1369 narrow medial sclerite related dorsally to the palpal coxal process. In 1370 Pseudoscorpionida, it is known as the so-called lophognath. It is crested and fits in 1371 the grooved ventral surface of the epistemolabral plate, or trophognath (Snodgrass 1372 1948). A similar elongated sclerite may be found in some Endeostigmata, e.g. 1373 Orthacarus tremli Zakhvatkin, 1949 (Bimichaelidae; Jesionowska 2003). Because of 1374 its position, this sclerite is regarded as a deuto- or protosternum and thus not 1375 homologous to the labium as it is considered here. For a similar reason we exclude a 1376 'labium' from phalangid Opiliones (Shultz \& Pinto-da-Rocha 2007). We regard this as 1377 more likely to be a sternapophysis associated with first leg rather the pedipalp 1378 (Winkler 1957).

1379 15. Epistomal-labral plate $(0=$ absent; $1=$ present $)$.

1380 The labrum is fused to the epistome in Solifugae, Pseudoscorpiones and Acari (see 1381 also Snodgrass 1948, contra Shultz 2007a). The whole structure protrudes 1382 noticeably between the chelicerae and is flanked by a pair of so-called lateral lips 1383 (Hammen 1989; Dunlop 2000a). The plate and lips are here scored together as a 1384 single character complex. The plate itself is sometimes referred to as a 'beak' or 1385 'rostrum', especially in the solifuge literature.

1386 16. Ventroposterior wall of pre-oral chamber $(0=$ formed by labium; $1=$ formed by 1387 palpal coxae).

1388 This specific morphology of the epipharyngeal sclerite was proposed by Shultz 1389 (1990, character 5) as a putative synapomorphy of Pedipalpi. Its condition in other 1390 arachnids without a labium (see previous character) was not discussed and we score 1391 such taxa here as (?). This highlights a general problem with many of the putative 1392 skeleto-muscular synapomorphies proposed for Pedipalpi, namely that they are 
1393 sometimes hard to assess across all arachnids and their outgroups.

1394 17. Stomatheca ( 0 = absent; $1=$ present $)$.

1395 This character was defined by Shultz (2007a) as a preoral chamber formed by the 1396 lateral sides of the palpal coxae and ventrally by extensions of the coxae of leg 1 1397 and to a lesser extent leg 2. Shultz treated it as a synapomorphy of Scorpiones and 1398 Opiliones, although it has been criticised (Dunlop 2010), not least because it seems 1399 to be absent in stem-group (fossil) scorpions in which the coxae lack clearly 1400 developed apophyses. Shultz (2007a) speculated that early fossil scorpions may 1401 have had a stomatheca formed from soft lips in place of sclerotised projections, but 1402 the material available neither supports nor rejects this supposition. This is reflected 1403 in the coding of the Silurian species Proscorpius osborni (Dunlop et al. 2008), the 1404 Devonian Palaeoscorpius devonicus (Kühl et al. 2012). This character is also coded 1405 herein as absent in the fossil species Hastocularis argus (Garwood et al. 2014), 1406 which bears small coxapophyses on only the palpal and second walking leg coxae 1407 such growths are entirely absent on leg 1, further supporting a convergent 1408 development of this character in Scorpiones and Opiliones.

1409 18. Ingestion of solid material ( 0 = present; $1=$ absent).

1410 Most arachnids do not ingest solid material. Xiphosura possess gnathobases and a 1411 muscular gizzard suited for macerating solid food. There is no evidence for liquid 1412 feeding in non-arachnid fossils, and it is quite common to observe sediment (Hou \& 1413 Bergström 1997) and even prey hard parts (e.g. within Sidneya; Bruton 1981) 1414 among the gut remains. Pycnogonida have a pharyngeal filter apparatus that 1415 certainly precludes the intake of anything larger than subcellular material (King 1416 1973, Fahrenbach \& Arango 2007). The latter authors also described 180-220 small 1417 salivary glands per jaw of Ammothea hilgendorfi - indicative of primarily liquid 1418 material intake. Digestion occurs largely as a result of salivary glands and 1419 musculature within the proboscis and oesophagus, and accordingly we have coded 1420 ingestion of solid material as absent for extant pycnogonid taxa. Several Opiliones 1421 and some mites (Opiliacarida, Oribatida, some Endeostigmata and free-living 1422 Astigmata; Pinto-da-Rocha, Machado \& Giribet 2007, Walter \& Proctor 1998) 1423 consume solid particles of food, although all of them have a well-developed preoral 1424 chamber so exhibit a certain degree of extraintestinal digestion. All other arachnids 1425 are liquid feeders and apparently digest their food preorally, often using specialised 1426 filtering devices (see e.g. character 20) to hinder the uptake of particulate matter. 1427 Finally, for Paleozoic scorpions this character is uncertain given that they seem to 1428 lack a well-developed pre-oral chamber (see above).

1429 19. Palate plate ( $0=$ absent; $1=$ present).

1430 This specific modification of the dorsal pharynx wall with fringed platelets used as 1431 filters to trap particulate matter from the preorally digested food is an 1432 autapomorphy of Araneae; e.g. Giribet et al. (2002, character 159).

1433 20. Filtering preoral setae ( $0=$ absent; $1=$ present)

1434 In Ricinulei and in at least Palaeocharinus among the Trigonotarbida there is a 
1435 similar-looking filtering structure in front of the mouth consisting of either 1436 downward-pointing setae or platelets. This feature is a potential synapomorphy of 1437 these arachnids.

1438 21. Three-branched epistomal skeleton ( $0=$ absent; $1=$ present $)$.

1439 This specific form of the epistome skeleton with three processes for the pharyngeal 1440 dilator muscles was described in detail by Shultz (2000) who proposed it as a 1441 putative synapomorphy of (Scorpiones + Opiliones).

1442 22. Intercheliceral epipharyngeal sclerite (0, absent; 1, present).

1443 Coding follows Shultz (2000, character 191).

1444 23. Epipharyngeal sclerite large, projecting posteriorly (0, absent; 1 , present).

1445 Coding follows Shultz (2000, character 192). Inapplicable to taxa lacking an 1446 epipharyngeal sclerite

1447 Segmentation, tagmosis and telson

1448

1449

1450

1451

1452

1453

1454

1455

1456

1457

1458

1459

1460

1461

1462

1463

1464

1465

1466

1467

1468

1469

1470

1471

24. Metasoma ( $0=$ absent; $1=$ present $)$.

Cotton \& Braddy (2003) defined this character as a "post-abdomen lacking appendages". This definition is hard to apply in most chelicerates since some lack recognizable abdominal appendages altogether (e.g. Palpigradi, Opiliones, Pseudoscorpiones, Acari). We seek to redefine this tagmosis character here as a posterior, limbless set of segments, typically with a cylindrical exoskeleton which is, to a greater or lesser extent, set off from the mesosoma by a narrowing of the body.

25. Prosoma and opisthosoma form a single functional unit $(0=$ absent; $1=$ present)

In Opiliones and some mite taxa, the prosoma and opisthosoma fuse form a single unit. After Legg, Sutton \& Edgecombe (2013) character 602.

26. Metasoma length ( $0=$ three segments; 1 = five segments; $2=$ nine segments). This character is inapplicable for taxa which do not express a metasomal tagmosis.

27. Well-developed post-anal telson ( $0=$ absent; $1=$ present $)$.

Given that various potential outgroups among early Palaeozoic arthropods have a post-anal telson, its presence in Xiphosura, Scorpiones, Palpigradi, Thelyphonida and Schizomida is probably plesiomorphic for Chelicerata. No Recent sea spiders have a telson, but some fossil taxa do, including Palaeisopus (Vilpoux \& Waloszek 2003); see also Walossek \& Müller 1998 for discussions of ground patterns.

28. Flagellate telson ( $0=$ absent; $1=$ present $)$.

In Palpigradi, Thelyphonida and (albeit in a shortened form) Schizomida, among the extant orders, and now Uraraneida, among the fossils, the telson is subdivided into multiple articles to form a distinctly flagellate, whip-like structure. Not applicable to taxa without a telson (see above). 
1472 29. Telson with vesicle and aculeus ( $0=$ absent; $1=$ present).

1473 This feature is regarded here as an autapomorphy of Scorpiones.

1474 30. Specialized male postanal flagellum ( $0=$ absent; $1=$ present $)$.

1475 This modified male flagellum plays an important role during courtship - the female 1476 holds onto the male flagellum and is pulled over a spermatophore - and is widely 1477 regarded as a convincing autapomorphy of Schizomida.

1479 31. Number of chelicerae articles ( $0=$ more than three, $1=$ three; $2=$ two).

1480 Solifugae, Pseudoscorpiones, Ricinulei and the Terapulmonata sensu Shultz (1990) 1481 have only two cheliceral articles. This is widely accepted as the apomorphic 1482 condition compared to the three articles seen in other (euchelicerate) taxa. Indeed, 1483 gene expression data now suggest that the presence of two articles could have 1484 arisen through loss of developmental domains along the proximo-distal axis of the appendage (Sharma et al 2012). Acariformes is scored here as having two articles. Those supporting the hypothesis that Acariformes have a proximal trochanter in the chelicerae argued that the proximoventral region of the fixed digit is a fused remnant of this article. This is based on the attachment of the cheliceral retractor muscles in this region (Evans 1992), and developmental studies support this suggestion in one species (Barnett and Thomas 2013). At least one pycnogonid species has been figured with four cheliceral articles (see e.g. Dunlop \& Arango 2005) - including the fossil species included herein. The Megacheiran taxa included in the current analysis both have a deutocerebral great appendage comprising more than three articles (Tanaka et al., 2013; Haug et al. 2012), a state also seen in the synziphosurine taxa Dibasterium durgae (Briggs et al. 2012) and Offacolus kingi (Sutton et al. 2002). This outgroup choice accordingly implies the possession of more than three articles in the deutocerebral appendage the plesiomorphic state for the chelicerates.

32. Presence of elbowed chelicerae ( $0=$ absent, $1=$ present $)$. is a geniculate joint between the forward-projecting the basal cheliceral element and the distal two elements (forming the claw). This arrangement allows the claws to move in the proximity of the mouth. By contrast, in groups like scorpions all three cheliceral elements simply project forwards. We do not consider the joint in the pycnogonids geniculate: the proboscis limits the required range of motion in the chelifores, which have a greater variability in orientation and podomere proportions than observed in arachnid taxa. Scored as inapplicable for those taxa with only two 1508 cheliceral articles, or more than three. dorsally; 2 = articulates laterally).

In Solifuges, Pseudoscorpiones and both major groups of Acari the distalmost 
1512 cheliceral segment (the apotele) articulates ventrally against the preceding article 1513 (e.g. Dunlop 2000). In Tetrapulmonata and Ricinulei it is more or less dorsal (keeping 1514 in mind the torsion of the chelicerae in labidognath spiders). Three segmented 1515 chelicerae with an 'elbowed' articulation, such as in harvestmen and palpigrades, do 1516 not fit comfortably into either of these schemes and are tentatively coded as a 1517 separated character state.

1518 34. Cheliceral 'fang' ( $0=$ chelate; $1=$ 'clasp-knife' type; $2=$ Prostigmata styliform 1519 or 'Anystys'-like chelicerae).

1520 So-called 'clasp-knife' chelicerae, sensu Shear et al. (1987), in which the apotele 1521 forms a fang rather than the movable finger of an explicitly chelate claw, are found 1522 in Araneae, Uraraneida, Amblypygi, Thelyphonida, Trigonotarbida and Schizomida 1523 (see also Kraus 1976). The chelicerae of Ricinulei also approach this condition (see 1524 e.g. Dunlop 1996, fig. 11) with a longer 'fang' articulating against a shorter fixed 1525 tooth and are thus scored 0/1 here for this character. Several Prostigmata also have 1526 the fixed digitus reduced, but the movable digit is ventral and the condition is 1527 clearly non-homologous to the condition observed in Tetrapulmonata and is scored 1528 separately here.

1529 35. Naked cheliceral fang ( $0=$ absent; $1=$ present).

1530 Selden, Shear \& Sutton (2009) suggested that the loss of setae (or other similar 1531 sorts of projections) on the cheliceral fang was an autapomorphy of Araneae. 1532 Selden, Shear \& Bonamo (1991) and Selden, Shear \& Sutton (2009) demonstrated a 1533 naked fang in Attercopus; i.e. this character would support (Uraraneida + Araneae). 1534 The fang (or movable finger) in other arachnids seems usually to be setose and/or 1535 dentate. The condition observed in some mites is not considered as primarily 1536 homologous to this character.

1537 36. Plagula ventralis ( $0=$ absent, $1=$ present $)$.

1538 This specific small sclerite between the fang and the basal segment of the chelicera 1539 has been proposed as a synapomorphy of Araneae, Amblypygi, Thelyphonida and 1540 Schizomida (Homann 1985).

1541 37. Cheliceral venom gland ( $0=$ absent; $1=$ present).

1542 Traditionally treated as an autapomorphy of Araneae, venom glands opening 1543 through the movable finger (or fang) of the chelicerae are present in all the spiders 1544 scored here. Venom glands are also absent in the ingroup spider family Uloboridae 1545 (not scored here) and while there have been claims that they are absent in the basal 1546 Mesothelae spider clade, this proposal has since been refuted. As a result of the 1547 observation of a venom gland in Attercopus, this character also supports a 1548 (Uraraneida + Araneae) clade.

1549 38. Endocephalic spinning apparatus ( $0=$ absent; $1=$ present).

1550 The endocephalic spinning apparatus, together with its associated spinnerets or 1551 galea, is an autapomorphy of Pseudoscorpiones (Harvey 1992). Whether these 1552 glands - which open on the movable finger of the chelicerae (Weygoldt 1969) - are 
homologous with the venom gland of spiders is unclear.

1554

1555

1556

1557

1558

1559

1560

1561

1562

1563

1564

1565

1566

1567

1568

1569

1570

1571

1572

1573

1574

1575

1576

1577

1578

1579

1580

1581

1582

1583

1584

1585

1586

1587

1588

1589

1590

39. Cheliceral flagellum ( $0=$ absent; $1=$ present $)$.

This sometimes complex projection from the dorsal surface of the fixed finger of chelicerae in male Solifugae can take a number of forms, but is (secondarily) absent in the solpugid family Eremobatidae (Punzo 1998). Its precise function in solifuges is not well understood. The character has been treated as an autapomorphy of this order. However, Harvey (1992) regarded the cheliceral flagella of Solifugae and Pseudoscorpiones (see e.g. Weygoldt 1969, fig. 2) as potentially synapomorphic and this is reflected in the scoring here. Notice that the flagellum occurs on the fixed finger and should not be confused with the galea which is on the movable finger of the pseudoscorpion chelicerae (see previous character).

\section{Chelicerocarapacal articulation $(0=$ absent; $1=$ present $)$.}

A specific antero-lateral articulation between the prosomal shield and the basal cheliceral article has been described from Solifugae and (most) Pseudoscorpiones, and suggested as a potential synapomorphy for these orders; see e.g. Shultz (1990, character 13).

41. Mesal fusion of chelicerae ( $0=$ absent; $1=$ chelicerae proximally fused $)$.

Mesal fusion of the chelicerae is seen in mites of the following groups: Tetranychoidea, Raphignathidae, Caligonellidae, Tarsonemina, and in some Tydeidae and Stigmaeidae (Evans 1992). A similar arrangement can also occur (certainly secondarily) in some spiders such as Filistatidae, but not among the taxa scored here.

42. Movable digit ( $0=$ 'Anystis' type; $1=$ styliform $)$.

Among those Acariformes with a reduced digitus fixus, two conditions may be observed: the mostly curved, dorsally serrate digits of Trombidiidae, Halacaridae, Trombiculidae, Anystidae and Paratydeidae on the one hand and a smooth movable digit of Erythraeidae, Smariididae, Cheyletidae and Tetranychidae, suited for piercing, on the other. This character is only applicable to mites without the digitus fixus (cf. character 36 , state 2 ).

\section{Pedipalps or second head appendage}

43. Palpal coxae ( $0=$ free; $1=$ fused medially).

This is a somewhat problematic character in that it is potentially part of the same character complex which embraces the gnathosoma of mites and, perhaps, ricinuleids (see below). Irrespective of the gnathosoma, a straightforward medial fusion of the pedipalpal coxae is seen in both major groups of Acari, as well as in Ricinulei, Thelyphonida and Schizomida. In the latter two orders it is usually referred to explicitly as a camerostome; see e.g. Yoshikura (1975, table 24) and Shultz (1990, character 18). 
1591

1592

1593

1594

1595

1596

1597

1598

1599

1600

1601

1602

1603

1604

1605

1606

1607

1608

1609

1610

1611

1612

1613

1614

1615

1616

1617

1618

1619

1620

1621

1622

1623

1624

1625

1626

1627

1628

1629

1630

1631

44. Gnathosoma ( $0=$ absent; $1=$ present $)$.

The gnathosoma essentially consists of the fused palpal coxae (see previous character) forming the subcapitulum, plus the chelicerae and mouth lips. All these elements articulate together as a single movable unit against the rest of the body. It has been cited (Lindquist 1984) as one of the most convincing characters for defining mites as a monophyletic group, although its homology was challenged by Hammen (1989) who noted significant differences in the patterns of muscular insertion (see also Alberti 2006). Confusingly, some authors also recognise a gnathosoma as present in Ricinulei; thus essentially the same character has been used by different authors to support either a monophyletic Acari or (Acari + Ricinulei). We find the latter interpretation problematic, and followed here Shultz (2007a) in coding this as ambiguous.

45. Subcapitular rutella $(0=$ absent; $1=$ present).

These modified, thickened setae are found in basal members of both Parasitiformes and Acariformes among the mites. Although absent in more derived Anactinotrichida and often cited as lost in prostigmatid mites, they were noted as present in Rhagidiidae by Zacharda (1980) although the structures observed in Rhagidiidae and scored here do not resemble the Oribatida or Opilioacarida rutella. Irrespective of ingroup reversals, rutella appear to be one of the more convincing characters defining Acari as a monophylum (Lindquist 1984, character 1). Alberti (2006, and references therein) has, however, questioned how well this character is understood and cautioned about accepting its homology in all groups where it occurs.

46. Palpal chelae $(0=$ leg like; $1=$ subraptorial; $2=$ chelate; $3=$ 'scorpionid'; $4=$ 'thumb and claw').

Large, subraptorial pedipalps characterise Amblypygi, Thelyphonida and Schizomida. The pedipalps or equivalent appendages of Xiphosura, Ricinulei and at least Palaeocharinus and Anthracomartus among the Trigonotarbida, end in small terminal claws or pincers in which the apotele opposes a corresponding projection from the tarsus. Scorpiones and Pseudoscorpiones share a specific and potentially homologous 'scorpionid' claw morphology involving a large manus, containing a similar musculature, and elongate fingers; see e.g. Shultz (1990, characters 16 and 17) for details. Several Prostigmata among the mites have a strong 'claw' (in fact, a hypertrophied seta) in the palptibia which acts against the palpal tarsi. This 'thumb and claw' organisation is seen in Tetranychoidea, Stigmaeidae, Cheyletidae, terrestrial Parasintegona, Erythreaoidea, and Anystidae among the taxa scored here.

47. Palpal cleaning organ ( $0=$ absent; $1=$ present $)$.

This specialised brush of two highly organised rows of tarsal setae (e.g. Weygoldt 2000, figs 133-139) has been called the 'cleaning organ' or 'cleaning brush'. It is one of the few explicit autapomorphies of Amblypygi (Shear et al. 1987).

48. Pedipalpal venom glands ( $0=$ absent; $1=$ present $)$.

Poison glands within the palpal chelae - which can open in one or both fingers 
1632 (Weygoldt 1969) - represent a convincing apomorphy of the ingroup pseudoscorpion 1633 clade locheirata sensu Harvey (1992)/Murienne, Harvey \& Giribet (2008). It should 1634 be reiterated that venomous pedipalpal claws are not an autapomorphy of all 1635 Pseudoscorpiones.

1636 49. Palpal apotele $(0=$ differentiated from tarsus; $1=$ not differentiated from 1637 tarsus).

1638 Although proposed by Shultz (1999, character 14) as a putative synapomorphy of 1639 Pedipalpi only, it is also applicable to the large claws making up the pedipalps of 1640 Scorpiones and Pseudoscorpiones too. Apoteles are also absent from the palps of 1641 Acariformes and have been convergently lost in at least some Opiliones, such as the 1642 genera Nemastoma and Sabacon (Alberti 2006; Giribet et al. 2002).

1643 50. Adhesive palpal organ ( $0=$ absent; $1=$ present $)$.

1644 An adhesive structure at the end of the pedipalp (Punzo 1998) is a putative 1645 autapomorphy of Solifugae. Given that solifuges do not express a palpal apotele 1646 sensu stricto (but see previous character) and that the palpal organ articulates via 1647 lateral condyles, it could potentially represent a highly modified claw (Dunlop 1648 2000b).

Ovigers and legs

51. Ovigers ( $0=$ absent; $1=$ present $)$.

Modification of the third limb into an egg-carrying oviger is an autapomorphy of the ground pattern of Pycnogonida Giribet et al. (2002, characters 11,40). However, like the chelifores and pedipalps, ovigers are secondarily reduced in some derived ingroup sea spiders - for example Endeis lack ovigers completely - as well as 1655 females of Pycnogonidae and Phoxichilidiidae (Arango 2002).

52. Gnathobases ( $0=$ present; $1=$ absent). Among recent Chelicerata, only Xiphosura retains dentate gnathobases along all postcheliceral limb coxae. This is widely accepted as a plesiomorphic mode of feeding. Among fossils they are present in several taxa, including trilobites, eurypterids, various arachnomorphs, and the outgroup taxon Alalcomenaeus - in the current analysis, which implies that gnathobasal feeding is at some level the original mode of ingestion. Serrula on the pedipalpal coxae (or gnathocoxae) of spiders have to some extent 'reinvented' the masticatory function of the gnathobases, but in detail they differ from the dentate xiphosuran/eurypterid gnathobase and are not scored as homologous here.

53. Antenniform first leg $(0=$ absent; $1=$ present $)$. synapomorphy of Pedipalpi. Solifugae and Palpigradi also walk hexapodally to some extent and probe ahead with the first leg. However, they do not show the same leg pair is markedly different from those used in walking. 
1672

1673

1674

1675

1676

1677

1678

1679

1680

1681

1682

1683

1684

1685

1686

1687

1688

1689

1690

1691

1692

1693

1694

1695

1696

1697

1698

1699

1700

1701

1702

1703

1704

1705

1706

1707

1708

1709

1710

54. Leg 1 sternocoxal articulation ( $0=$ absent; $1=$ present).

This specific pattern of articulation was proposed by Shultz (1999, character 25) as a putative synapomorphy of Pedipalpi.

55. Apotele of first leg $(0=$ present; $1=$ lost $)$.

This reduction of the apotele in these antenniform legs was suggested by Shultz (1999, character 17) as a potential synapomorphy of Amblypygi, Thelyphonida and Schizomida. The apotelic claws is retained in Amblypygi, but in a highly reduced form (e.g. Wegoldt 2000, fig. 81). The leg 1 apotele is replaced by a bush of hairs in some Solifugae (Roewer 1934) which are here scored 0/1 for this character.

56. Leg 2 ( 0 = unmodified; $1=$ elongate).

In Ricinulei and most Opiliones - but not in the putatively basal Cyphophthalmi - the second walking leg (or $4^{\text {th }}$ prosomal limb) is noticeably longer and is typically used to probe ahead of the animal (see also Giribet et al.2002, character 70).

57. Exopods $(0=$ retained on more than one prosomal limb; $1=$ on sixth prosomal limb, 2 = lost).

From the original biramous limb, the exopod is retained as the so-called flabellum on the coxa (or basipod in some terminologies) of the last pair of legs in Xiphosura. The exopod on this limb is lost in all Arachnida; see e.g. Giribet et al. (2002, character 110). Dunlop, Anderson \& Braddy (2003) reported a dissociated biramous leg belonging to Chasmataspis that resembles the flabellum on prosomal limb VI of Xiphosuran. As with most Arachnomorpha, the enigmatic Herefordshire taxa Offacolus (Orr et al. 2000, Sutton et al. 2002) and Dibasterium (Briggs et al. 2012) retain biramous legs in the prosomal appendages. Weinbergina is reported as possesing only uniramous appendages (Stürmer \& Bergström 1981; Moore et al. 2005) - although this could be worthy of restudy based on these recent discoveries from Herefordshire.

58. Coxotrochanteral joint ( $0=$ simple; $1=$ complex).

The coxotrochanteral joint of Araneae, Amblypygi, Thelyphonida and Schizomida has been described as being of a more complex nature - specifically through including so-called intercalary sclerites - compared to the simple bicondylar articulation seen in other taxa; cf. Shultz (1989, 1990 character 24) for details.

59. Divided femora in legs 3 and 4 ( $0=$ present; $1=$ lost $)$.

Shultz (1989, 1990 character 25) discussed previous interpretations of this 'extra' limb article which has been variously regarded either as a double trochanter or an extra femur. It was treated by Shultz as plesiomorphic retention of a basi- and telofemur; a character thus retained in Pycnogonida, Ricinulei, Solifugae and Acari. In some schemes (e.g. Hammen 1989) Palpigradi was also interpreted as having two femurs, but this assumption was not followed by Shultz (1989) whose interpretations based on musculature we rely on here for scoring the character. 
1711 60. Femoropatella articulation ( $0=$ transverse hinge; $1=$ bicondylar articulation; 2 1712 = monocondylar articulation).

1713 Interpreted by Shultz (2007a, character 69) as a hinge in most arachnids, the 1714 bicondylar condition occurs in Opiliones, Scorpiones and Pseudoscorpiones. A 1715 monocondylar articulation here appears to be autapomorphic for Solifugae.

1716

1717

1718

1719

1720

1721

1722

1723

1724

1725

1726

1727

1728

1729

1730

1731

1732

1733

1734

1735

1736

1737

1738

1739

1740

1741

1742

1743

1744

1745

1746

1747

1748

1749

1750

61. Patellotibial articulation ( $0=$ monocondylar; $1=$ hinge; $2=$ bicondylar $)$.

The monocondylar condition of this joint was assumed (Shultz 1990, character 31) to be plesiomorphic, with modification to a hinge in Acari, Ricinulei and Solifugae and to a bicondylar structure with an additional ventral articulation in Opiliones, Scorpiones and early derivative Pseudoscorpiones.

62. Patellatibial articulation with auxiliary posterior articulation $(0=$ absent; $1=$ present).

This specific pattern of leg articulation was proposed by Shultz (1999, character 22) as a putative synapomorphy of Pedipalpi. How this relates to the previous character is unclear and these ventral/posterior articulations may turn out to be part of a single character complex; perhaps homologous with the additional ventral articulation alluded to in character state 2 above.

63. Appendages of postoral somites III-V with fused tibia and tarsus $(0=$ absent; $1=$ present).

A fused tibia-tarsus is observed in extant Xiphosura, where it forms the fixed finger of the distal claw and articulates against the tarsus as the movable finger. This arrangement is apparently not seen in the Devonian synziphosurine Weinbergina (Moore et al. 2005) which seems to retain the tibia and tarsus as separate elements, but is not apparent in the other included fossil taxa.

64. Tarsus ( $0=$ tarsus divided into basi- and telotarsus; $1=$ tarsus undivided).

The 'basitarsus' sensu Shultz is equivalent to the metatarsus in more usual arachnological terminology. State 1 occurs in extant Xiphosura (Shultz 1989) and in Acariformes (Lindquist 1984, Evans 1992), with the exception of Erythracarinae among Anystidae; a probable convergence. It also occurs in the anterior two pairs of legs in chthonioid pseudoscorpions, for which the character is coded here as $0 / 1$, and all legs in Feaelloidea (Chamberlin 1931). A circumtarsal ring in Anactinotrichida may represent a joint between a basi- and telotarsus (Evans 1992), however we follow Shultz (2007a) in coding the tarsus as undivided.

65. Telotarsi of walking legs 2-4 with three tarsomeres ( $0=$ absent; $1=$ present).

This specific pattern of tarsal division was proposed by Shultz (1999, character 18) as a putative synapomorphy of Pedipalpi, but also appears to occur in the extinct order Haptopoda; these together forming a putative Schizotarsata clade Shultz (2007a). Some other arachnids, particularly various long-legged Opiliones, may show numerous tarsomere divisions at the distal ends of their legs; but not the specific arrangement scored for this character. 
1751 66. Apotele $(0=$ a simple cone or blade; $1=$ a medial piece, comprising a claw or 1752 pulvillus, more frequently bearing a pair of lateral claws).

1753 Most Arachnomorpha present a tridactyl terminal piece at the ends of their legs. The 1754 main exceptions comprise Eurypterida, Chasmastaspis, some fossil scorpions and 1755 extant Xiphosura (Dunlop 2002b). For outgroup Emeraldella brocki, this is coded as 1756 absent as the taxon has a conical, central spine surrounded by possibly movable 1757 spines - however, these do not appear to form a claw (Stein and Selden 2013).

1758 67. Pulvillus ( $0=$ absent; $1=$ present $)$.

1759 A fleshy (?adhesive) pad between the claws of the legs has been variously named a 1760 pulvillus or empodium. This structure can be found in Pseudoscorpions, Solifugae, 1761 'pulvillate' Amblypygi and Parasitiformes among the mites. When a fleshy structure 1762 similar to a pulvillus occurs among the Acariformes sampled, such as Sancassania or 1763 Rhizoglyphus, it is invariably accompanied by a medial claw.

1764

1765

1766

1767

1768

1769

1770

1771

1772

1773

1774

1775

1776

1777

1778

1779

1780

1781

1782

1783

1784

1785

1786

1787

1788

1789

68. Chelate legs $(0=$ absent; $1=$ present $)$.

The legs (i.e. limbs III-VI) in extant Xiphosura, Offacolus, Dibasterium, and Chasmastaspis (where known) end in claws formed by the subterminal apotele moving against the tarsus or tibiotarsus. Note that some of the anterior limbs in the Recent Xiphosura from SE Asia are more subchelate in nature.

69. Divided claws ( $0=$ absent; $1=$ present $)$.

Subdivided claws, or ungues, on the walking legs in which the tips articulate against the rest of the claw (Roewer 1934, Weygoldt 1969, Dunlop 2000b) are a putative autapomorphy of Solifugae.

\section{Opisthosoma and opisthosomal appendages}

Incomplete data on the embryology of some arachnid orders makes opisthosomal structure, and its possible appendages, one of least well-understood issues in chelicerate morphology. Almost all structures associated with opisthosomal segments have been argued as limb-derivatives at some stage. Only xiphosuran chilaria, the scorpion pectines, spider spinnerets, the book lungs, book gills, and certain spider trachea can presently be positively identified as appendage derivatives (Damen, Saridaki \& Averof 2002). Our coding strategy assumes that these structures are homologous to the posterior limbs of arachnomorph arthropods; probably corresponding mainly to the exopods (but see individual characters like lungs and lung opercula for details). See discussion section of Pepato, da Rocha \& Dunlop (2010) for further details of possible leg derivatives.

70. Plate-like opisthosomal appendages ( $0=$ absent; $1=$ present). Weygoldt \& Paulus' (1979) defining character for Euchelicerata, these plate-like appendages, or opercula, are not seen in Pycnogonida - not even in fossil forms (e.g. Palaeoisopus) which retain a longer trunk behind the last walking leg. They occur as largely gill-bearing structures in Xiphosura and have been demonstrated (Shultz 
$17901993,1999)$ in the lung-bearing somites of at least the tetrapulmonate arachnids. 1791 Thus the traditional second and third 'sternites' of the opisthosoma are in fact highly 1792 modified, lung-bearing appendages. These probably occur in early fossil Scorpiones 1793 and may thus contribute to the sternites of modern scorpions (Jeram 2001) - a 1794 hypothesis supported by developmental studies (Farley 2005, and citations therein). 1795 The character is harder to score for those arachnids which lack lungs as it is unclear 1796 whether their sternites in the anterior opisthosomal region are true sternites, 1797 sutured on opercula or conceivably combinations of both as per the Jeram (2001) 1798 hypothesis for scorpions. Such equivocal taxa are thus scored (?).

1799 71. Limb VI ( $0=$ unmodified; $1=$ "pusher"; $2=$ paddle)

1800 The sixth limb in arachnids is generally a pediform structure used as a walking leg. 1801 In modern xiphosurans the sixth limb has flaps near the distal end which can splay 1802 out and, similar to a snowshoe, provide extra traction when the limb is pushed down 1803 onto the substrate. It is conventionally called the 'pusher' as it helps push the 1804 animal forwards. Whilst Dibasterium possesses a specialised sixth limb, this in a 1805 single elongate, slender projection and is thus coded as unmodified for this 1806 character. In some eurypterids and chasmataspidids the sixth limb is modified into a 1807 paddle and presumably enabled the animal to swim.

1808 72. Number of body segments $(0=$ twenty; $1=$ nineteen; $2=$ eighteen; $3=$ 1809 seventeen; $4=$ sixteen; $5=$ fifteen; $6=$ fourteen; $7=$ thirteen; $8=$ twelve; $9-8$ 1810 segments or less).

1811 Shultz (2007a, character 95) scored the number of opisthosomal segments. This 1812 approach works for chelicerates since the prosoma/opisthosoma boundary may be 1813 accurately determined by the presence of a reliable marker in the form of the genital 1814 opening on $2^{\text {nd }}$ opisthosomal segment, something absent in Pycnogonida. We 1815 followed Wills et al.'s (1998, character 41) approach of simply coding the total 1816 number of body segments. For Euchelicerata this means adding seven (one limbless 1817 plus six appendage bearing prosomal segments) to the number coded by Shultz. 1818 Acariformes mites often have some degree of anamorphosis, i.e. the addition of new 1819 segments during post-embryonic development. The scoring for them tries to 1820 encompass the inside group polymorphism by following Kethley's (1990) account on 1821 this aspect. In Leanchoilid outgroup taxa we have not considered the telson a 1822 segment. Scorpions are coded as possessing twenty segments on the basis of 1823 evolutionary developmental for an additional segment, lost in adult scorpions 1824 (Simonetti 2006).

73. Prosoma-opisthosoma junction ( $0=$ broad; $1=$ Xiphosuran 'cephalothorax'; $2=$ narrow, pedicel).

1827 At least the extant Xiphosura seem to have taken the trend of adding segments to 1828 the head even further. Their 'cephalothorax' sensu Scholl (1977) and Shultz (2001) 1829 incorporates dorsal elements of the $7^{\text {th }}$ and $8^{\text {th }}$ somites; a potentially derived 1830 condition giving them a longer head shield than that of the arachnid prosomal 1831 shield. This character is difficult to assess in fossil xiphosurans where embryological 1832 and musculature data are lacking. Note that this specific use of cephalothorax 
1833 should be differentiated from its more traditional usage in general arachnological 1834 terminology as a synonym of prosoma.

1835 Although some authors previously recognised a simplistic division into 'Latigastra', 1836 with a broad prosoma-opisthosoma junction and 'Caulogastra', with a narrow 1837 junction; this character proves to be rather more complex, especially when applied 1838 to arachnid outgroups. According to their incipient tagmosis, most Arachnomorpha 1839 lacks any sharp distinction between their anterior and posterior trunk segments. In 1840 early aquatic Euchelicerata like Chasmataspidida, and several Xiphosurida, the 1841 seventh tergite, or first opisthosomal tergite is distinctively narrower than the 1842 subsequent opisthosomal tergites. In other Xiphosurida and Scorpiones, the 'broad' 1843 connection between the prosoma and opisthosoma is probably a reversal from state 18441 , due to loss of most or all of the external expression of the seventh (i.e. 1845 pregenital) segment: cf. the xiphosuran microtergite and the incorporation of 1846 opisthosomal segments into its 'cephalothorax'. This condition has been 1847 presupposed for eurypterids too (Dunlop and Webster 1999), however in the 1848 absence of developmental or muscular evidence, the junction is coded as broad 1849 here. The junction between the two body tagma is narrow in Solifugae, Palpigradi, 1850 Ricinulei and Amblypygi and Araneae. Some authors (Weygoldt \& Paulus 1979) 1851 would term it the pedicel and restrict it to Araneae and Amblypygi; others prefer to 1852 consider several distinct kinds of 'pedicel' (Shultz 2007a, character 97). We 1853 acknowledge such difficulties of definition and prefer to recognise a more general 1854 narrowing, a probable result of the constriction of the $7^{\text {th }}$ segment that may have 1855 affected other segments (e.g. Ricinulei).

1856 74. First opisthosomal tergite ( $0=$ unmodified; $1=$ very short $)$

1857 This character concerns the size of the first opisthosomal tergite in comparison to 1858 those immediately posterior. Inapplicable to Pycnogonids where the first 1859 'opisthosomal' segment bears a pair of walking legs. In modern Xiphosura segment 1860 one is incorporated into the prosoma, and this character has been coded 1861 inapplicable, and unknown for fossil taxa where the nature of the first segment is 1862 unknown. Present in eurypterids, haptopods, and chasmataspids, and also coded as 1863 present in the Haptopoda on the basis of Dunlop (1999) and the current work.

1864 75. Six abbreviated opisthosomal tergites ( $0=$ absent; $1=$ present)

1865 The extinct Phalangiotarbida uniquely express a dorsal opisthosomal surface in 1866 which the first six tergites form short bands across the back of the animal. The sixth 1867 tergite may be a little longer.

1868 76. Opisthosomal sternite $1(0=$ present, $1=$ absent $)$

1869 Assuming that the lung-bearing elements on the ventral surface of Trigonotarbida 1870 are (as in Thelyphonida) the anterior and posterior opercula respectively, then 1871 studies of well-preserved trigonotarbids suggest that a first sternite is absent here, 1872 which seems to be unique for this extinct order.

1873 77. Locking mechanism between opisthosoma and prosoma $(0=$ absent; $1=$ 
1874 present).

1875 A specific 'locking mechanism' in which a modified first opisthosomal tergite slots 1876 into a corresponding fold at the back of the prosomal shield is observed in Ricinulei 1877 and Trigonotarbida (Dunlop 1996).

1878 78. Opisthosomal tergites $7-10$ ( 0 = separate; $1=$ fused into a single plate)

1879 As noted above, all Phalangiotarbida have six abbreviated tergites. Behind this there 1880 are either a series of longer tergites (e.g. Bornatarbus) or in some taxa, such as 1881 Goniotarbus addressed here, these tergites have fused completely to create a single 1882 dorsal plate covering the posterior half of the opisthosoma.

1883 79. Opisthosomal tergites trilobate (with a distinct axial region) $(0=$ absent; $1=$ 1884 present).

1885 State 1 is found in Ricinulei and Trigonotarbida (Dunlop 1996). Coded as absent in 1886 outgroups which lack differentiated median and lateral plates for the tergites, even if 1887 trilobate in general form.

1888 80. Diplosegments ( $0=$ absent; $1=$ present)

1889 Selden (1981) noted that the three large dorsal tergites posterior to the locking 1890 structure in the fossil Ricinulei Terpsicroton alticeps are fused together, since they 1891 preserve two putative pairs of muscular attachment scars. Fusion of at least the two 1892 tergites behind the locking ridge into a single diploterite is a character apparently 1893 shared with (most) Trigonotarbida (Dunlop 1996).

1894 81. Fused opisthsomal segments ( 0 = absent; $1=$ buckler; 2 = thoracatron).

1895 In crown-group Xiphosura - but not the fossil stem-assemblage known as 1896 synziphosurines (see e.g. Anderson \& Selden 1997) - the opisthosomal tergites are 1897 fused together into a single, rigid plate termed the thoracatron or tergum sensu 1898 Shultz (2001). In chasmataspids three tergites are fused into a structure 1899 conventionally called the 'buckler' (Dunlop, Anderson \& Braddy 2003).

1900 82. Appendages on opisthosomal segment 1 ( $0=$ present; $1=$ lost).

1901 Modern Xiphosura retain this appendage as the chilaria and in some early 1902 synziphosurines like Weinbergina it may even have been retained as a fully1903 developed leg. At least in recent homology schemes (Vilpoux \& Waloszek 2003), a 1904 limb on the first opisthosomal segment as per arachnids is also present as the last 1905 walking leg of sea spiders. Their four pairs of walking legs on segments 4-7 are, in 1906 this model, no longer serially homologous with those of arachnids (segments 3-6). 1907 Shultz (1990, character 39) proposed loss of appendages on opisthosomal segment 19081 as a putative synapomorphy of arachnids, making specific reference to adult 1909 instars.

1910 83. Median abdominal appendage ( 0 = absent; $1=$ present).

1911 Eurypterids and at least those chasmataspids which are well-preserved ventrally 1912 express an often elongate and/or segmented element projecting backwards from the 1913 second opisthosomal segment; the putative site of the genital opening. For this 
1914 reason this structure is conventionally referred to as the median abdominal (or 1915 genital) appendage, although it has also been referred to as a 'Zipfel' in some 1916 publications. It presumably plays a role in either mating or oviposition, which some 1917 debate in the literature about its gender assignment and precise function.

1918 84. Two anteriormost abdominal appendages fused to form genital operculum $(0=$ 1919 absent; $1=$ present).

1920 In eurypterids the first two pairs of mesosomal appendages are fused to form a plate 1921 called the Blatfuss/genital operculum.

1922 85. Embryonic appendages on $7^{\text {th }}$ segment ( $0=$ absent; $1=$ present).

1923 Scorpiones and Solifugae clearly retain limb buds on the $7^{\text {th }}$ (or first opisthosomal) 1924 segment during early embryogenesis (Farley 2005, fig. 1) and there are hints that 1925 the scorpion sternum may be derived (at least in part) from elements of 1926 opisthosomal segment 1 (Farley 2005, see also the next character). Unknown in 1927 fossil taxa.

1928 86. Genital operculum overlaps sternite of third opisthosomal segment ( 0 = absent; 19291 = present).

1930 This so-called 'megoperculate' condition is clearly present in Amblypygi, 1931 Thelyphonida and Schizomida, whereby the second opisthosomal (or genital) 1932 operculum - see above - is quite large and overlaps a largely vestigial 'true sternite'. 1933 This overlap was scored by Shultz (1990, character 42) as present in spiders too, but 1934 this is hard to reconcile with the fact that only Mesothelae retain the full genital 1935 sclerite (in other taxa it is reduced to a pair of book-lung opercula) and even in 1936 mesotheles evidence for the overlap of the third sternite seems to us equivocal. This 1937 is, however, tentatively coded as present. Palpigradi clearly lack a 'megoperculum', 1938 since the unpaired anterior lobe which accompanies the genital opening evidently 1939 does not overlap the sternite; contra Shultz (2007a).

1940 87. Opisthosomal silk glands and spigots ( $0=$ absent; $1=$ present).

1941 These complex glandular structures, producing silk and opening via spigots are 1942 synapomorphic for serikodiastida (Araneae + Uraraneida; Selden, Shear \& Sutton 1943 2009).

1944 88. Opisthosomal spinnerets ( $0=$ absent; $1=$ present).

1945 Spider spinnerets are appendage-derived opisthosomal structures which represent 1946 an unequivocal autapomorphy of Araneae. Specifically, they are not seen in 1947 Uraraneida in which the spigots appear to have been loosely distributed across the 1948 relevant segments of the ventral opisthosoma (Selden, Shear \& Sutton 2009).

1949 89. Ventral sacs ( $0=$ absent, $1=$ present $)$.

1950 Ventral sacs are enigmatic structures - possibly highly modified appendages - found 1951 on the underside of the opisthosoma in Amblypygi, Palpigradi and Trigonotarbida. 1952 Their function is unclear, but there have been suggestions that they play a role in 1953 osmoregulation. We score them simply as absent or present here, but note that in 
1954 the different groups they occur on different segments which may raise some 1955 questions about their serial homology.

1956 90. Pygidial defensive secretions ( $0=$ absent; $1=$ present).

1957 Thelyphonida have long been known to use defensive secretions of acetic / caprylic 1958 acid, leading to the group's common name 'vinegaroon'. These secretions are 1959 derived from pygidial glands at the back of the opisthosoma. We tentatively score 1960 this as present in Schizomida too (as per Shultz 1990, character 46); although we 1961 caution that it has only be confirmed in a handful of schizomid species; see e.g. 1962 Reddell \& Cokendolpher (1995).

1963 91. Genital acetabula ( $0=$ absent; $1=$ present)

1964 These structures are a characteristic trait of Acariformes among the mites, which 1965 usually bear three pairs (but see character 91) probably associated with 1966 opisthosomal segments 3-5. It is well-established that they are serially homologous 1967 with the Claparède organs or 'Urstigmata', sharing the same ultrastructure (Alberti 1968 1977) and function (Bartsch 1973). They are highly likely to be appendage 1969 derivatives, judging from evidence concerning the development of the Claparède 1970 organs (Thomas \& Telford 1999).

1971 92. Number of genital acetabula ( $0=$ three; $1=$ two; $2=$ several)

1972 Among Acariformes the number of genital acetabula may vary in relation to their 1973 function in water and ion balance. Freshwater species in particular have an 1974 increased number of genital acetabula designed for supplying ions to the 1975 hemolymph. Only applicable to acariform mites possessing genital acetabula.

1976

1977

1978

1979

1980

1981

1982

1983

1984

1985

1986

1987

1988

1989

1990

1991

93. Dorsal anal operculum $(0=$ absent; $1=$ present $)$ In Phalangiotarbida there is a round plate located dorsally at the posterior end of the opisthosoma. This has been interpreted as the anal operculum, albeit with some reservations regarding its functional morphology. Nevertheless in well-preserved phalangiotarbids this plate always preserves dorsally and does not seem to be, for example, a ventral structure pushed up through in compression fossils. A dorsal anal operculum would be unique to phalangiotarbids.

\section{Sensory systems}

94. Lateral eyes ( 0 = absent; $1=$ present)

Lateral eyes are absent in Opiliones - except for members of the suborders Cyphophthalmi and the extinct Tetropthalmi (Garwood et al. 2014) - and Pycnogonida.

95. Lateral eye lenses $(0=$ compound; $1=$ five or more pairs of lenses; $2=$ three primary pairs [excluding any microlenses]; 3 = two pairs; 4 = one pair)

The eyes of most of Arachnomorpha are compound in nature, as are the eyes of modern Xiphosura. This was apparently also the case in many Palaeozoic 
1992 Scorpiones, Eurypterida and Chasmataspidida; although individual facets cannot 1993 always be resolved in the fossils. Coding otherwise follows Shultz (2007a, character 1994 140) for arachnids. Extant Ricinulei have lateral light sensitive areas without lenses, 1995 thus they are coded as having lateral eyes but with an undetermined lens number. 1996 The same approach is adopted for rhagiidids among Acariformes mites. Inapplicable 1997 in those lacking lateral eyes.

1998 96. Lateral eye rhabdomes ( $0=$ net-like; $1=$ star-shaped $)$.

1999 The rhabdomes of Xiphosura and Scorpiones share a distinct, star-like shape, 2000 whereas those of the remaining arachnids have a net-like arrangement. This star2001 shape was treated as an argument for a basal position for scorpions by, e.g., 2002 Weygoldt \& Paulus (1979, character 21). The character is inapplicable to taxa 2003 lacking lateral eyes.

2004 97. Median eyes ( $0=$ four; $1=$ two or three; $2=$ absent).

2005 Pycnogonida have an ocular tubercle with four eyes and it has been argued 2006 (Weygoldt \& Paulus 1979) that this is plesiomorphic. All Euchelicerata have either 2007 two eyes, or have reduced them completely as in Ricinulei, Pseudoscorpiones, and 2008 Schizomida; see e.g. Weygoldt and Paulus (1979, character 14), Giribet et al. (2002, 2009 character 1). They can be either present or absent among Acariformes although 2010 they are absent in all Anactinotrichida.

2011 98. Retinula cells of medial eyes $(0=$ organized into closed rhabdomes; $1=$ 2012 organized into a network of rhabdomeres; 2 = disorganized; 3 , inverse retina; - = 2013 inapplicable due absence of median eyes)

2014 Scoring follows Shultz's (2007a) character 137.

2015 99. Slit sense organs ( $0=$ absent; $1=$ present $)$.

2016 These slit-shaped structures function as cuticular strain-gauges. They can be 2017 grouped together into so-called lyriform organs in some taxa and are often referred 2018 to as lyrifissures in mites. Slit sense organs have been recorded in all Arachnida 2019 except Palpigradi; see e.g. Shultz (1990, character 47) and Shultz (2007a, character 2020 142). They could thus be considered a potential arachnid synapomorphy with a 2021 presumptive reversal in palpigrades.

2022 100. Trichobothria ( $0=$ absent; $1=$ present $)$.

2023 These sensory hairs set into a specific, cup-shaped socket (the bothridium) detect 2024 air vibrations and are a key sensory system in many arachnids for detecting prey or 2025 other sources of movement in their vicinity. They are not seen in Pycnogonida and 2026 Xiphosura, but apparently occur in all arachnid orders with the exception of 2027 Solifugae, Ricinulei and Opiliones (Selden, Shear \& Bonamo 1991), and probably 2028 Trigonotarbida too.

2029 101. Tibial trichobothria with 2-1-1-1 distribution ( $0=$ absent; $1=$ present).

2030 This specific pattern of trichobothria on the tibia was proposed by Shultz (1990, 2031 character 48) as an explicit synapomorphy of (Thelyphonida + Schizomida). It is 
2032 inapplicable for taxa which lack trichobothria (see previous character).

2033 102. Prodorsal trichobothria $(0=$ absent; $1=$ present $)$

2034 These specific trichobothria on the prodorsum are a textbook synapomorphy for 2035 acariform mites as compared to anactinotrichid species; although they are 2036 secondarily lost in several acariform taxa. As with some other 'mite-specific' 2037 characters, they can be difficult to assess in (the usually much larger) non-acarine 2038 taxa.

2039 103. Pectines ( $0=$ absent; $1=$ present $)$.

2040 These unique structures in Scorpiones appear to be modified appendages, which 2041 primarily act as chemosensory organs. Although occurring immediately behind the 2042 gonopore, authors such as Weygoldt \& Paulus (1979) argued that they belonged to 2043 the $2^{\text {nd }}$ (or genital) segment as part of a 12-segmented groundplan for the 2044 opisthosoma. Hox gene data from Simonnet, Célérier \& Quéinnec (2006) 2045 corroborated by morphological data from Shultz (2007b) indicates that the pectines 2046 are in fact derived from the $3^{\text {rd }}$ opisthosomal segment as part of a 13-segmented 2047 opisthosoma. It is worth noting that recent studies of some early fossil scorpions 2048 failed to find pectines, even in well otherwise ventrally well-preserved material - for 2049 example see Proscorpius (Dunlop, Tetlie \& Prendini 2008) and Compsoscorpius (Legg 2050 et al. 2012). It is conceivable that they were genuinely absent in the most basal 2051 stem-group scorpions which (if true) would render them no longer synapomorphic 2052 for the whole Scorpiones clade. The coding of Palaeoscorpius reflects the 2053 uncertainty reported by Kühl et al. (2012). See also the section on respiratory organs 2054 for an account of the alignment of respiratory organs on the euchelicerate 2055 opisthosoma.

2056 104. Malleoli $(0=$ absent; $1=$ present $)$.

2057 These unique sensory structures, sometimes called racquet organs, are a convincing 2058 autapomorphy for Solifugae, where they occur on the basal articles of the posterior 2059 legs (Punzo 1998).

2060 105. Tarsal organ on leg I $(0=$ absent; $1=$ present $)$.

2061 The tarsal organs or Haller's organs occurs on leg I of Opilioacariformes, Holothryda 2062 and Ixodida (Klompen 2000), in leg I and II of Ricinulei (Talarico et al. 2005) and in all 2063 legs of Araneae and, perhaps, Scorpiones (Foelix 1985). Scoring of this - and the 2064 subsequent character - follows Shultz (2007a, characters 149, 150).

2065 106. Tarsal organ on leg II ( $0=$ absent; $1=$ present $)$.

2066 A tarsal organ, similar to the character above, is present in Araneae and Ricinulei leg 2067 II.

2068 107. Opisthosomal ganglia in adults ( $0=$ absent; $1=$ present).

2069 In some arachnids, such as most spiders and all mites, there is a tendency to 2070 consolidate the ganglia of the central nervous system (CNS) anteriorly into the 2071 prosoma, effectively forming a unitary 'brain'. In other taxa ganglia remain along the 
2072 length of the CNS into the opisthosoma; the plesiomorphic condition on the basis of 2073 outgroup Alalcomenaeus cambricus (Tanaka et al. 2013).

2074 108. Perineural membrane enveloping arterial sinus ( $0=$ present; $1=$ absent).

2075 Firstman (1973) related this membrane structure to the presence of book lungs and 2076 it thus scores as present for all (living) lung-bearing taxa.

2077 109. Intercheliceral median organ ( $0=$ absent; $1=$ present).

2078 This tiny movable structure emerges from beneath the prosomal shield and between 2079 the chelicerae of Palpigradi. Whether it represents a modified seta or, conceivably, a 2080 vestigial element homologous with some sort of precheliceral appendage is unclear. 2081 Van der Hammen (1982) speculated if it could be homologous with the Acariformes 2082 naso.

2083 Respiratory system

2084 110. Respiratory organs ( $0=$ book gills or lungs present; $1=$ tracheae; $2=$ absent). 2085 In this character, no attempt is made of distinguishing between lamellate gills and 2086 lungs. Their differences, as highlighted by Scholtz \& Kamenz (2006) are recognized 2087 and coded separately below. Although traditionally scored as a 'lungs 2088 absent/present' character, our revised coding recognises that the ground pattern in 2089 the aquatic common ancestor was presumably gills, retained today in Xiphosura. In 2090 (modern) Scorpiones and Tetrapulmonata these have been transformed into lungs. 2091 Note that many derived spiders have both lungs and trachea (hence the 0/1 score) 2092 while various chelicerates respire only with trachea, have lost the respiratory organs 2093 all together, or perhaps never developed such structures at all (Palpigradi, 2094 Pycnogonida, some mites?). A simple division into pulmonate and apulmonate 2095 arachnids has been criticized in the past and we score this character with 2096 reservations given that not all lungs and/or trachea in arachnids open in serially 2097 homologous positions. Some of these difficulties are reflected in the characters 2098 elaborated below.

2099 111. Book lung/gill on $2^{\text {nd }}$ (i.e. genital) opisthosomal segment $(0=$ present; $1=$ 2100 absent).

2101 Assuming the plesiomorphic condition was a series of respiratory organs along the 2102 trunk/opisthosoma, it is noticeable that in some chelicerates these have been lost on 2103 particular segments. As putative basal euchelicerates, Offacolus and Dibasterium 2104 bear a series of flattened appendages along the opisthosoma from the second to the 2105 seventh segment, the first to third among them bearing preserved accessory flaps in 2106 the former (Sutton et al. 2002), and first to fourth in the latter (Briggs et al. 2012). A 2107 similar state is observed in Weinbergina. By contrast Xiphosura and Scorpiones are 2108 notable for completely lacking a lamellate respiratory organ on the second (or 2109 genital) opisthosomal segment.

2110 112. Book lung/gill on $3^{\text {rd }}$ (i.e. postgenital) opisthosomal segment $(0=$ present; $1=$ 
2111 absent).

2112 A lamellate respiratory organ has been retained on this segment in: both modern 2113 Xiphosura and the fossil horseshoe crabs Weinbergina, Dibasterium, and Offacolus; 2114 in Trigonotarbida; and in Tetrapulmonata. They have been lost in segment 3 in 2115 Scorpiones - whereby it is interesting to speculate whether the pectines in this 2116 position are homologous appendicular elements - and, perhaps, in Eurypterida too 2117 (Braddy et al. 1999). Note that in more derived spiders (Araneae: Araneoclada) the 2118 second book lung has almost certainly been modified directly into trachea. This 2119 condition is also scored 1 here, but is presumably homoplastic with respect to other 2120 euchelicerates.

2121 113. Book lung/gill on $4^{\text {th }}$ to $7^{\text {th }}$ opisthosomal segment ( $0=$ present; $1=$ absent).

2122 A lamellate respiratory organ has been retained on these segments in both modern 2123 Xiphosura and the fossil horseshoe crabs Weinbergina, Dibasterium, and Offacolus; 2124 and in Scorpiones. The gill/lung has been (apomorphically) lost on these segments in 2125 the Pantetrapulmonata. Note that characters $111-113$ are related to the 2126 transformation of book gills into book lungs, thus they are again coded only for taxa 2127 fundamentally bearing lamellate respiratory organs.

2128 114. Spiracles ( 0 = absent; 1 = present)

2129 Early fossil scorpions do not express ventral spiracles opening within the relevant 2130 sclerite. It is possible that the spiracle opening in fossil scorpions was marginal on a 2131 segment and concealed beneath a sclerite, rather like in Pedipalpi, but this is 2132 difficult to assess from the available material. Marginal spiracles can be clearly seen 2133 in well preserved examples of Trigonotarbida. In the coding adopted here, it was 2134 assumed that the spiracles of Scorpions and Tetrapulmonata are homologous, a 2135 controversial assumption; see also character 117.

2136 115. Spines on book lung lamellar margins ( $0=$ absent; $1=$ present)

2137 All book lungs express spines from the margins of the lamellae pointing into the 2138 atrial chamber which possibly help filter out particles and prevent them from 2139 entering the delicate lamellae themselves (Scholtz \& Kamenz 2006). These spines 2140 are absent in the xiphosuran book gills, and they can be seen in the remarkable 2141 well-preserved fossil lungs of the trigonotarbid Palaeocharinus (Kamenz et al. 2008).

2142 116. Shape of pillars of the haemolymph spaces inside the gill/lung lamellae $(0=$ at 2143 least two perikarya meeting midway in the haemolymph space; $1=$ pillars, including 2144 a strong axis of microtubules).

2145 State 1 is found in Xiphosuran book gills (Scholtz \& Kamenz 2006). This character is 2146 inapplicable to those taxa which lack book gills/lungs.

2147 117. Prosomal spiracles ( 0 = absent; $1=$ between the coxae of the second and third 2148 walking legs; 2 = associated with coxae of third and fourth walking leg; $3=$ between 2149 cheliceral basis; 4 = brachypyline oribatid tracheal system).

2150 Tracheal openings between coxae II and III (e.g. Giribet et al. 2002, character 25) are 2151 a potential autapomorphy of Solifugae. Openings between coxae II and IV are 
2152 observed in Ricinulei and are tentatively scored here for Anactinotrichida except 2153 Opilioacarus (see subsequent character). Spiracular openings between the 2154 chelicerae are found in some prostigmatid mites - hence their name - although 2155 further taxon-specific respiratory structures are found among ingroup members 2156 (Evans 1992, Alberti and Coons 1999). Most Astigmata and Endeostigmata lack 2157 respiratory organs. Brachypyline oribatids have spiracles opening in acetabula or 2158 sockets of legs I and II and between legs II and III. Among Oribatida many other 2159 respiratory structures occur, but the details do not seem to be informative for a 2160 higher level phylogeny (Alberti \& Coons 1999). This character touches on the 2161 question of whether tracheal systems can be easily reduced to simple 2162 presence/absence characters and/or whether the segment on which the respiratory 2163 organ opens carries as much phylogenetic information as the fact that it is a lung or 2164 a trachea; see also comments below. On current data a simple answer to this 2165 question does not present itself.

2166 118. Opisthosomal spiracles $(0=$ absent; $1=$ paired ventral stigmata on genital 2167 segment; 2 = paired ventral stigmata on $3^{\text {rd }}$ and $4^{\text {th }}$ opisthosomal segments; $3=$ 2168 four pairs of dorsal stigmata on the anterior opisthosoma).

2169 Character state 1 is scored for Opiliones. State 2 is scored for Pseudoscorpiones and 2170 Solifugae, although the latter also has an unpaired spiracle on the $5^{\text {th }}$ opisthosomal 2171 segment. State 3 is autapomorphic for Opilioacariformes. If tracheae are derived 2172 from book-lungs it is likely that the positions of the tracheal openings are serially 2173 homologous with the relevant book lungs in other arachnids. In the absence of 2174 unequivocal lung/trachea homology across all arachnids (cf. the prosomal or dorsal 2175 opisthosomal spiracles above) we score these here as independent characters for 2176 now.

2177 119. Kiemenplatten ( $0=$ absent; $1=$ present $)$

2178 Well-preserved eurypterids uniquely possess modified oval areas on the underside of 2179 the body, located within the gill chambers. These are conventionally referred to as 2180 Kiemenplatten or sometimes simply 'gill tracts'. Assuming that eurypterids retained 2181 lamellate book gills, these Kiemenplatten have been interpreted as an accessory 2182 respiratory system with possible parallels to the branchial lungs of certain modern 2183 crabs which allow these animals to undertake temporary excursions onto land.

2185 120. Postcerebral crop and proventriculus ( $0=$ reduced, $1=$ present).

2186 A large crop is associated with the posteriorly-directed mouth in Xiphosura. They 2187 may thus form part of a character complex together. Such a crop is not recorded in 2188 arachnids or pycnogonids and reduction of the crop was proposed as a putative 2189 synapomorphy of Arachnida by Shultz (2007a, character 202).

2190 121. Well-developed sucking stomach $(0=$ absent; $1=$ present $)$. 
2191 Clearly present in Araneae and Amblypygi, and treated as a synapomorphy of these 2192 taxa by e.g. Weygoldt \& Paulus (1979, character 31). Shultz (1990, character 5) 2193 noted its vestigial presence in Uropygi and some Scorpiones too, while Shultz (2001) 2194 further noted that Xiphosura also have a muscular postcerebral pharynx. Scoring 2195 follows Weygoldt \& Paulus (1979).

2196 Endosternite

2197 122. Endosternite ( $0=$ absent; $1=$ present $)$.

2198 This structure may be homologous with Dohrn's septum in Pycnogonida, but it 2199 occurs in a specifically plate-like form in Euchelicerata; with the exception of 2200 Solifugae. Firstman (1973) gave a detailed account, whereby its absence in 2201 Solifugae was considered a secondary reversal. Shultz (1990) also sought to define 2202 an endosternite sensu stricto as "a broad sheet of non-contractile connective 2203 tissue".

2204 123. Anterior endosternal horn ( $0=$ terminating in muscular attachment to labrum; 22051 = terminating in muscular attachment to palpal coxa).

2206 This specific morphology of the endosternal horn was proposed by Shultz (1990, 2207 character 4) as a putative synapomorphy of Pedipalpi. It is inapplicable to taxa 2208 which lack an endosternite (see above).

2209 124. Fenestrate endosternite $(0=$ absent; $1=$ present $)$.

2210 This specific form of the endosternite is restricted to Thelyphonida and Schizomida 2211 (1990, character 8). It is inapplicable to taxa which lack an endosternite (see above).

2212 Excretory organs

2213 125. Malpighian tubules ( $0=$ absent; $1=$ present).

2214 These excretory organs are another 'typical' textbook arachnid character. They have 2215 been recorded in all Recent arachnids except Palpigradi, Opiliones, 2216 Pseudoscorpiones and most Acariformes; see e.g. Shultz (1990, character 62). 2217 Among Acariformes, structures similar to Malpighian tubules have been found in 2218 Acaridae, thus they are tentatively scored here as present.

2219 126. Coxal glands opening on proximal podomere of chelifore $(0=$ absent; $1=$ 2220 present).

2221 Coxal glands are modified nephridia and as such of mesodermal origin. The coxal 2222 gland opening is an ectodermal invagination and may not correspond to the 2223 segment from which the coxal gland sacculi originate. We prefer a simplified account 2224 for the coxal glands considering an anterior and a posterior coxal gland opening as 2225 the Bäuplan condition, as has been suggested by Weygoldt (2000). It reflects our 2226 poor understanding of the embryology and organogenesis of several orders. 2227 Fahrenbach \& Arango (2007) described the presence of a pair of coxal glands 2228 associated with the Nymphopsis spinosissima chelifores - the first occurrence of 2229 excretory organs of any kind in Pycnogonida. King (1973) suggested that excretory 
2230

2231

2232

2233

2234

2235

2236

2237

2238

2239

2240

2241

2242

2243

2244

2245

2246

2247

2248

2249

2250

2251

2252

2253

2254

2255

2256

2257

2258

2259

2260

2261

2262

2263

2264

2265

2266

2267

2268

2269

2270

2271

2272

organs may be present on other leg bases based on dying techniques, but these results require confirmation. We accept here the existence of this anterior pair of coxal glands, but current data does not rule out the existence of more posterior pairs. Therefore, the following two characters are scored as ambiguous for Pycnogonida.

127. Coxal glands opening at base of leg 1 ( $0=$ absent; $1=$ present $)$.

State 0 is coded here for all living Euchelicerata, except Xiphosurans, Scorpiones, Opiliones and Pseudoscorpiones. Coxal gland openings in this position are thus retained in Acari, Ricinulei, Palpigradi, Solifugae, Araneae, Amblypygi, Thelyphonida and Schizomida (e.g. Shultz 1990, character 64; Shultz 2007a, character 180). Opening of the coxal glands associated with the pedipalps (the second prosomal segment) have been mooted as an autapomorphy of Solifugae (Shultz 1990), but Buxton (1917) described them opening in the same position in Palpigradi. The condition of Solifugae is quite similar to that found in several Acariformes were a cuticle-lined channel lead the fluids of the coxal gland towards the pre-oral chamber. It is worth also mentioning the so-called 'hatching glands' associated with the pedipalp in spider embryos (Yoshikura 1975) as well the second ozopore in some opilionids (Hara 2003) could be homologous with coxal glands (Moritz 1959, Yoshikura 1975).

128. Coxal glands opening on leg 3 segment ( $0=$ absent; $1=$ present).

Coxal gland openings in this position are plesiomorphically retained in Xiphosura, mygalomorph Araneae, basal Amblypygi, Opiliones, Scorpiones and Pseudoscorpiones (e.g. Shultz 1990, character 63). It is scored as ambiguous for the extinct Eurypterida except Baltoeurypterus (now Eurypterus) where Selden (Selden 1981) reported a pit near insertion of leg III.

129. Contribution of the coxal gland to saliva $(0=$ absent; $1=$ Buxton's group II coxal gland; $2=$ coxal glands and saliva converging into the pre-oral chamber through external taenidia or gutters; $3=$ podocephalic channel).

The onycophoran salivary gland is a modified nephridium, where a terminal sac lined with podocites is found along with a hypertrophied secretory region (Buxton 1913; Storch, Alberti \& Ruhberg 1979). This structure is quite similar to the coxal glands of Palpigradi and Solifugae (Buxton 1913, 1917; Alberti 1979). In Solifugae the putative function of the coxal gland secretion as saliva is congruent with its opening as an excretory organ in close association to the pre-oral chamber. In Palpigradi this relation is not so clear; our coding recognizes the internal structural similarity with Solifugae (contra Shultz, 2007a). The condition presented by Parasitiformes approaches that of Solifugae. The so-called podocephalic channel, which leads the coxal gland secretions to the exterior, receives the products from up to three salivary glands and delivers them to the pre-oral chamber (Alberti \& Coons 1999). However, each gland has its own distal portion lined by cuticle, being therefore the connection among the podocephalic glands made by an ectodermic structure (e.g. Shatrov 2005). Although functionally very similar, the condition presented by Acariformes apparently evolved from structures of different embryological origins 
2273

2274

2275

2276

2277

2278

2279

2280

2281

2282

2283

2284

2285

2286

2287

2288

2289

2290

2291

2292

2293

2294

2295

2296

2297

2298

2299

2300

2301

2302

2303

2304

2305

2306

2307

2308

and is coded here as a distinct state. Tetrapulmonata, Ricinulei, Holothyrida, and Opiliocariformes present prosomal furrows that lead the product from the coxal glands to the pre-oral chamber where it contributes to the saliva (Shultz 2007a, character 14). Scorpiones, Opiliones, Pseudoscorpiones, Xiphosura, Pycnogonida and ticks have no documented relationship between coxal glands and saliva secretion and are scored as 0.

130. Dorsomedian excretory organ ( 0 , absent; 1 , present).

This is a specialized, post-colon, region of the midgut modified for excretion which is present in Prostigmata (Alberti \& Coons 1999) among the mites.

\section{Musculature}

Pharyngeal musculature

131. Lateral extrinsic precerebral pharyngeal muscle $(0=$ arising from anterior endosternal horns; 1 = arising from medial surface of palpal coxae; - inapplicable for taxa lacking an endosternite).

This specific arrangement of the pharyngeal musculature was proposed by Shultz (1990, character 6) as a putative synapomorphy of Pedipalpi.

132. Ventral extrinsic precerebral pharyngeal muscle and tergopharyngeal muscle of precerebral pharynx ( $0=$ present; $1=$ absent $)$.

A further specific arrangement of the pharyngeal musculature was proposed by Shultz (1990, character 7 and 8) as a putative synapomorphy of Pedipalpi. Shultz (1990) interpreted these two muscles listed above as independent characters, but we prefer to treat them as a single character complex in order to avoid weighting the analysis too heavily towards patterns of individual muscle insertions.

\section{Cheliceral musculature}

133. Cheliceral tergal-deutomerite muscle ( $0=$ absent; $1=$ present).

Among those taxa whose chelicerae have three articles, this muscle running from the prosomal shield to the proximal margin of the second article (the deutomerite sensu Shultz) has so far only been recorded in Scorpiones and Opiliones (Shultz 2000), for which it was proposed as a putative synapomorphy. It is scored as inapplicable here for taxa with only two cheliceral articles.

134. Lateral tergocheliceral muscle $(0=$ one head; $1=$ three heads).

This specific pattern of tergocheliceral musculature was proposed by Shultz (1990, character 10) as a putative synapomorphy of Pedipalpi.

135. Paired muscle arising from posterior margin of anterior carapacal doublure and inserting on prosomal shield ( $0=$ absent; $1=$ present).

Shultz (1990, character 1 ) described this specific muscle pairing as a putative 
synapomorphy of Pedipalpi.

2310 Endosternal musculature

2311 136. Posterior oblique muscles of box-truss axial muscle system (BTAMS) of postoral

2312 somites I-V ( 0 = absent; 1 = present in one or more somites).

2313 Shultz (2001) investigated the so-called box-truss axial muscle system in detail. 2314 State 0 occurs in Xiphosura, and state 1 occurs in Palpigradi, Araneae, Amblypygi, 2315 Thelyphonida, Schizomida and Scorpiones (Shultz 2001; 2007a, character 127). The 2316 condition in Acari, Ricinulei, Opiliones and Solifugae is not recorded.

2317 137. Anterior oblique muscles of BTAMS posterior to postoral somite VI ( $0=$ absent; 23181 = present).

2319 State 1 occurs in Xiphosura and may represent the primitive condition based on 2320 comparison with other arthropods (Shultz 2001; 2007a, character 128). State 0 2321 occurs in all arachnids examined thus far.

2322 138. Intercoxal endosternal extensor muscles ( $0=$ absent; $1=$ present).

2323 The presence of these specific muscles was tentatively proposed as a 2324 synapomorphy of (Scorpiones + Opiliones) by Shultz (2000).

2325 139. Endosternal dorsal suspensors of somites $I$ and $I I \quad(0$ = present; $1=$ 2326 absent/detached).

2327 The absence of these suspensor muscles was suggested by Shultz (1990) as a 2328 putative synapomorphy of Arachnida; although the possibility that these muscles 2329 have become modified in other ways was also discussed; see Shultz (2001, p. 301) 2330 for details. Inapplicable to taxa which lack an endosternite (see above).

2331 140. Endosternal dorsal suspensor muscles in somite four with anterolateral 2332 carapacal insertion ( $0=$ absent; $1=$ present).

2333 The specific insertion of the endosternal suspensor muscles in Palpigradi, basal 2334 Araneae, Amblypygi and Uropygi is more posteromedial and often associated with 2335 the median prosomal shield depression typically seen in such arachnids (Shultz 2336 1990, character 7). Inapplicable to taxa which lack an endosternite (see above).

2337 141. Endosternal dorsal suspensor muscle of somite five ( $0=$ present; $1=$ absent). 2338 This specific pattern of endosternal musculature was proposed by Shultz (1990) as a 2339 putative synapomorphy of Pedipalpi. Inapplicable to taxa which lack an endosternite 2340 (see above).

2341 142. Ventral endosternal suspensor muscles ( $0=$ attaching primarily to sternum; 1 2342 = attaching primarily to coxa of appendage of anteriorly adjacent somite).

2343 This specific pattern of musculature was proposed by Shultz (1990, character 7$)$ as a 2344 putative synapomorphy of Pedipalpi. Inapplicable to taxa which lack an endosternite 2345 (see above).

2346 Pedipalp musculature 
2347 143. Palpal posteromedial tergocoxal muscle $(0=$ present; $1=$ absent $)$.

2348 This specific pattern of tergocoxal musculature was proposed by Shultz (1990) as a 2349 putative synapomorphy of Pedipalpi.

2350 144. Palpal posteromedial endosternocoxal muscle ( $0=$ originates on endosternite, 2351 inserts on coxa; 1 = originates and inserts on coxa).

2352 This specific pattern of endosternal musculature was proposed by Shultz (1990) as a 2353 putative synapomorphy of Pedipalpi.

\section{Leg musculature}

2355 145. Intracoxal muscle ( 0 = absent; 1 = present).

2356 This specific muscle in the walking leg coxae was proposed by Shultz (2007a, 2357 character 54) as a putative synapomorphy of Pedipalpi.

2358 146. Insertion process of anteromedial tergocoxal muscle ( $0=$ weakly developed; 1 $2359=$ large, well developed).

2360 This specific pattern of leg musculature was proposed by Shultz (2007a, character 2361 57) as a putative synapomorphy of Pedipalpi.

2362 147. Femoropatellar flexor ( $0=$ symmetrical; $1=$ asymmetrical).

2363 The asymmetrical arrangement of this muscle complex in the leg was proposed by 2364 Shultz (1990, character 27) as a putative synapomorphy of Pedipalpi.

2365 148. Pedal anterior femur-patella muscle ( 0 = inserting primarily on patellar margin; 23661 = inserting primarily on patellar plagula).

2367 This specific pattern of leg musculature was proposed by Shultz (1990, character 27) 2368 as a putative synapomorphy of Pedipalpi.

2369 149. Pedal posterior femeropatella-tibia muscle ( $0=$ present; $1=$ absent).

2370 Absence of this specific muscle in the walking legs was proposed by Shultz (1990, 2371 character 33) as a putative synapomorphy of Pedipalpi.

2372 150. Pedal patellotibia-tarsus muscle ( 0 = present; $1=$ absent).

2373 Absence of this specific muscle in the walking legs was proposed by Shultz (19, 2374 character 29) as a putative synapomorphy of Pedipalpi.

2375

2376

2377

2378

2379

2380

2381
151. Posterior transpatellar muscles insertion $(0=$ dorsoposterior femur/ posterior patella; $1=$ distal process of femur; $2=$ absent).

Shultz (1990 character 28) regarded a femoral and/or patellar origin of this muscle as the plesiomorphic condition, regarding its specific origin from a distodorsal process as an apomorphy seen in Scorpiones, Opiliones and Pseudoscorpiones. This muscle is absent in Solifugae, Ricinulei and Schizomida, which is interpreted as a further derived state. 
2382

2383

2384

2385

2386

2387

2388

2389

2390

2391

2392

2393

2394

2395

2396

2397

2398

2399

2400

2401

2402

2403

2404

2405

2406

2407

2408

2409

2410

2411

2412

2413

2414

2415

2416

2417

2418

152. Patellotibial extensor ( $0=$ absent; $1=$ present $)$.

According to Shultz (1990, character 29) the posterior transpatellar muscle in Scorpiones and Pseudoscorpiones has a specific dorsal insertion point and appears to act as a patellotibial extensor.

153. Anterior transpatellar muscle insertion $(0=$ anteriorly/anteroventrally; $1=$ ventrally / posteroventrally; 2 = absent).

This muscle was reported (1990, character 30) as normally inserting on the anterior margin of the tibia, but as inserting ventrally in Scorpiones, Pseudoscorpions and Solifugae and as being absent in Ricinulei and Schizomida.

154. Anterior patellotibial muscle insertion on tibia $(0=$ anterior; $1=$ ventral; $2=$ absent).

Shultz (1990, character 32) described this muscle as having a ventral insertion point in Ricinulei, Scorpiones and Solifugae and as (uniquely) being absent in Pseudoscorpiones.

155. Posterior patellotibial muscle ( $0=$ present; $1=$ absent $)$.

This specific muscle was reported by Shultz (1990, character 33 ) as apomorphically absent in Scorpiones, Pseudoscorpiones, Solifugae and Schizomida.

156. Origin of apotele depressor ( $0=$ tarsus; $1=$ tibia $)$.

A tibial origin of the apotele (or pretarsus) depressor muscle was suggested by Shultz (1990, character 35) as a possible synapomorphy for Arachnida.

157. Patellar head of apotele depressor ( $0=$ absent; $1=$ present).

The apotele depressor muscle has a head extending into the patella in Araneae, Thelyphonida, Schizomida, Opiliones, Scorpiones, Pseudoscorpiones and Solifugae Shultz (1989, 1990 character 36).

158. Patellar head of apotele depressor originates on posterior patellar wall $(0=$ absent; 1 = present).

This specific position of the patella head of these depressor muscles was suggested by Shultz (1990, character 37 ) as a putative synapomorphy for Thelyphonida and Schizomida. It is not applicable to those taxa (see above) that lack a patella head.

\section{Opisthosomal musculature}

159. Attachments of opisthosomal posterior oblique axial muscles. $(0=$ tergal; $1=$ pleural).

The pleural attachment of these muscles was suggested as a possible synapomorphy for Arachnida by Shultz (2001). Given the highly reduced trunk in extant forms, all these opisthosomal musculature characters are scored here as inapplicable for Pycnogonida.

160. Opisthosomal pleural muscle $(0=$ continuous dorsoventral sheet; $1=$ divided 
2419

2420

2421

2422

2423

2424

2425

2426

2427

2428

2429

2430

2431

2432

2433

2434

2435

2436

2437

2438

2439

2440

2441

2442

2443

2444

2445

2446

2447

2448

2449

2450

2451

2452

2453

2454

2455

2456

into three components).

Division of this opisthosomal muscle sheet was proposed by Shultz (1999, character 28) as a putative synapomorphy of Pedipalpi.

161. Dorsal and ventral longitudinal muscles $(0=$ spanning full length of opisthosoma; 1 = spanning first and, perhaps, last four opisthosomal somites).

This specific pattern of longitudinal muscles was proposed by Shultz (1999, character 30) as a putative synapomorphy of Pedipalpi. How this should apply to acariform mites with their rather short 'opisthosoma' is unclear and they have been scored (?) here.

\section{Reproduction}

162. Internal fertilisation ( $0=$ absent; $1=$ present).

Male xiphosurans release sperm directly onto the eggs and thus fertilise them externally (Aberti 2000) - presumably the plesiomorphic behaviour - whereas all arachnids use various mechanisms (outlined as individual characters below) to achieve internal fertilisation. This is a putative synapomorphy of Arachnida. The precise mode of sperm transfer in Pycnogonida is uncertain (Alberti 2000), as is that of various fossil taxa. There is some circumstantial evidence that the extinct eurypterids used internal fertilization too with sperm perhaps being deposited and/or taken up by the genital appendage.

163. Gonopores ( $0=$ on limb bases; $1=$ on second opisthosomal segment).

The genital opening occurs on the second opisthosomal segment in all extant Euchelicerata, whereas Pycnogonida have genital openings on the limb bases. Whether the pycnogonid condition is plesiomorphic or apomorphic is subject to debate (Dunlop \& Arango 2005); arguments for both hypotheses can be formulated, such as the displacement of organ systems into the pycnogonid legs.

164. Gonopores ( $0=$ paired on second opisthosomal segment; $1=$ unpaired on second opisthosomal segment).

Consolidation of paired gonopores - as in for example xiphosurans - into a single genital opening has been suggested as a synapomorphy of Arachnida (Shultz 2001). The state of this character in fossil taxa, such as the eurypterids with their median abdominal appendage, is difficult to determine and scored as uncertain.

165. Anteriorly positioned gonopore ( 0 = absent; 1 = present).

In Opiliones and Ixodida, the genital opening is thrust forwards into a distinctly anterior position more or less between the leg coxae; see e.g. Giribet et al. (2002, character 165).

166. Ovipositor ( 0 = absent; 1 = present).

An ovipositor is present in Opiliones and in some Anactinotrichida - with the important exception of the ticks - as well as Acariformes among the mites sampled 
here.

2458 167. Penis / Spermatopositor ( 0 = absent; $1=$ present; 2 = acariforme aedagus).

2459 A penis is unequivocally present in Opiliones. A penis-like structure is also seen in 2460 some acariform mites; however in the latter group it is probably better to regard it 2461 as a spermatopositor which has (homoplastically) evolved into a copulatory device 2462 in various ingroup mites. Thus a true penis, as per Opiliones, may not be part of the 2463 acariform mite ground pattern. Anactinotrichid mites do not have a penis at all and 2464 attempts to use a penis to support (Opiliones + all Acari) are misleading. Indeed 2465 among Acariformes the presence of a "penis" has probably evolved several times. 2466 All are scored as " 2 " here, however, in Astigmata, Cheyletidae, Tetranychoidea and 2467 Stigmaeidae.

2468 168. Male palpal organ ( $0=$ absent; $1=$ present).

2469 Direct sperm transfer via the modified palpal organ of mature male spiders is an 2470 autapomorphy of Araneae. The uraraneid palp is unknown.

2471 169. Sperm transfer device on leg 3 ( $0=$ absent; $1=$ present).

2472 Functionally similar to the spider palpal organ (see above), a modified organ for 2473 direct sperm transfer on the third leg in mature males is an unequivocal 2474 autapomorphy of Ricinulei.

2475 170. Stalked spermatophore ( $0=$ absent; $1=$ present $)$.

2476

2477

2478

2479

2480

2481

2482

2483

2484

2485

2486

2487

2488

2489

2490

2491

2492

2493

2494

2495

2496

2497

Alberti (2000) commented on the possibility that some sort of spermatophore was part of the arachnid ground pattern, but noted difficulties in defining what exactly constitutes a spermatophore sensu stricto. Scorpiones, Pseudoscorpiones, Amblypygi, Thelyphonida and Schizomida transfer sperm via an explicitly stalked spermatophore; e.g. Shultz (1990, character 57). Among mites most of Acariformes produces spermatophores while most of Anactinothrichida exhibits espermdactly insemination or transfer the sperm employing the chelicerae. The exact mechanism of sperm transfer in Opilioacariformes and Holothyrida remains unknown.

171. Spermatophore uptake $(0=$ without mating; $1=$ face-to-face uptake; $2=$ mating parade).

Various arachnids perform ritualised mating behaviours or 'dances'. In Scorpiones and Amblypygi the male manoeuvres the female over the spermataphore with the animals face-to-face. This is often called the 'promenade-de-deux' in scorpions and this face-to-face behaviour is tentatively treated as a potential apomorphy, although details of courtship may differ between groups. Pseudoscorpiones are more complex. Some, probably basal, taxa simply leave a spermataphore and do not strictly speaking mate (Weygoldt 1969; Alberti 2000). Others have a scorpion-like courtship. We score pseudoscorpions $0 / 1$ here for the character. A specific behaviour pattern identified for Thelyphonida and Schizomida is what Weygoldt (1978) termed the 'mating parade' (see also Shultz 1990; character 58) in which the female grabs the male opisthosoma and is pulled over a previously deposited spermatophore with the animals facing in the same direction. This character is inapplicable for taxa 
2498

2499

2500

2501

2502

2503

2504

2505

2506

2507

2508

2509

2510

2511

2512

2513

2514

2515

2516

2517

2518

2519

2520

2521

2522

2523

2524

2525

2526

2527

2528

2529

2530

2531

2532

2533

2534

which do not use spermatophores and the behaviour of Acariformes is too diverse to allow useful coding of this character at this stage.

172. Testis ( $0=$ glandular area unspecialised; $1=$ glandular area distinctly larger). Alberti \& Peretti (2002) described distinct and potentially apomorphic similarities in the morphology of the testis in Solifugae and Acariformes only among the mites. In detail, they observed that in both groups there is a large glandular area, probably producing secretions needed for spermatophore formation, which has not been observed in other arachnids.

173. Tubular genital accessory glands ( $0=$ absent; $1=$ present $)$.

These so-called holocrine glands occur among arachnids only within the genital system of Amblypygi, Thelyphonida and Schizomida (Alberti 2000, 2005), and thus potentially support the Pedipalpi clade.

174. Brood sac $(0=$ absent; $1=$ present $)$.

Pseudoscorpiones, Amblypygi, Thelyphonida and Schizomida construct a brood sac in which eggs - or in the case of pseudoscorpions, embryos - develop; see e.g. Shultz (1990, character 59) and Shultz (2007a, character 172).

\section{Sperm morphology}

175. Sperm cell flagellum ( $0=$ present; $1=$ absent $)$.

Plesiotypic sperm cells are supposed to be flagellate among animals. Loss of the flagellum is associated with specialization of the sperm transfer mechanisms.

176. Sperm cells coiled ( $0=$ present; $1=$ absent).

This character is inapplicable for taxa without a flagellum.

177. Microtubule arrangement in axoneme $(0,9+0 ; 1,9+1 ; 2,9+2 ; 3,9+3)$

The $9 \times 2+3$ arrangement of microtubules in the sperm axoneme is widely regarded as a convincing synapomorphy of Tetrapulmonata (Alberti 2000, 2005 and references therein). Note that some ingroup spiders show further modifications of this pattern (Michalik \& Alberti 2005). Inapplicable in taxa without an axonem.

178. Corkscrew-shaped helical nucleus ( $0=$ absent; $1=$ present).

The specific morphology of a helically-shaped nucleus with sharp edges was suggested by Alberti $(2000,2005)$ as a potential synapomorphy of (Araneae + Amblypygi). Pseudoscorpiones were also noted as having a corkscrew-shaped nucleus, but here derived from a peculiar spiral band. This raises questions about whether it is really homologous with the spider/whip-spider condition and pseudoscorpions are thus scored (?) here for this character.

179. Postcentriolar nucleus ( $0=$ unmodified; $1=$ asymmetrical, elongate).

The latter condition of the nucleus was suggested as a potential synapomorphy for (Araneae + Amblypygi) by Alberti $(2000,2005)$. 
2535

2536

2537

2538

2539

2540

2541

2542

2543

2544

2545

2546

2547

2548

2549

2550

2551

2552

2553

2554

2555

2556

2557

2558

2559

2560

180. Implantation fossa $(0=$ shallow; $1=$ deep $)$.

In arachnids with flagellate sperm the implantation fossa - a posterior part of the nucleus which usually contains the centrioles or their derivatives (Alberti 2000) - is usually shallow, but in many Araneae and Schizomida it is deep and effectively makes the sperm an almost a hollow tube. This character is inapplicable to aflagellate sperm, and only visible in basal Opiliones which develop a transient flagellum.

181. Manchette of microtubules ( $0=$ absent; $1=$ present).

Alberti (2000) noted that a manchette of microtubules associated with the nucleus and perhaps related to nuclear shaping - is only seen in Ricinulei and the Tetrapulmonata orders; see also Giribet et al. (2002).

182. Nuclear envelope $(0=$ absent; $1=$ present $)$.

A nuclear envelope, which disappears at the end of spermatogenesis, is observed in Solifugae and Acariformes among the mites, although a similar phenomenon may occur in some Xiphosuran (Alberti 1995, 2000).

183. Persisting flagellar tunnel $(0=$ absent; $1=$ present $)$.

This tunnel surrounding the axoneme persists throughout spermiogenesis only in Scorpiones and Pseudoscorpiones (Alberti 2000); see also Giribet et al. (2002, character 203).

184. Vacuolated sperm ( $0=$ absent; $1=$ present $)$.

Alberti (2000, especially fig. 33) described the quite fundamental differences between the sperm types seen in the Anactinotrichida and Actinotrichida groups of mites. He thus concluded that at least the sperm characters offer no characters in support of monophyletic Acari. Vacuolated sperm were suggested as a synapomorphy of Anactinotrichida, with some further modifications to this ground pattern to form 'ribbon-type' sperm in the gamasid mites.

\section{Embryology/Development}

2562

185. Eggs ( 0 = centrolecithal; $1=$ isolecithal/telolecithal).

2563 Yohsikura (1975, table 1) described the eggs of most arachnids as centrolecithal. The eggs of scorpions and pseudoscorpions are quite different and show yolk reduction. Yoshikura (1975) related this reduction to ovoviviparity and viviparty in scorpions and the laying of eggs in a brood pouch in pseudoscorpions, both of which 2568 consequently reduce the reliance on yolk.

2570

186. Growth zone ( 0 = gives rise to prosoma and opisthosoma; $1=$ gives rise to opisthosoma only).

2571 Anderson (1973) and Yoshikura (1975) described a fairly fundamental difference in 2572 the way the opisthosoma develops in Xiphosura and Scorpiones, as compared to 
2573 non-scorpion arachnids. In the former, the growth zone gives rise to both tagmata, 2574 in the latter the prosoma develops directly from the blastoderm (see also Giribet et 2575 al. 2002, character 192).

2576

2577

2578

2579

2580

2581

2582

2583

2584

2585

2586

2587

2588

2589

2590

2591

2592

2593

2594

2595

2596

2597

2598

2599

2600

2601

2602

2603

2604

2605

2606

2607

2608

2609

2610

2611

187. Hexapodal instar $(0=$ absent; $1=$ present $)$.

An early instar with only six legs is one of the strongest character proposed in support of (Ricinulei + Acari) - see e.g. Lindquist (1984), and Shultz (1990, character 61 ) - although it should be cautioned that adding limbs during ontogeny could be treated as a plesiomorphic, anamorphic mode of development.

188. Egg teeth on pedipalpal coxae ( $0=$ absent; $1=$ present).

Yoshikura (1975) observed various serrations in arachnids which probably function to break open the egg while hatching. Of these, a specific pair of teeth restricted to the dorsal surface of the pedipalpal coxae, and which are shed after hatching, was mentioned for Araneae and Amblypygi and is thus a potential synapomorphy of these taxa (see also Wheeler \& Hayashi 1998, character 32). It is not clear to what extent this character has been investigated in other taxa.

189. Lateral organs ( $0=$ absent; $1=$ present $)$.

This is a problematic character, in that the lateral organs seen during development in Solifugae, Amblypygi and Uropygi (Yoshikura 1975) may well be vestigial, plesiomorphic retentions of an exopod from the base of the second walking leg and are probably homologous with the Claperède organ of Acariformes (Thomas \& Telford 1999). All four taxa are scored as having this character here. There is a socalled lateral organ in Xiphosura too, but Thomas \& Telford (1999) questioned whether it was really homologous with that of arachnids - it does not really occur on the limb base in horseshoe crabs - and this is reflected in the scoring adopted here where its presence is restricted to the above-mentioned arachnids.

\section{Ecology}

191. Heteromorphic parasitic larvae $(0=$ absent; $1=$ present $)$.

This specialised life cycle with an obligatory parasitic larva is a putative apomorphy of the Parasintegona group among prostigmatid mites.

192. Hypopi $(0=$ absent; $1=$ present $)$.

The deutonymphal stage in Astigmata has reduced mouthparts, provided with a posterior clasping or sucking device related to dispersion by phoresis. This trait is exclusive to Astigmata (Sancassania and Rhizoglyphus among the taxa sampled in this study) among the mites.

193. Anamorphic development with protonymphal stage $(0=$ present, $1=$ absent $)$ Pycnogonida show anamorphic development in which the hatching stage, or protonymph, is fundamentally different from the adult in having less segments and appendages. Subsequent segments and limbs are added during development. Xiphosurans and arachnids hatch as miniature versions of the adult, although in 
2612 some cases the full complement of limbs is only achieved with later instars (see 2613 hexapodal larva).

\section{References}

2615 Alberti, G. (1977). Zur Feinstruktur und Funktion der Genitalnäpfe von Hydrodroma 2616 despiciens (Hydrachnellae, Acari). Zoomorphologie, 87(2), 155-164.

2617 Alberti, G. (1979). Licht- und elektronenmikroskopische Untersuchungen an 2618 Coxaldrüsen von Walzenspinnen (Arachnida: Solifugae). Zoologischer Anzeiger, 203, 2619 48-64.

2620

2621

2622

2623

2624

2625

2626

2627

2628

2629

2630

2631

2632

2633

2634

2635

2636

2637

2638

2639

2640 2641

2642 2643

Alberti, G. (1995). Comparative spermatology of Chelicerata: review and perspective. Advances in Spermatozoal Phylogeny and Taxonomy.(BGM Jamieson, J. Ausio \& J.-L. Justine, eds.) Mémoires du Muséum National d'Histoire Naturelle, 166, 203-230.

Alberti, G. (2000). Chelicerata. Reproductive biology of invertebrates, 9(Part B), 311388.

Alberti, G. (2005). Double spermatogenesis in Chelicerata. Journal of morphology, 266(3), 281-297.

Alberti, G. (2006). On some fundamental characteristics in acarine morphology. Atti Accad Naz Ital Entomol, 2005, 315-360.

Alberti, G., \& Coons, L. B. (1999). Acari: mites. Microscopic anatomy of invertebrates, 8, 515-1265.

Alberti, G., Lipke, E., \& Giribet, G. (2008). On the ultrastructure and identity of the eyes of Cyphophthalmi based on a study of Stylocellus sp.(Opiliones, Stylocellidae). Journal of Arachnology, 36(2), 379-387.

Alberti, G., \& Peretti, A. V. (2002). Fine structure of male genital system and sperm in Solifugae does not support a sister-group relationship with Pseudoscorpiones (Arachnida). Journal of Arachnology, 30(2), 268-274.

Anderson, D. T. (1973). Embryology and phylogeny in annelids and arthropods. Pergamon Press, Oxford, UK.

Anderson, L. I., \& Selden, P. A. (1997). Opisthosomal fusion and phylogeny of Palaeozoic Xiphosura. Lethaia, 30(1), 19-31.

Arango, C. P. (2002). Morphological phylogenetics of the sea spiders (Arthropoda: Pycnogonida). Organisms Diversity \& Evolution, 2(2), 107-125. 
2644 Barnett, A. A., \& Thomas, R. H. (2013). The expression of limb gap genes in the mite 2645 Archegozetes longisetosus reveals differential patterning mechanisms in 2646 chelicerates. Evolution \& development, 15(4), 280-292.

2647 Bartsch, I. (1973). Porohalacarus alpinus (Thor)(Halacaridae, Acari), ein 2648 morphologischer Vergleich mit marinen Halacariden nebst Bemerkungen zur Biologie 2649 dieser Art. Entomol tidskr, 74, 116-123.

2650 Börner, C. (1902). Arachnologische Studien (II und III). Zool. Anz, 25, 433-466.

2651 Braddy, S. J., Aldridge, R. J., Gabbott, S. E., \& Theron, J. N. (1999). Lamellate book2652 gills in a late Ordovician eurypterid from the Soom Shale, South Africa: support for a 2653 eurypterid-scorpion clade. Lethaia, 32(1), 72-74.

2654 Briggs, D. E., Siveter, D. J., Siveter, D. J., Sutton, M. D., Garwood, R. J., \& Legg, D. 2655 (2012). Silurian horseshoe crab illuminates the evolution of arthropod limbs. 2656 Proceedings of the National Academy of Sciences, 109(39), 15702-15705.

2657 Bruton, D. L. (1981). The arthropod Sidneyia inexpectans, Middle Cambrian, Burgess 2658 Shale, British Columbia. Philosophical Transactions of the Royal Society of London. 2659 Series B, Biological Sciences, 619-653.

2660 Buxton, B. H. (1913). Coxal glands of arachnids. Zoologische Jahrbücher, Abteilung 2661 für Anatomie und Ontogenie der Tiere, 14, 231-282.

2662 Buxton, B. H. (1917). Notes on the anatomy of arachnids. Journal of Morphology, 2663 29(1), 1-31.

2664 Chamberlin, J. C. (1931). The arachnid order Chelonethida. Stanford University Press 2665 Stanford USA.

2666 Cotton, T. J., \& Braddy, S. J. (2003). The phylogeny of arachnomorph arthropods and 2667 the origin of the Chelicerata. Transactions of the Royal Society of Edinburgh: Earth 2668 Sciences, 94(03), 169-193.

2669 Damen, W. G., Saridaki, T., \& Averof, M. (2002). Diverse adaptations of an ancestral 2670 gill: a common evolutionary origin for wings, breathing organs, and spinnerets. 2671 Current Biology, 12(19), 1711-1716.

2672 Dencker, D. V. (1974). Das Skeletmuskelsystem von Nymphon rubrum Hodge, 1862 2673 (Pycnogonida: Nymphonidae). Zool. Jbr. Anat, 93, 272-287.

2674 Dunlop, J. A. (1996). Evidence for a sister group relationship between Rininulei and 2675 Trigonotarbida. Bulletin of the British Arachnological Society, 10, 193-204.

2676 Dunlop, J. A. (1999). A redescription of the Carboniferous arachnid Plesiosiro 
2677 madeleyi Pocock, 1911 (Arachnida: Haptopoda). Transactions of the Royal Society of 2678 Edinburgh, Earth Sciences 90,29-47.

2679 Dunlop, J. A. (2000a). The epistomal-labral plate and lateral lips in solifuges, 2680 pseudoscorpions and mites. Ekol. Bratslava, 19, 67-78.

2681 Dunlop, J. A. (2000b). Character states and evolution of the chelicerate claws. 2682 European arachnology 2000, 345-354.

2683 Dunlop, J. A. (2010). Geological history and phylogeny of Chelicerata. Arthropod 2684 structure \& development, 39(2), 124-142.

2685 Dunlop, J. A., Anderson, L. I., \& Braddy, S. J. (2003). A redescription of Chasmataspis 2686 laurencii Caster \& Brooks, 1956 (Chelicerata: Chasmataspidida) from the Middle 2687 Ordovician of Tennessee, USA, with remarks on chasmataspid phylogeny. 2688 Transactions of the Royal Society of Edinburgh: Earth Sciences, 94(03), 207-225.

2689 Dunlop, J. A., \& Arango, C. P. (2005). Pycnogonid affinities: A review. Journal of 2690 Zoological Systematics and Evolutionary Research, 43(1), 8-21.

2691 Dunlop, J. A., Tetlie, E. O., \& Prendini, L. (2008). Reinterpretation of the Silurian 2692 scorpion Proscorpius osborni (Whitfield): integrating data from Palaeozoic and 2693 Recent scorpions. Palaeontology, 51(2), 303-320.

2694 Dunlop, J. A., \& Webster, M. (1999). Fossil evidence, terrestrialization and arachnid 2695 phylogeny. Journal of Arachnology, 86-93.

2696 Evans, G. O. (1992). Principles of acarology. CAB international.

2697 Fahrenbach, W. H., \& Arango, C. P. (2007). Microscopic anatomy of Pycnogonida: II. 2698 Digestive system. III. Excretory system. Journal of morphology, 268(11), 917-935.

2699 Farley, R. D. (2005). Developmental changes in the embryo, pronymph, and first 2700 molt of the scorpion Centruroides vittatus (Scorpiones: Buthidae). Journal of 2701 morphology, 265(1), 1-27.

2702 Firstman, B. (1973). The relationship of the chelicerate arterial system to the 2703 evolution of the endosternite. Journal of Arachnology, 1-54.

2704 Foelix, R. F. (1985). Mechano-and chemoreceptive sensilla. In Neurobiology of 2705 arachnids (pp. 118-137). Springer Berlin Heidelberg.

2706 Garwood, R. J., Sharma, P. P., Dunlop, J. A., \& Giribet, G. (2014). A Paleozoic Stem 2707 Group to Mite Harvestmen Revealed through Integration of Phylogenetics and 2708 Development. Current Biology, 24(9), 1017-1023. 
2709 Giribet, G., Edgecombe, G. D., Wheeler, W. C., \& Babbitt, C. (2002). Phylogeny and 2710 systematic position of opiliones: A combined analysis of chelicerate relationships 2711 using morphological and molecular data1. Cladistics, 18(1), 5-70.

2712 Hammen, L. V. D. (1982). Comparative studies in chelicerata II. Epimerata (Palpigradi 2713 and Actinotrichida). Zoologische Verhandelingen, 196, 1-70.

2714 Hammen, L. V. D. (1989). An introduction to comparative arachnology. SPB Academic 2715 Publishing bv.

2716 Hara, M. R., \& Gnaspini, P. (2003). Comparative study of the defensive behavior and 2717 morphology of the gland opening area among harvestmen (Arachnida, Opiliones, 2718 Gonyleptidae) under a phylogenetic perspective. Arthropod structure \& 2719 development, 32(2), 257-275.

2720 Harvey, M. S. (1992). The phylogeny and classification of the Pseudoscorpionida 2721 (Chelicerata: Arachnida). Invertebrate Systematics, 6(6), 1373-1435.

2722 Homann, H. (1985). Die Cheliceren der Araneae, Amblypygi und Uropygi mit den 2723 Skleriten, den Plagulae (Chelicerata, Arachnomorpha). Zoomorphology, 105(2), 69272475.

2725 Hou, X., \& Bergström, J. (1997). Arthropods of the lower Cambrian Chengjiang fauna, 2726 southwest China. Fossils Strata, 45: 1-116.

2727 Jeram, A. J. (2001). Paleontology. Scorpion biology and research, 370-392. Edyted by 2728 Brownell P, Polis G A, Oxford, Oxford

2729 University Press, 2001

2730 Jesionowska, K. (2003). Observations on the morphology of some eupodoid and 2731 endeostigmatic gnathosomata (Acariformes, Actinedida, Eupodoidea and 2732 Endeostigmata). Acta zoologica cracoviensia, 46(3), 257-268.

2733 Kamenz, C., Dunlop, J. A., Scholtz, G., Kerp, H., \& Hass, H. (2008). Microanatomy of 2734 Early Devonian book lungs. Biology letters, 4(2), 212-215.

2735 Kethley, J. (1990). Acarina: Prostigmata (Actinedida). Soil biology guide, 1, 667-756. 2736 Dindal DL (ed), A Wiley -Interscience Publication, John Wiley \& Sons, New York, USA.

2737 King, P. E. ( 1973). Pycnogonids. Hutchinson University Library.

2738 Klompen, J. S. H. (2000). Prelarva and larva of Opilioacarus (Neocarus) texanus 2739 (Chamberlin and Mulaik)(Acari: Opilioacarida) with notes on the patterns of setae 2740 and lyrifissures. Journal of Natural History, 34(10), 1977-1992.

2741 Kraus, O. (1976). Zur phylogenetischen Stellung und Evolution der Chelicerata. 
2742 Entomologica Germanica, 3, 1-12.

2743 Kühl, G., Bergmann, A., Dunlop, J., Garwood, R. J., \& Rust, J. (2012). Redescription 2744 and palaeobiology of Palaeoscorpius devonicus Lehmann, 1944 from the Lower 2745 Devonian Hunsrück Slate of Germany. Palaeontology, 55(4), 775-787.

2746 Legg, D. A., Garwood, R. J., Dunlop, J. A., \& Sutton, M. D. (2012). A taxonomic 2747 revision of orthosternous scorpions from the English Coal Measures aided by $\mathrm{x}$-ray 2748 micro-tomography (XMT). Palaeontologia Electronica, 15(1), 1-16.

2749 Legg, D. A., Sutton, M. D., \& Edgecombe, G. D. (2013). Arthropod fossil data increase 2750 congruence of morphological and molecular phylogenies. Nature communications, 4, 27512485.

2752 Lindquist, E. E. (1984). Current theories on the evolution of major groups of Acari 2753 and on their relationships with other groups of Arachnida, with consequent 2754 implications for their classification. Acarology VI/editors, DA Griffiths and CE 2755 Bowman.

2756 Michalik, P., \& Alberti, G. (2005). On the occurrence of the 9+ 0 axonemal pattern in 2757 the spermatozoa of sheetweb spiders (Araneae, Linyphiidae). Journal of 2758 Arachnology, 33(2), 569-572.

2759 Moore, R. A., Briggs, D. E., \& Bartels, C. (2005). A new specimen of Weinbergina 2760 opitzi (Chelicerata: Xiphosura) from the Lower Devonian Hunsrück Slate, Germany. 2761 Paläontologische Zeitschrift, 79(3), 399-408.

2762 Moritz, M. (1959). Zur Embryonalentwicklung der Phalangiiden (Opiliones; 2763 Palpatores) II. Die Anlage und Entwicklung der Coxaldrüse bei Phalangium opilio L. 2764 Zoologische Jahrbucher. Abtheilung für Anatomie und Ontogenie der Thiere, 77, 2292765240.

2766 Murienne, J., Harvey, M. S., \& Giribet, G. (2008). First molecular phylogeny of the 2767 major clades of Pseudoscorpiones (Arthropoda: Chelicerata). Molecular 2768 phylogenetics and evolution, 49(1), 170-184.

2769 Orr, P. J., Siveter, D. J., Briggs, D. E., Siveter, D. J., \& Sutton, M. D. (2000). A new 2770 arthropod from the Silurian Konservat-Lagerstätte of Herefordshire, UK. Proceedings 2771 of the Royal Society of London. Series B: Biological Sciences, 267(1452), 1497-1504.

2772 Pepato, A. R., da Rocha, C. E., \& Dunlop, J. A. (2010). Phylogenetic position of the 2773 acariform mites: sensitivity to homology assessment under total evidence. BMC 2774 Evolutionary Biology, 10(1), 235.

2775 Pinto-da-Rocha, R., Machado, G., \& Giribet, G. (Eds.). (2007). Harvestmen: the 2776 biology of Opiliones. Harvard University Press.

2777 Punzo, F. (1998). Biology of camel-spiders (Arachnida, Solifugae). Kluwer Academic 2778 Publishers Boston USA.

2779 Reddell, J. R., \& Cokendolpher, J. C. (1995). Catalogue, bibliography, and generic 
2780

2781

2782

2783

2784

2785

2786

2787

2788

2789

2790

2791

2792

2793

2794

2795

2796

2797

2798

2799

2800

2801

2802

2803

2804

2805

2806

2807

2808

2809

2810

2811

2812

2813

revision of the order Schizomida (Arachnida). Texas Memorial Museum Monologues 4, 1-170.

Roewer, C. F. (1934). Solifugae, palpigradi. In Klassen und Ordnungen des Tierreichs 5: Arthropoda. IV: Arachnoidea. Edited by Bronns H G, Leipzig, Akademische Verlagsgesellschaft M.B.H., 1934, 5(IV)(4)(4-5): 481-723

Rowland, J. M., \& Cooke, J. A. (1973). Systematics of the arachnid order Uropygida (= Thelyphonida). Journal of Arachnology, 55-71.

Scholl, G. (1977). Beiträge zur Embryonalentwicklung von Limulus polyphemus L. (Chelicerata, Xiphosura). Zoomorphologie, 86(2), 99-154.

Scholtz, G., \& Kamenz, C. (2006). The book lungs of Scorpiones and Tetrapulmonata (Chelicerata, Arachnida): evidence for homology and a single terrestrialisation event of a common arachnid ancestor. Zoology, 109(1), 2-13.

Selden, P. A. (1981). Functional morphology of the prosoma of Baltoeurypterus tetragonophthalmus (Fischer)(Chelicerata: Eurypterida). Transactions of the Royal Society of Edinburgh: Earth Sciences, 72(01), 9-48.

Selden, P. A., Shear, W. A., \& Bonamo, P. M. (1991). A spider and other arachnids from the Devonian of New York, and reinterpretations of Devonian Araneae. Palaeontology, 34, 241-281.

Selden, P. A., Shear, W. A., \& Sutton, M. D. (2008). Fossil evidence for the origin of spider spinnerets, and a proposed arachnid order. Proceedings of the National Academy of Sciences, 105(52), 20781-20785.

Shatrov, A. B. (2005). Ultrastructural investigations of the salivary glands in adults of the microtrombidiid mite Platytrombidium fasciatum (CL Koch, 1836)(Acariformes: Microtrombidiidae). Arthropod Structure \& Development, 34(1), 49-61.

Shear, W. A., Selden, P. A., Rolfe, W. I., Bonamo, P. M., \& Grierson, J. D. (1987). New terrestrial arachnids from the Devonian of Gilboa, New York (Arachnida, Trigonotarbida). American Museum Novitates, 2901, 1-74

Shultz, J. W. (1989). Morphology of locomotor appendages in Arachnida: evolutionary trends and phylogenetic implications. Zoological Journal of the Linnean Society, 97(1), 1-55.

Shultz, J. W. (1990). Evolutionary morphology and phylogeny of Arachnida. Cladistics, 6(1), 1-38.

Shultz, J. W. (1993). Muscular anatomy of the giant whipscorpion Mastigoproctus giganteus (Lucas)(Arachnida: Uropygi) and its evolutionary significance. Zoological 
2814 Journal of the Linnean Society, 108(4), 335-365.

2815 Shultz, J. W. (1999). Muscular anatomy of a whipspider, Phrynus longipes (Pocock) 2816 (Arachnida: Amblypygi), and its evolutionary significance. Zoological Journal of the 2817 Linnean Society, 126(1), 81-116.

2818

2819

2820

2821

2822

2823

2824

2825

2826

2827

2828

2829

2830

2831

2832

2833

2834

2835

2836

2837

2838

2839

2840

2841

2842

2843

2844

2845

2846

2847

Shultz, J. W. (2000). Skeletomuscular anatomy of the harvestman Leiobunum aldrichi (Weed, 1893) (Arachnida: Opiliones: Palpatores) and its evolutionary significance. Zoological Journal of the Linnean Society, 128(4), 401-438.

Shultz, J. W. (2001). Gross muscular anatomy of Limulus polyphemus (Xiphosura, Chelicerata) and its bearing on evolution in the Arachnida. Journal of Arachnology, 283-303.

Shultz, J. W. (2007a). A phylogenetic analysis of the arachnid orders based on morphological characters. Zoological Journal of the Linnean Society, 150(2), 221265.

Shultz, J. W. (2007b). Morphology of the prosomal endoskeleton of Scorpiones (Arachnida) and a new hypothesis for the evolution of cuticular cephalic endoskeletons in arthropods. Arthropod structure \& development, 36(1), 77-102.

Shultz, J. W., \& Pinto-da-Rocha, R. (2007). Morphology and functional anatomy. Harvestmen: the Biology of Opiliones. Harvard University Press, Cambridge, 14-61.

Simonnet, F., Célérier, M. L., \& Quéinnec, E. (2006). Orthodenticle and empty spiracles genes are expressed in a segmental pattern in chelicerates. Development genes and evolution, 216(7-8), 467-480.

Snodgrass, R. E. (1948). The feeding organs of Arachnida, including mites and ticks (Vol. 3944). Smithsonian Institution Misc Collection, 110, 1-93.

Stein, M., \& Selden, P. A. (2012). A restudy of the Burgess Shale (Cambrian) arthropod Emeraldella brocki and reassessment of its affinities. Journal of Systematic Palaeontology, 10(2), 361-383.

Storch, V., Alberti, G., \& Ruhberg, H. (1979). Light and electron microscopical investigations on the salivary glands of Opisthopatus cinctipes and Peripatopsis mosleyi (Onychophora: Peripatopsidae). Zoologischer Anzeiger, 203(1-2), 35-47.

Stürmer, W., \& Bergström, J. (1981). Weinbergina, a xiphosuran arthropod from the Devonian Hunsrück Slate. Paläontologische Zeitschrift, 55(3-4), 237-255.

Sutton, M. D., Briggs, D. E., Siveter, D. J., Siveter, D. J., \& Orr, P. J. (2002). The arthropod Offacolus kingi (Chelicerata) from the Silurian of Herefordshire, England: computer based morphological reconstructions and phylogenetic affinities. 
2848 Proceedings of the Royal Society of London. Series B: Biological Sciences, 269(1497), 2849 1195-1203.

2850 Talarico, G., Palacios-Vargas, J. G., Silva, M. F., \& Alberti, G. (2005). First 2851 ultrastructural observations on the tarsal pore organ of Pseudocellus pearsei and $P$. 2852 boneti (Arachnida, Ricinulei). Journal of Arachnology, 33(2), 604-612.

2853 Thomas, R. H., \& Telford, M. J. (1999). Appendage development in embryos of the 2854 oribatid mite Archegozetes longisetosus (Acari, Oribatei, Trhypochthoniidae). Acta 2855 Zoologica, 80(3), 193-200.

2856 Vilpoux, K., \& Waloszek, D. (2003). Larval development and morphogenesis of the 2857 sea spider Pycnogonum litorale (Ström, 1762) and the tagmosis of the body of 2858 Pantopoda. Arthropod structure \& development, 32(4), 349-383.

2859 Walossek, D., \& Müller, K. J. (1998). Cambrian 'Orsten'-type arthropods and the 2860 phylogeny of Crustacea. In Arthropod relationships (pp. 139-153). Springer 2861 Netherlands.

2862 Walter, D. E., \& Proctor, H. C. (1998). Feeding behaviour and phylogeny: 2863 observations on early derivative Acari. Experimental \& applied acarology, 22(1), 39286450.

2865 Weygoldt, P. (1969). Biology of pseudoscorpions. Harvard University Press 2866 Cambridge USA.

2867 Weygoldt, P. (1978). Paarungsverhalten und Spermatophorenmorphologie bei 2868 Geißelskorpionen: Thelyphonellus amazonicus Butler und Typopeltis crucifer Pocock 2869 (Arachnida, Uropygi). Zoomorphologie, 89(2), 145-156.

2870 Weygoldt, P. (1999). Evolution and systematics of the Chelicerata. In Ecology and 2871 Evolution of the Acari (pp. 1-14). Springer Netherlands.

2872 Weygoldt, P., \& Paulus, H. F. (1979). Untersuchungen zur Morphologie, Taxonomie 2873 und Phylogenie der Cheliceratal II. Cladogramme und die Entfaltung der 2874 Chelicerata. Journal of Zoological Systematics and Evolutionary Research, 17(3), 2875 177-200.

2876 Weygoldt, P. (2000). Whip spiders (Chelicerata: Amblypygi): their biology, 2877 morphology and systematics. ISBS.

2878 Wheeler, W. C., \& Hayashi, C. Y. (1998). The phylogeny of the extant chelicerate 2879 orders. Cladistics, 14(2), 173-192.

2880 Wills, M. A., Briggs, D. E., Fortey, R. A., Wilkinson, M., \& Sneath, P. H. (1998). An 2881 arthropod phylogeny based on fossil and recent taxa. Arthropod fossils and 
2882 phylogeny. Columbia University Press, New York, 33-105.

2883 Winkler, D. (1957). Die Entwicklung der äusseren Körpergestalt bei den Phalangiidae 2884 (Opiliones). Mitteilungen aus dem Museum für Naturkunde in Berlin. Zoologisches 2885 Museum und Institut für Spezielle Zoologie (Berlin), 33(2), 355-389.

2886 Yoshikura, M. (1975). Comparative embryology and phylogeny of Arachnida. 2887 Kumamoto journal of science, Biology, 12(2), 71-142.

2888 Zacharda, M. (1980). Soil mites of the family Rhagidiidae (Actinedida: Eupodoidea): 2889 Morphology, systematics, ecology. Acta Universitatis Carolinae Biologica, 5-6, 4892890785.

2891 Zakhvatkin, A. A. (1949). New representatives of apparently segmented mites 2892 (Acarina: Pachygnathidae). Ent. Obozer. Moscow, 30, 291-295. 


\section{Figure 1}

Digital visualisations of the haptopod Plesiosiro madeleyi (NHM 17923; A-D), and phalangiotarbid Goniotarbus angulatus (NHM In22838; E-I)

A. Dorsal view of $\boldsymbol{P}$. madeleyi, showing opisthosomal segmentation and prosomal shield architecture. B. Lateral view of the anterior ventral prosoma, nearest limbs and lateral prosoma removed, showing the nature of haptopod chelicerae. C. Ventral view, showing ventral segmentation, and divided sternum. D. Haptopod walking leg. E. First left walking leg of $G$. angulatus, showing typical segmentation. F. Lateral view of the anterior ventral prosoma, showing the small pedipalps, median ridge, and possible chelicerae - below the resolution of the scan. G. Fourth right walking leg. H. Dorsal view showing median eyes and dorsal opisthosomal segmentation. I. Ventral view showing opisthosomal segmentation and coxo-sternal region. Abbreviations: 1-10 - opisthosomal segment number; as anterior sclerite; ch - chelicerae; cx - coxa; fa - fang; fe- femur; L1-L4 - walking legs 1-4; me - media eyes; mt - metatarsus; pa - paturon; pp - pedipalps; ps posterior sclerite; pt - patella; ta - tarsus; ti - tibia; tr - trochanter. Scale bars: $A, C, F-I=3 \mathrm{~mm} ; B, D, E=1 \mathrm{~mm}$. 


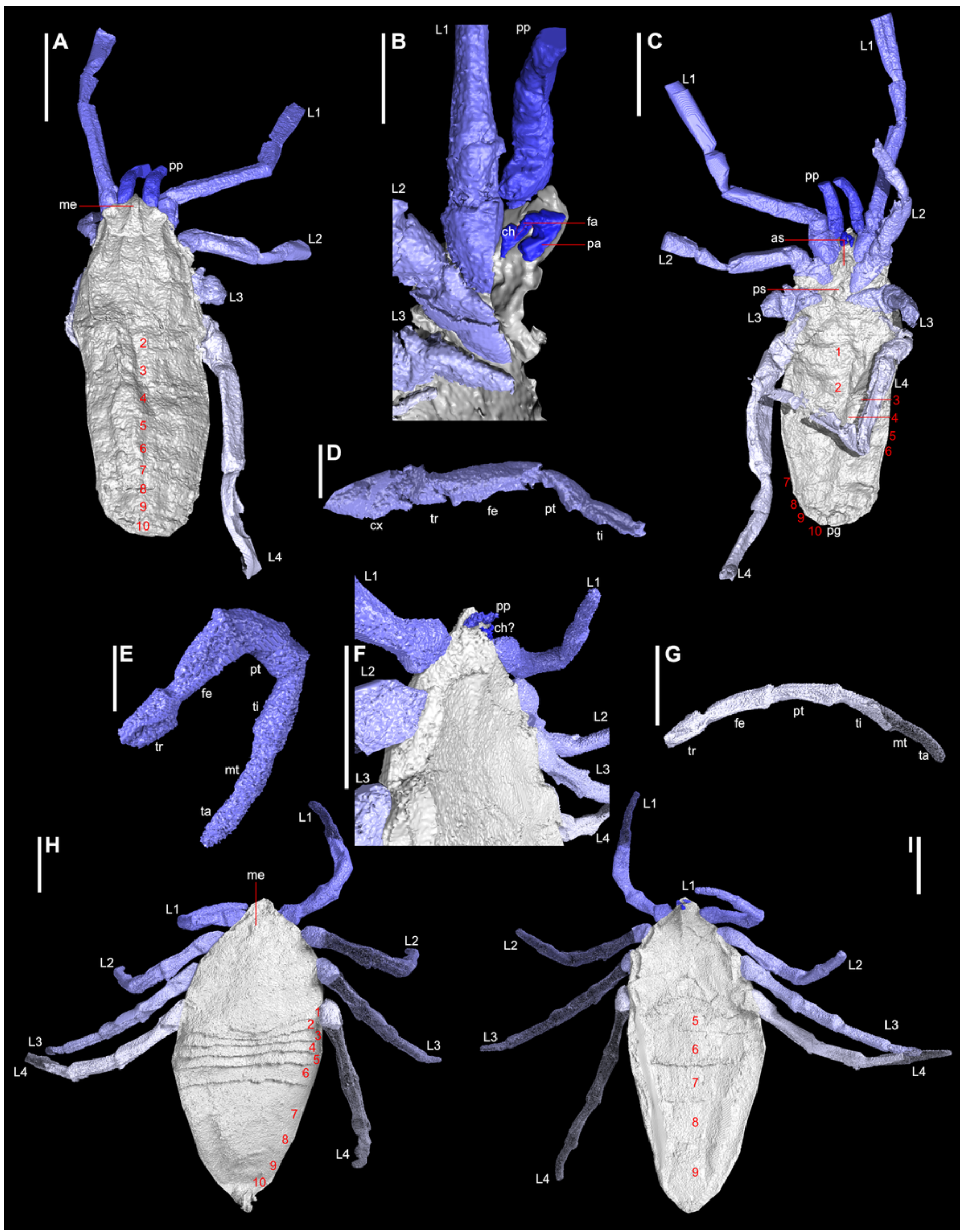




\section{Figure 2}

Holotype and only known specimen of phalangiotarbid Goniotarbus angulatus (NHM $\ln 22838)$

A. Dorsal view, showing prosoma and opisthosoma, and legs $4 \mathrm{~L}$ and $2 \mathrm{~L}$. Proximal portions of Leg $1 \mathrm{~L}$ are visible at the anterior of the fossil, as are the trochanters of several of the legs on the right. B. Ventral view showing coxo-sternal arrangement and ventral opisthosomal segmentation. Proximal portions of Leg $1 \mathrm{~L}$, then $2 \mathrm{~L} 3 \mathrm{~L}$ and $4 \mathrm{~L}$ are visible. C. A close up of the sternum, anterior to the left showing five constituent plates. D. Detail of the anterior opisthosomal segmentation, including the posterior median bulge of the prosomal shield, and associated accommodation in the anterior opisthosomal segments. E. The posteriormost segments (7-10) fused to create a single dorsal plate, with a terminal anal operculum. Scale bars: $A, B=2 \mathrm{~mm} ; C-E=1 \mathrm{~mm}$. 

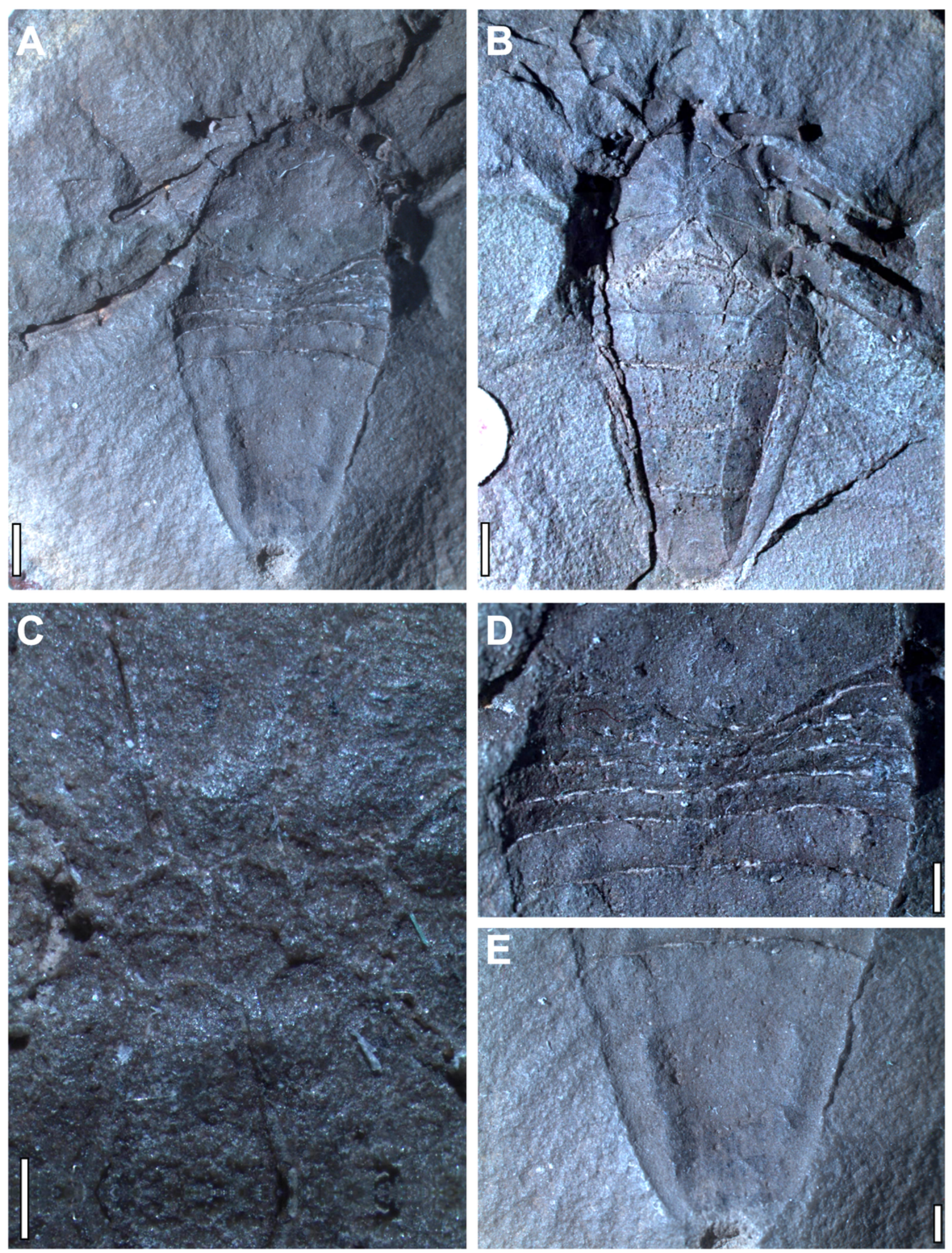
Figure 3

Results of the cladistic analysis presented herein under equal weights analysis.

The trees show the strict consensus of equally weighted analyses of the matrices presented here (SI file 2,3, morphobank project 1274). A. Tree showing the analysis results with fossils included. Bremer, jackknife and bootstrap support values are provided for each node as shown in the key. B. Tree recovered with fossil terminals removed - ordinal clades are collapsed for clarity. 


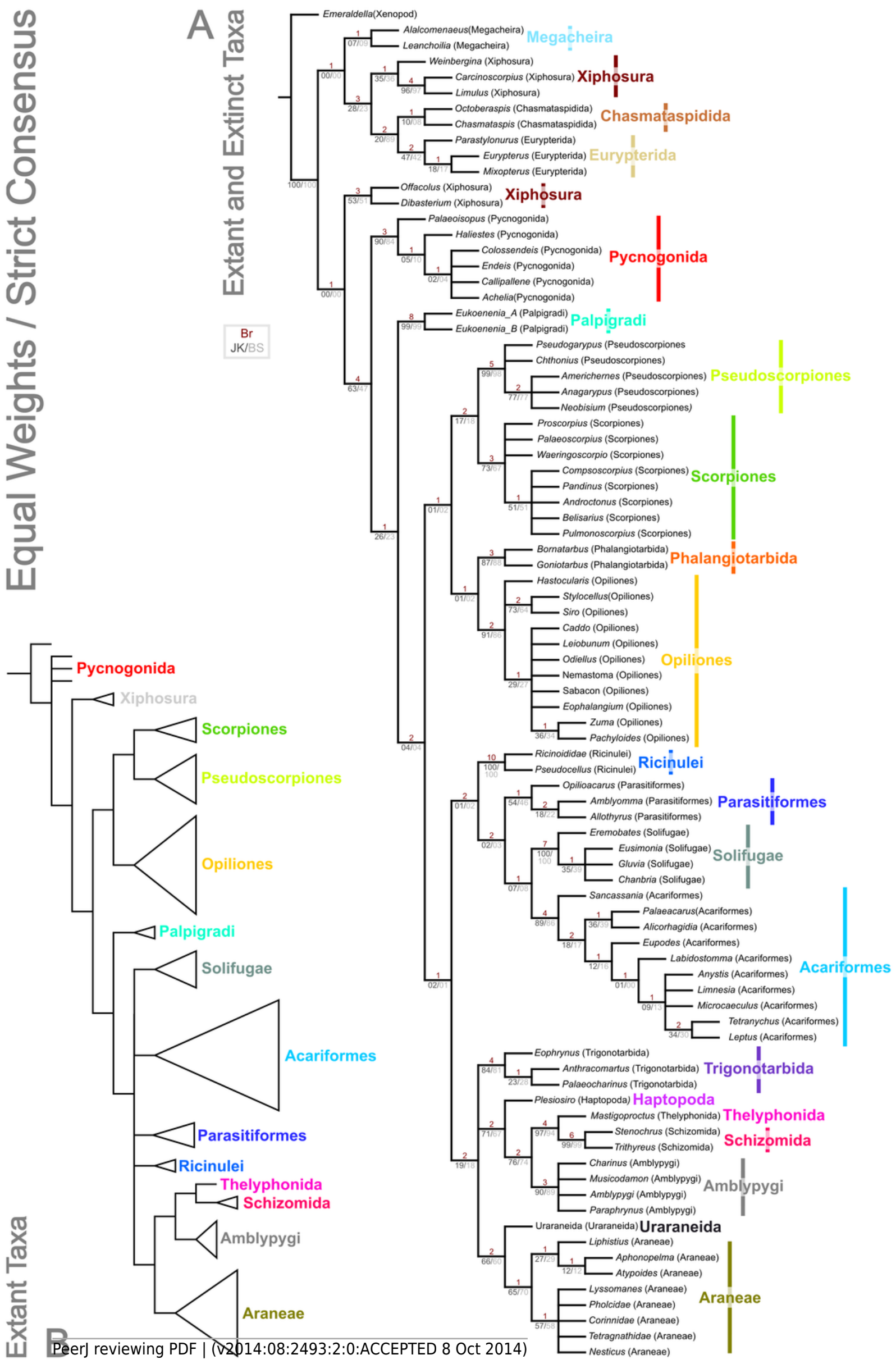


Figure 4

Results of the cladistic analysis presented herein under implied weights.

The trees show the strict consensus of implied weights analyses of the matrices presented here (SI file 2, morphobank project 1274). Symmetric resampling support values are provided on the basis that these are unaffected by character weights. A. The topology for concavity constants ( $k$ values) 0.25 and 1.0 , which are identical. $K=0.25$ support value above each node in red, $K=1.0$ below in grey. $B$. Tree for $k=3.0$. C. Topology for $k=10.0$.

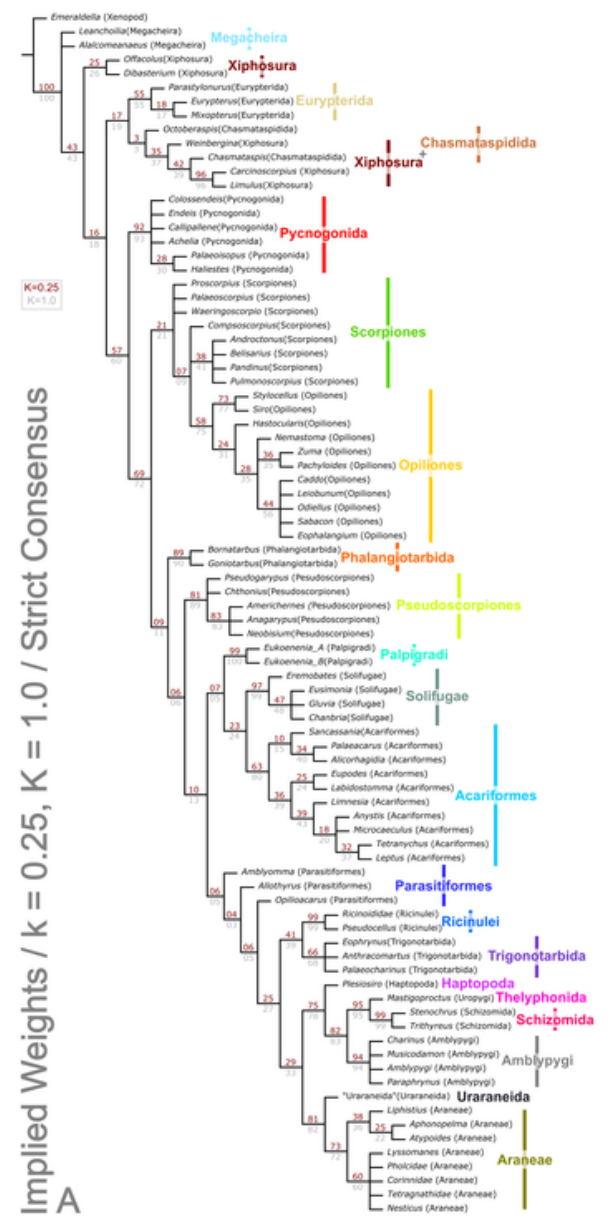

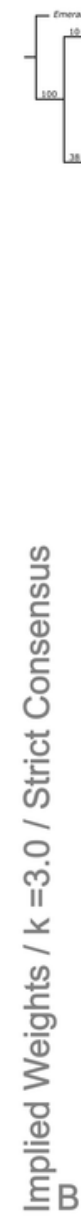

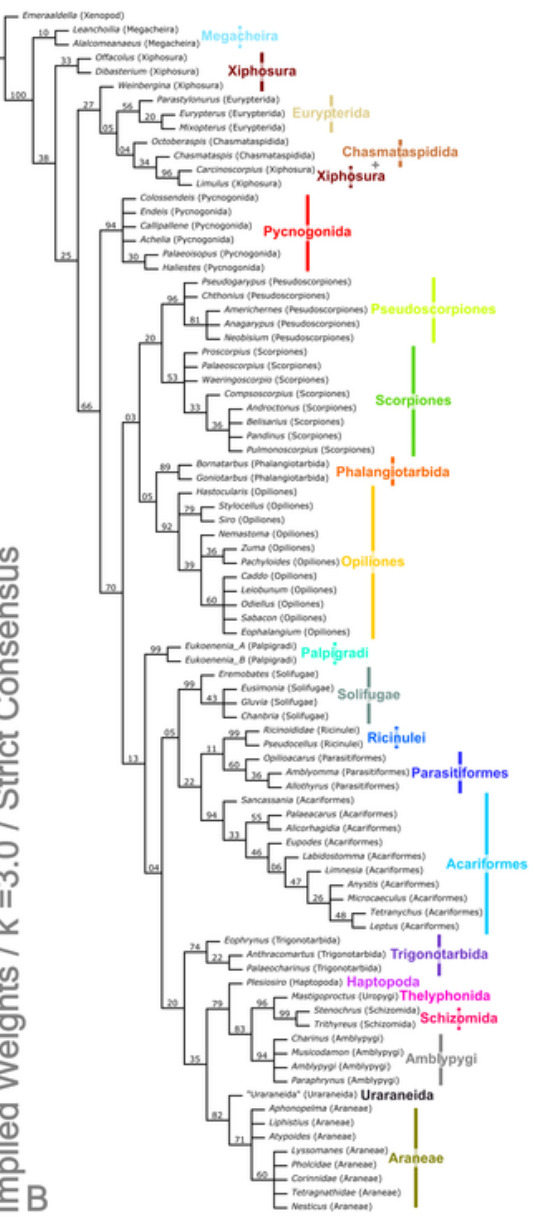

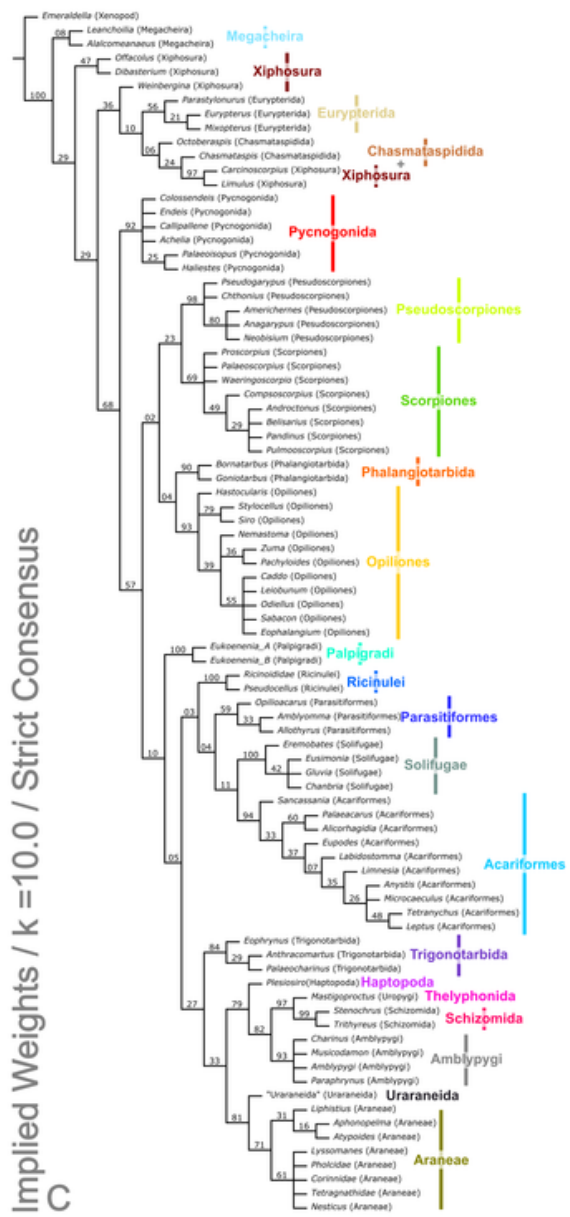

